Merci d'utiliser le titre suivant lorsque vous citez ce document :

Duran, J., N. Mulder et O. Onodera (2008-03-10),

" Libéralisation des échanges et performances économiques :

Comparaison en l' Asie de l'Est et l'Amérique

latine,1970-2006 », Éditions OCDE, Paris.

http://dx.doi.org/10.1787/243456546688

\title{
Libéralisation des échanges et performances économiques
}

\author{
COMPARAISON EN L' ASIE DE L'EST ET \\ L'AMÉRIQUE LATINE,1970-2006
}

Jose Duran,

Nanno Mulder,

Osamu Onodera

La version originale de ce document a été publiée comme suit :

Duran, J., N. Mulder and O. Onodera (2008-02-07), "Trade Liberalisation and Economic Performance: Latin America versus East Asia 1970-2006", OECD Trade Policy Papers, No. 70, OECD Publishing, Paris.

http://dx.doi.org/10.1787/244284387510 
DIRECTION DES ÉCHANGES ET DE L'AGRICULTURE COMITÉ DES ÉCHANGES

\title{
Groupe de travail du comité des échanges
}

\section{LIBÉRALISATION DES ÉCHANGES ET PERFORMANCES ÉCONOMIQUES : COMPARAISON ENTRE L'ASIE DE L'EST ET L'AMÉRIQUE LATINE, 1970-2006}

\author{
Jose E. Duran Lima et Nanno Mulder (CEPLAC)
}

13 décembre 2007

OBJET ET ACTION REQUISE : ce document est la deuxième version du document de comparaison régionale élaboré dans le cadre du rapport du Comité des échanges sur l'ajustement structurel dans les économies non membres qui fait suite au projet sur les échanges et l'ajustement structurel. Il tient compte des commentaires formulés par écrit et verbalement à la réunion que le Groupe de travail du Comité des échanges a tenue les 27 et 28 mars 2007. Le rapport se compose actuellement de six documents, la partie I [TAD/TC/WP(2007)6/PART 1] qui résume les implications pour l'action des pouvoirs publics, la partie 2/A qui est une étude comparative des expériences de libéralisation des échanges en Amérique latine et en Asie de l'Est, et les parties 2/B à E qui sont des études de cas consacrées au Chili, à l'Équateur, aux Philippines et à la Thaïlande. Le document est soumis au Groupe de travail pour examen et commentaires en vue de sa révision et de sa déclassification ultérieures. CALENDRIER : le présent document ainsi que le document TAD/TC/WP(2007)6/PART1/REV1sont soumis au Groupe de travail du Comité des échanges pour examen à sa réunion du 13 décembre 2007.

LIEN AVEC LE PROGRAMME DE TRAVAIL ET CONSÉQUENCES DU POINT DE VUE DES RESSOURCES : les travaux faisant suite au projet sur les échanges et l'ajustement structurel sont envisagés dans le domaine de résultats 3.1 .1 (Pour la libéralisation des échanges) du Programme de travail et budget pour 2006 et ils sont financés sur les ressources de la Partie $I$.

Contact: Osamu Onodera; Tél.: +33 -1-45248937; e-mail: osamu.onodera@oecd.org 


\section{RESUME}

Le présent document s'inscrit, comme les quatre autres études de cas, dans le cadre d'un vaste programme de recherches sur les échanges et l'ajustement structurel dans les économies non membres, qui a été entrepris à la suite de l'étude Trade and Structural Adjustment : Embracing Globalisation (OCDE, 2005) sur les politiques d'ajustement structurel dans le domaine des échanges. Il étudie les expériences de libéralisation des échanges et d'ajustement structurel en Asie de l'Est et en Amérique latine, ainsi que leurs résultats en termes de performances économiques et commerciales.

Le rapport comprend cinq grandes sections; après une introduction, la section A examine tout d'abord les résultats obtenus en matière de croissance et le rôle des échanges et de l'IDE. La section B traite de l'évolution des politiques relatives aux échanges dans les deux régions, tandis que la section $\mathrm{C}$ passe en revue quelques indicateurs des échanges et de l'investissement direct étranger. La section D compare l'ajustement structurel dans les deux régions. Enfin, la section E expose les conclusions de l'étude.

Mots-clefs : échanges, ajustement structurel, libéralisation, Amérique latine, Asie de l'Est

\section{REMERCIEMENTS}

Ce projet a été réalisé par Jose Duran (CEPALC), Nanno Mulder (CEPALC) et Osamu Onodera sous la direction d'Anthony Kleitz, Direction des échanges et de l'agriculture de l'OCDE. Les auteurs tiennent à exprimer leurs remerciements à Mark Melatos qui a bien voulu commenté une version antérieure de l'étude.

Le Groupe de travail du Comité des échanges a examiné ce rapport et est convenu de donner une diffusion plus large à ses conclusions en le déclassifiant sous sa responsabilité. Il est publié en français et en anglais sur le site web de l'OCDE : http://oecd.org/trade.

OCDE, 2007

Les demandes d'autorisation de reproduction ou de traduction totale ou partielle de cette publication doivent être adressées aux Editions de l'OCDE, 2 rue André Pascal, 75775 Paris Cedex 15, France. 


\section{TABLE DES MATIÈRES}

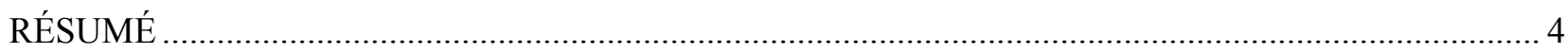

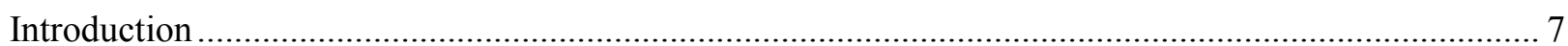

A. Résultats obtenus en matière de croissance, contexte macroéconomique et rôle des échanges et de l'IDE 8

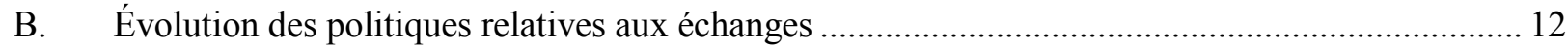

I. L'abandon des politiques de remplacement des importations au profit de politiques de

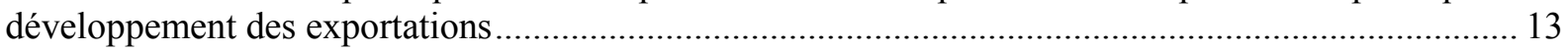

II. Libéralisation unilatérale des échanges complétée par des accords multilatéraux ................... 14

III. Libéralisation régionale et bilatérale des échanges................................................................ 17

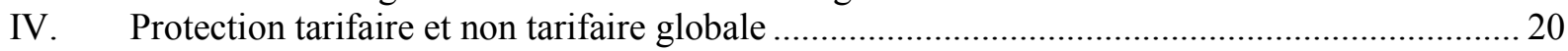

C. Indicateurs des échanges et de l'investissement direct étranger..................................................25

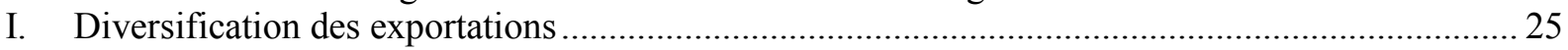

II. Rôle des exportations de produits manufacturés de moyenne et haute technicité ....................27

III. Rôle de l'investissement direct étranger et des réseaux régionaux de production........................33

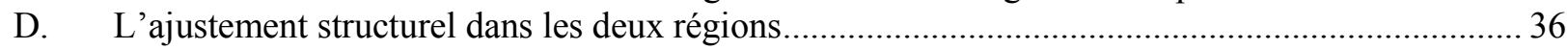

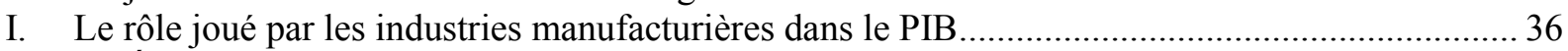

II. Évolution de la structure de la valeur ajoutée et de l'emploi manufacturiers............................. 37

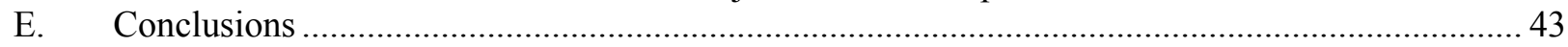

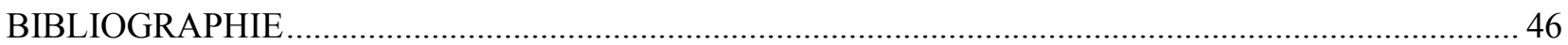




\section{RÉSUMÉ}

L'Asie de l'Est et l'Amérique latine constituent des cas intéressants pour une comparaison des expériences en matière de libéralisation des échanges et d'ajustement structurel et de leurs résultats en termes de performances économiques et commerciales. Ces deux régions présentaient des points communs aux alentours de 1980: elles exportaient principalement des ressources naturelles et des produits liés à elles ( $80 \%$ environ des exportations des deux régions) et leurs politiques commerciales étaient orientées vers le remplacement des importations, avec des droits de douane élevés et progressifs et de nombreux obstacles non tarifaires. Elles sont passées, au cours des décennies suivantes, d'un régime axé sur le remplacement des importations à un régime orienté vers les exportations et davantage fondé sur le jeu du marché en procédant, unilatéralement, à une libéralisation tarifaire poussée. Dans les deux régions, à l'exception des pays candidats à l'accession à l'OMC, cette libéralisation unilatérale a été le principal vecteur de la réduction des barrières commerciales, complété par les efforts régionaux et multilatéraux de libéralisation des échanges.

Les performances économiques et commerciales ont été très différentes. Entre 1970 et 2006, le PIB par habitant a progressé en moyenne de $4.5 \%$ et $7.4 \%$ par an en Asie de l'Est (6 pays considérés) et en Chine, respectivement, et de $1.5 \%$ en Amérique latine ( 8 pays considérés). La croissance a également été plus régulière en Asie de l'Est et en Chine. Les économies est-asiatiques ont en outre mieux réussi à s'intégrer dans l'économie mondiale si l'on en juge par la part des échanges dans le PIB. La contribution des exportations et du solde extérieur à l'accroissement du PIB est aussi sensiblement plus importante dans ces pays qui ont également mieux réussi à diversifier la structure de leurs exportations et à créer de nouveaux avantages comparatifs dynamiques pour des produits à forte valeur ajoutée. À l'inverse, l'Amérique latine est restée plus spécialisée dans les produits de base et les produits manufacturés en contenant une forte proportion. La restructuration des industries manufacturières a aussi été plus marquée en Asie de l'Est qu'en Amérique latine. L'accroissement des exportations des secteurs de moyenne et haute technicité a eu pour effet d'augmenter notablement la contribution de ces secteurs à la valeur ajoutée manufacturière en Asie de l'Est. Cette augmentation a atteint jusqu'à 10 points dans certaines industries de cette région (l'électronique) contre 2 à 3 points en Amérique latine (secteur alimentaire). Il est permis de penser que ce décalage reflète les différences constatées dans l'évolution des avantages comparatifs dans les deux régions et dans l'aptitude des économies qui les composent à s'adapter à la réforme des échanges.

Le succès relatif avec lequel les pays d'Asie de l'Est ont accru leurs exportations et restructuré leurs économies découle du plus net succès avec lequel ils sont parvenus à susciter une réaction plus forte et plus large des exportations. Il est certain que de nombreux facteurs peuvent expliquer cette aptitude à s'adapter aux réformes des échanges tels, entre autres, que des institutions, un capital humain et des infrastructures de meilleure qualité ainsi que des différences dans les politiques mises en oeuvre à l'égard de la main-d'œuvre et des marchés financiers et dans l'étendue de la libéralisation des services effectuée. Le présent document conclut, dans la perspective de l'examen de l'applicabilité des recommandations de bonnes pratiques énoncées dans l'étude de l'OCDE sur l'ajustement structurel (2005), en considérant plus particulièrement les aspects liés aux politiques commerciales et macroéconomiques, que si l'ajustement a été dans l'ensemble plus réussi en Asie de l'Est, c'est peut-être en raison 1) de différences dans l'échelonnement et la teneur de la réforme des échanges ; 2) de la stabilité macroéconomique ; 3) de la prévention d'une surévaluation des taux de change ; et 4) du rôle efficace joué par l'investissement direct étranger (IDE) et les réseaux de production qui sont associés aux flux commerciaux. 
En ce qui concerne les différences dans l'échelonnement et la teneur de la réforme des échanges, la plupart des pays d'Amérique latine ont réduit rapidement leurs droits de douane entre le milieu des années 80 et le début des années 90, plus tôt que ne l'ont fait les pays d'Asie de l'Est. Ces derniers ont dans l'ensemble adopté une démarche plus progressive à l'égard de la libéralisation des échanges en éliminant tout d'abord le biais défavorable aux exportations à l'aide de divers dispositifs comme des exemptions de droits à l'exportation et des ristournes de droits de douane et en procédant à des réductions tarifaires plus graduelles entre le milieu et la fin des années 90 . En revanche, ils ont ramené à moins de $10 \%$ le taux de couverture de leurs obstacles non tarifaires dès la fin des années 80 alors que ce taux atteignait encore jusqu'à $60 \%$ au début des années 90 dans de nombreux pays d'Amérique latine. On peut peut-être en déduire que pour faciliter l'ajustement structurel, 1) les réformes des échanges doivent être menées à un rythme et d'une façon qui facilitent la réaction des exportations, et 2) les obstacles non tarifaires comme les restrictions quantitatives doivent être réduits pendant la première phase des réformes commerciales pour que les réductions tarifaires soient efficaces.

S'agissant de la stabilité macroéconomique, la croissance économique des pays d'Asie de l'Est a été nettement moins instable que celle des pays d'Amérique latine avec des taux d'inflation et d'intérêt relativement bas. L'Amérique latine a connu dans les années 80 une "décennie noire » due à de graves crises d'endettement suivies, dans les années 90, par d'autres crises dans plusieurs pays de la région. En Asie de l'Est, au contraire, la croissance a été plus stable si l'on excepte une crise à la fin des années 90 . Les crises ont souvent déclenché des réformes commerciales, la fréquente participation de la Banque mondiale et du FMI ayant des degrés de succès variables. Si la stabilité économique n'a pas constitué un préalable à la réforme des échanges, l'instabilité macroéconomique a parfois obligé à faire temporairement machine arrière, ce qui montre que la stabilité est importante pour la durabilité de la réforme des échanges.

Prévenir une surévaluation du taux de change réel est la clef de la réussite des réformes des échanges et, en Asie de l'Est, les réductions tarifaires jointes au niveau généralement approprié des taux de change réels ont effectivement réduit le biais défavorable aux exportations. À l'inverse, le taux de change réel a été surévalué pendant de longues périodes en Amérique latine et, de ce fait, la réforme des échanges n'a pas permis de réduire autant qu'elle l'aurait pu le biais défavorable aux exportations. La réduction rapide et plus efficace de ce biais, associée à une stabilité macroéconomique, a provoqué une réaction plus profonde et plus étendue des exportations dans l'ensemble de l'économie, qui a conduit à la diversification de celles-ci. Cette diversification a peut-être elle-même contribué à l'accélération de la croissance économique observée dans cette région en réduisant l'instabilité des termes de l'échange.

Pour ce qui est du rôle joué par l'IDE, alors que les deux régions ont bénéficié de niveaux d'entrées comparables, l'Asie de l'Est a mieux réussi à les attirer dans le secteur manufacturier. L'IDE a été plus largement motivé par la recherche d'efficience et axé sur les exportations dans cette région que dans de nombreux pays d'Amérique latine et il y a contribué à l'expansion des exportations. De ce fait, les pays d'Asie de l'Est, ainsi que le Costa Rica et le Mexique qui constituent des exceptions en Amérique latine, sont mieux parvenus à s'intégrer dans les réseaux mondiaux de production, ce qui a contribué à la valorisation de leurs exportations. Certaines des différences observées dans les flux d'IDE peuvent certes tenir à des facteurs géographiques et historiques, mais les pays d'Amérique latine peuvent peut-être rendre plus favorable l'environnement des réseaux de production en axant davantage leur action sur le coût des services utilisés pour lier entre eux les blocs de production fragmentés et en améliorant les infrastructures et la gouvernance relatives à ces services dans toute la région ${ }^{1}$.

Les ressources naturelles sont considérées depuis longtemps comme un handicap pour le développement de l'Amérique latine. On est effectivement conduit à le penser lorsque l'on voit comment

\footnotetext{
${ }^{1}$ Voir le tableau 8 de Ando et autres (2006).
} 
les activités manufacturières ont permis aux pays d'Asie de l'Est de bénéficier, dans le passé, d'une plus forte croissance et d'une diminution des termes de l'échange. Il y a toutefois de plus en plus de raisons de croire qu'avec des politiques appropriées, la richesse naturelle peut aussi incorporer de la valeur ajoutée et du savoir. Les pays en développement qui entreprendront à l'avenir une réforme des échanges jugeront sans doute utile de ne pas perdre de vue les enseignements tirés des expériences passées décrites plus haut et de faire en sorte que l'envolée actuelle des prix des matières premières conduise à un développement durable à terme. 


\section{Introduction}

1. La Chine et l'Asie de l'Est ont régulièrement enregistré, depuis les années 70 , des taux de croissance du PIB plus élevés et relativement plus stables que ceux observés en Amérique latine. La première région a certes bénéficié d'un plus important effet de rattrapage, du fait que son niveau de revenu par habitant était plus faible au départ, mais ses résultats n'en sont pas moins remarquables pour autant. Les deux régions se trouvaient dans une situation comparable dans les années 70. Elles étaient toutes deux tributaires des ressources naturelles et des produits manufacturés à partir d'elles pour environ $80 \%$ de leurs exportations. Avant la libéralisation des échanges, les pays des deux régions avaient suivi une stratégie de développement axée sur le remplacement des importations qui se caractérisait par des droits de douane élevés et progressifs, une taxation directe ou indirecte des exportations et des obstacles non tarifaires qui se sont traduits par une mauvaise affectation des ressources et un biais nettement défavorable aux exportations. Tous les pays ont entrepris une réforme des échanges destinée à réduire les distorsions constatées dans l'affectation des ressources et à supprimer le biais allant à l'encontre des exportations. Ils ont généralement atteint ces objectifs en supprimant ou réduisant les restrictions quantitatives, en libéralisant leur tarif douanier et en éliminant progressivement les taxes à l'exportation.

2. Si la direction générale des réformes des échanges a été la même, leur teneur, leur rythme et leur ampleur ont fortement varié entre les régions et les pays. Plusieurs facteurs expliquent certes l'écart observé entre les résultats obtenus sur le plan de la croissance par les deux régions considérées (comme de plus forts taux de formation de capital fixe et d'épargne, par exemple), mais le présent document étudie comment la politique commerciale et l'ajustement structurel lié aux échanges dans les deux régions ont contribué à ces différences de résultats afin de déterminer l'applicabilité des dispositions énoncées sous le titre «Échanges et ajustement structurel: Recommandations de bonnes pratiques » dans l'étude de 2005 de l'OCDE, en considérant plus particulièrement les aspects liés aux politiques commerciales et macroéconomiques. S'il existe d'importantes différences au niveau des pays, nous estimons qu'il existe aussi de nettes tendances régionales qui justifient une analyse. Par exemple, les échanges ont généralement joué un rôle beaucoup plus dynamique dans le processus d'ajustement structurel en Asie de l'Est qu'en Amérique latine. Les exportations ont augmenté plus vite et ont été davantage diversifiées dans la première région que dans la seconde. Les deux régions ont reçu des montants comparables d'IDE, mais celui-ci a été plus orienté vers les activités manufacturières en Chine et en Asie de l'Est. De ce fait, l'Amérique latine est restée une économie reposant dans l'ensemble sur les produits de base alors que l'Asie de l'Est a réussi à diversifier son économie. Le présent document examine les différences générales que présentent les deux régions au niveau des politiques commerciales, de la structure des échanges et des modalités de l'ajustement structurel.

3. L'objet du document étant de comparer deux régions, l'analyse entreprise reste générale. Cette étude doit donc être considérée comme complétant les quatre monographies consacrées au Chili, à l'Équateur, aux Philippines et à la Thaïlande dans le cadre du projet d'étude de l'ajustement structurel lié aux échanges dans les économies non membres. L'analyse menée ici couvre à la fois des pays et des régions. Sept pays d'Asie de l'Est sont considérés: la Chine, l'Indonésie, la Malaisie, les Philippines, Singapour, la Thaïlande et le Vietnam. En raison de sa taille, la Chine est analysée séparément. Huit nations de l'Amérique latine sont également examinées: l'Argentine, le Brésil, le Chili, la Colombie, le Costa Rica, l'Équateur, le Mexique et le Pérou². Les chiffres régionaux sont les moyennes pondérées des résultats par pays, sauf indication contraire ${ }^{3}$.

\footnotetext{
${ }^{2}$ Les pays ont été choisis en fonction de leur taille et de la disponibilité des données.

${ }^{3}$ Bien que les moyennes pondérées fassent mieux apparaître les tendances régionales en tenant compte des différences entre les pays (du point de vue, par exemple, de la taille de l'économie, des chiffres du commerce, etc.),
} 
4. Le document s'ouvre par un exposé des performances économiques et commerciales des deux régions (partie A), suivi d'une comparaison de leur expérience en matière de libéralisation (partie B). Plusieurs indicateurs sont ensuite présentés pour mieux éclairer les performances respectives des deux régions dans le domaine des échanges et de l'investissement (partie $\mathrm{C}$ ). La partie $\mathrm{D}$ considère l'ajustement structurel des économies nationales ainsi que l'emploi. La dernière section conclut l'analyse.

\section{A. Résultats obtenus en matière de croissance, contexte macroéconomique et rôle des échanges et de l'IDE}

5. Les taux de croissance annuels du PIB et du PIB par habitant enregistrés, depuis les années 70, en Asie de l'Est et en Chine, en particulier, ont été sensiblement supérieurs à ceux observés en Amérique latine. Cela tient en partie au fait que la Chine et les autres pays d'Asie de l'Est sont en général partis d'un plus faible niveau de PIB par habitant. Le PIB total et le PIB par habitant ont progressé, respectivement, de $3.4 \%$ et $1.5 \%$ par an au cours des 36 dernières années en Amérique latine et de $6.0 \%$ et $4.5 \%$ en Asie de l'Est (hors Chine). Les taux de croissance enregistrés en Chine ont encore été plus élevés.

6. L'Asie de l'Est a comblé le retard de son revenu par habitant grâce à une croissance plus rapide (graphique 1). En 1975, son revenu par habitant (hors Chine) ne représentait qu'un tiers de celui de l'Amérique latine en termes de parité de pouvoir d'achat. En 2006, il en représentait 55\%. Le PIB par habitant a été multiplié par 2,5 en Asie de l'Est (hors Chine) alors qu'il n'a progressé que de $40 \%$ en Amérique latine. Le rattrapage accompli par la Chine a été plus spectaculaire puisque son revenu par habitant a presque décuplé pendant cette période. Les taux de croissance nationaux du PIB sont plus hétérogènes en Amérique latine qu'en Asie de l'Est. Le Chili et le Costa Rica ont été les deux seuls pays d'Amérique latine dans lesquels le niveau de vie s'est sensiblement amélioré. En revanche tous les pays d'Asie de l'Est, à l'exception des Philippines, ont enregistré des taux de croissance économique remarquables.

Graphique 1. Croissance du PIB par habitant, 1975-2006 ${ }^{a}$

\section{PIB par habitant, PPA (USD internationaux constants de 2000)}

2000

Indice du PIB par habitant $(1975=100)$
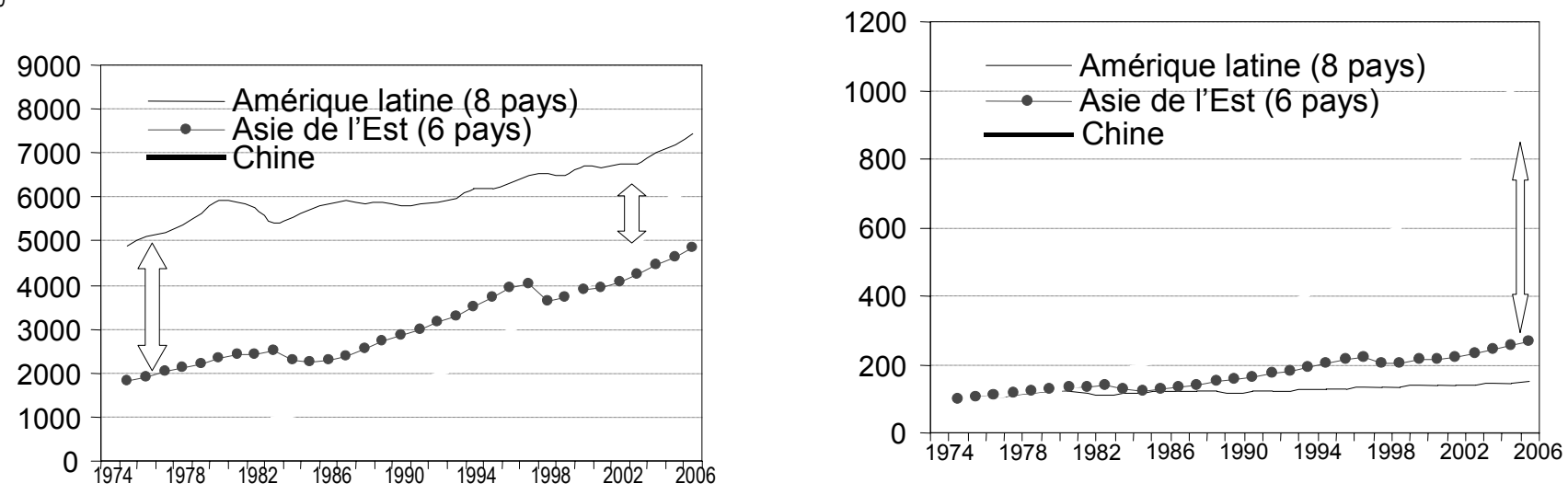

Source: calculs effectués par les auteurs à partir de la base de données de la CEPALC et des Indicateurs du développement dans le monde, 2007 de la Banque mondiale.

${ }^{2}$ Les chiffres régionaux sont la moyenne pondérée des taux de croissance nationaux par habitant en utilisant la population de chaque pays comme coefficients de pondération.

les résultats peuvent parfois être induits par un ou deux pays, comme le Mexique et le Brésil dans le cas de l'Amérique latine. 
7. La Chine et l'Asie de l'Est ont connu une croissance économique non seulement plus rapide, mais aussi moins irrégulière (graphique 2). Alors que l'Asie de l'Est n'a subi qu'une crise en 1997-1998, l'Amérique latine a traversé plusieurs récessions. Dans cette dernière région, la forte croissance des années 70 a été suivie par une " décennie perdue » se caractérisant par de piètres résultats dus à de graves crises de la dette, pendant les années 80 . Malgré une légère reprise pendant les années 90 , plusieurs pays ont continué de connaître des crises, comme le Mexique en 1995, le Brésil en1999 et l'Argentine entre 1999 et 2002. La croissance a repris dans tous les pays de la région entre 2003 et 2006. Elle a, par contre, été plus régulière en Asie de l'Est en dehors de la brève crise survenue à la fin des années $90^{4}$. Dans leur étude des pays latino-américains et d'asiatiques, Gregorio et Lee (2003) estiment, malgré des variations considérables, à environ 5.8 points, pour un pays en développement moyen, le coût en termes de production de chaque crise subie entre 1970 et 1999 . L'instabilité macroéconomique explique donc en partie les différences constatées dans les performances économiques.

8. La plus grande instabilité de l'environnement économique en Amérique latine est aussi attestée par l'irrégularité des taux de hausse des prix à la consommation (graphique 2). Pendant les années 70 et 80 , plusieurs pays de la région ont enregistré des taux d'inflation élevés, voire une hyperinflation, avec des taux de hausse des prix parfois supérieurs à $1000 \%$ sur une base annuelle. De nettes améliorations de la gestion macroéconomique (comptes budgétaires plus équilibrés, par exemple) se sont traduites par une réduction progressive de l'inflation dans les années 90 partout, sauf en Équateur. Dans les années 2000, la plupart des pays de la région ont vu leurs taux d'inflation tomber en dessous de 10\%. En Asie de l'Est, la hausse des prix à la consommation est faible depuis les années 70 en dehors de pics exceptionnels observés dans certains pays comme l'Indonésie à la fin des années 90 et lors de la première crise pétrolière des années 70 .

9. L'instabilité chronique de l'environnement économique qui caractérise l'Amérique latine par rapport à l'Asie de l'Est a profondément affecté son taux d'investissement dans le capital physique (voir le graphique 3). La contribution de l'investissement fixe à la croissance du PIB de la région a été négative pendant les années 80 et n'a atteint que $0.6 \%$ pendant les années 90 . La forte inflation et la grande variabilité des prix relatifs observée concurremment ont gêné les décisions à long terme des entreprises en compliquant les contrats et la planification. Dans un contexte marqué par l'instabilité, les entreprises ont évité de s'engager pour longtemps, les variations probables des prix relatifs risquant de compromettre leur rentabilité (CEPALC, 2006). Les taux d'investissement ont progressivement augmenté à mesure que l'environnement macroéconomique se stabilisait pendant la première moitié des années 2000. En Asie de l'Est et en Chine, le contexte économique plus stable a favorisé des taux d'investissement nettement plus élevés.

\footnotetext{
${ }^{4}$ Les Philippines, qui ont connu plusieurs crises, constituent une exception en Asie de l’Est.
} 
Graphique 2. Taux annuels de croissance du PIB réel et de hausse des prix à la consommation, 1971-2006

(en pourcentages)

Croissance annuelle du PIB réel
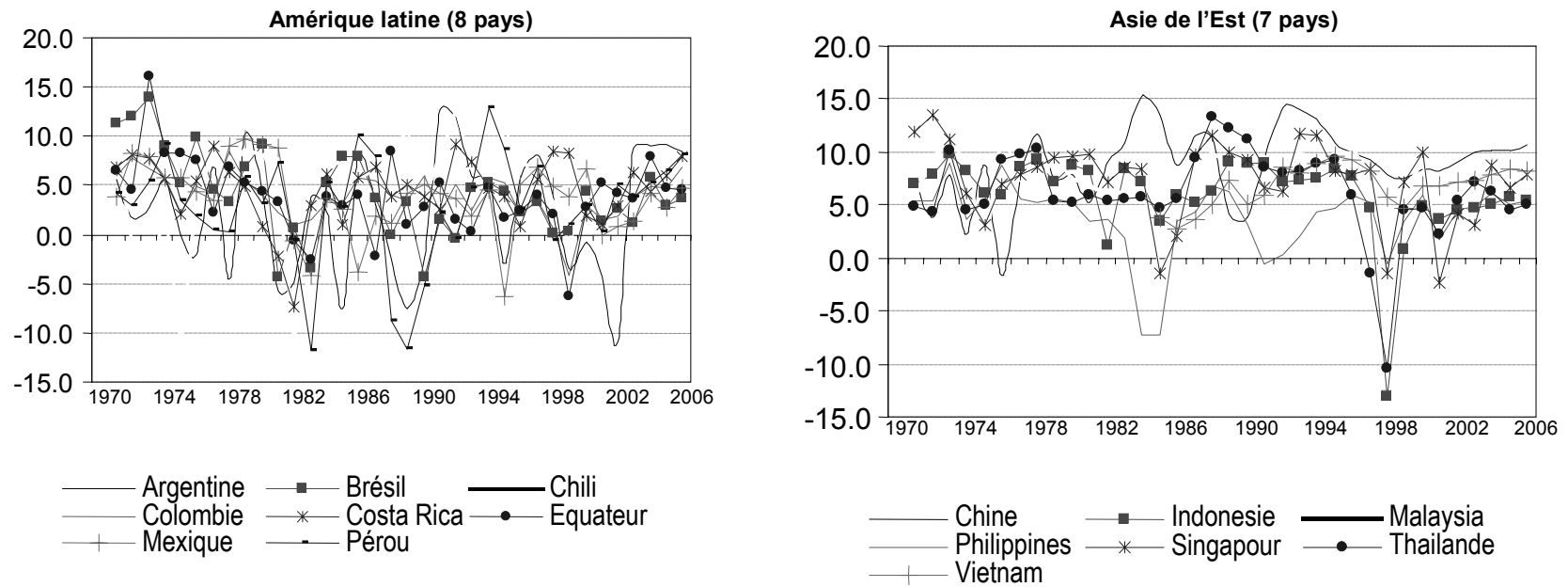

Hausse annuelle des prix à la consommation
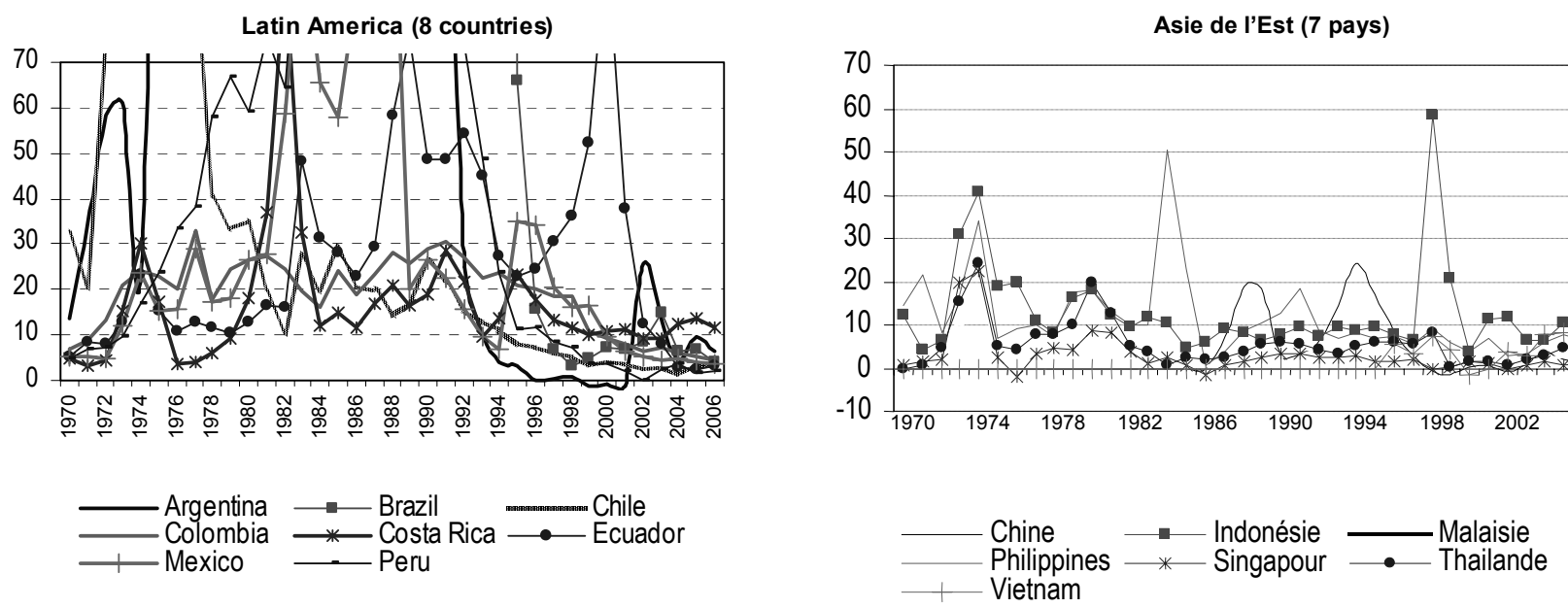

Source: calculs effectués par les auteurs à partir de la base de données de la CEPALC et des Indicateurs du développement dans le monde, 2007 de la Banque mondiale.

10. Si la croissance économique a été plus forte en Asie de l'Est et en Chine qu'en Amérique latine c'est aussi parce que les exportations (nettes) y ont joué un rôle plus dynamique (graphique 3). La contribution du solde extérieur à la croissance a toujours été comprise entre 0.5 et $1 \%$ en Asie de l'Est alors qu'en Amérique latine, elle s'est située aux alentours de $0.4 \%$ pendant les années 80 avant de devenir négative au cours des années 90 et d'être à peu près nulle pendant les années 2000. En Chine, la contribution du solde extérieur au PIB est passée de $-0.5 \%$ pendant les années 80 à plus de $1.5 \%$ durant les années 2000. Le contraste est encore plus net lorsque l'on considère les exportations. Comprise entre 8 et $10 \%$, leur contribution au PIB a été beaucoup plus importante en Asie de l'Est qu'en Amérique latine où 
elle s'est maintenue aux alentours de $2 \%$ pendant les années 2000 malgré une très nette progression au cours de la décennie précédente.

\section{Graphique 3. Décomposition de la croissance du PIB par postes de dépenses entre les années 80 et les années $2000^{\mathrm{a}}$}

(Contributions absolues en points de pourcentage)

Solde extérieur, investissement fixe et consommation

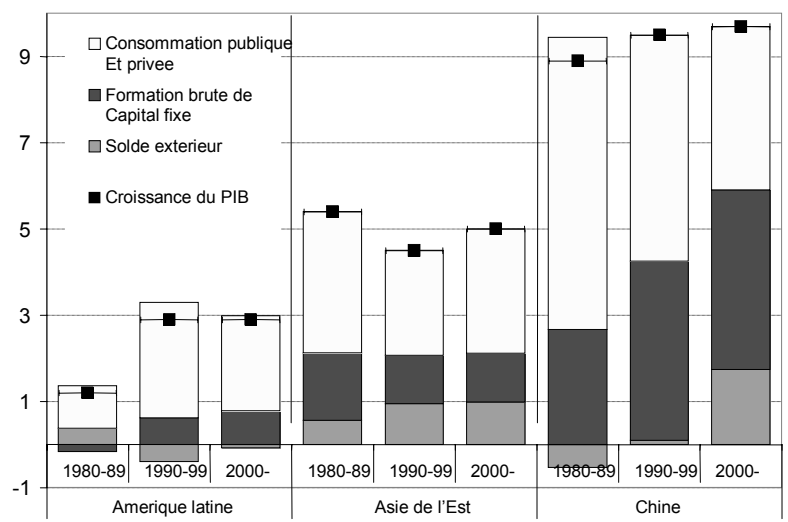

Exportations et importations

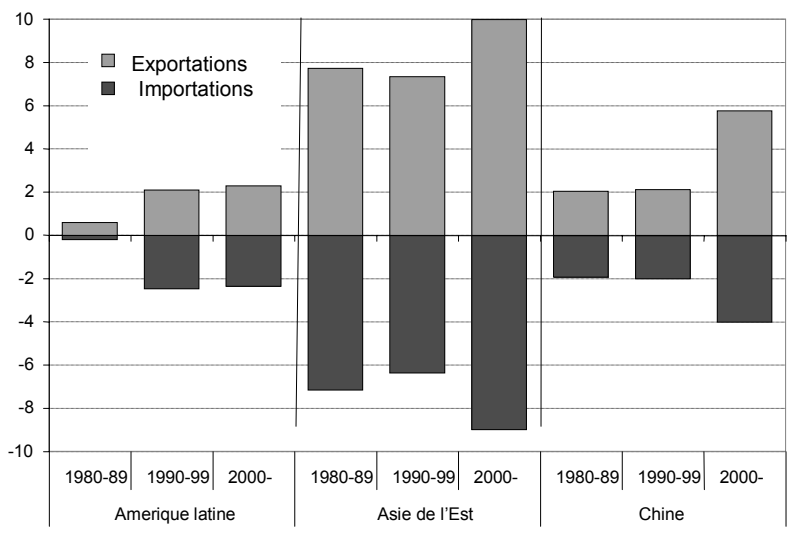

Source: calculs effectués par les auteurs à partir de la base de données sur les comptes nationaux - principaux agrégats du Département des affaires économiques et sociales de l'Organisation des Nations Unies.

a L'Amérique latine inclut ici 8 pays et l'Asie de l'Est 6 pays. Les chiffres régionaux sont la moyenne pondérée des taux nationaux calculée en utilisant le PIB de chaque pays en termes de PPA de 1990 comme coefficient de pondération.

11. La plus forte contribution des échanges à la croissance économique en Asie de l'Est et en Chine découle du fait que les échanges y ont connu une plus forte expansion qu'en Amérique latine (tableaux 1 et 2). Entre 1975 et 2006, la valeur des exportations a été multipliée par un facteur 29, 36 et 162 en Amérique latine, en Asie de l'Est et en Chine, respectivement. L'expansion considérable observée en Chine doit toutefois être relativisée puisque l'économie chinoise était presque entièrement fermée au reste du monde dans les années 70, son rapport échanges/PIB n'étant alors que de 1.6\%. Les exportations de l'Amérique latine ont progressé à un rythme supérieur à la moyenne mondiale à partir de 1990 mais moins vite qu'en Chine et en Asie de l'Est. La progression des exportations latino-américaines a été provisoirement interrompue par le ralentissement économique mondial en 2001-2002. Toutefois, depuis 2003, les exportations de la région augmentent à nouveau fortement sous l'effet de la hausse des prix des produits de base.

12. Bien que le stock d'IDE atteigne des niveaux comparables dans les deux régions (tableau 1), sa part dans le PIB a beaucoup plus augmenté en Amérique latine (tableau 1). Elle y est passée de $8.8 \%$ en 1990 à $29.6 \%$ en 2006 alors qu'elle n'a progressé que de $9.2 \%$ à $11.8 \%$, dans le même temps, en Asie de l'Est hors Chine. 
Tableau 1. Comparaison des niveaux de PIB par habitant, d'exportations et de stocks d'IDE, 1975-2006

\begin{tabular}{|c|c|c|c|c|c|c|c|c|c|}
\hline \multirow{2}{*}{$\begin{array}{l}\text { Indicateurs } \\
\text { Années }\end{array}$} & \multicolumn{3}{|c|}{$\begin{array}{c}\text { PIB par habitant, PPA (USD } \\
\text { internationaux constants de 2000) }\end{array}$} & \multicolumn{3}{|c|}{$\begin{array}{l}\text { Exportations totales } \\
\text { (milliards d'USD courants) }\end{array}$} & \multicolumn{3}{|c|}{$\begin{array}{c}\text { Stocks d'IDE } \\
\text { (milliards d'USD courants) }\end{array}$} \\
\hline & $\begin{array}{l}\text { Amérique } \\
\text { latine } \\
\text { (8 pays) }\end{array}$ & $\begin{array}{l}\text { Asie de } \\
\text { l'Est } \\
\text { (6 pays) }\end{array}$ & Chine & $\begin{array}{l}\text { Amérique } \\
\text { latine } \\
\text { (8 pays) }\end{array}$ & $\begin{array}{l}\text { Asie de } \\
\text { l'Est } \\
\text { (6 pays) }\end{array}$ & Chine & $\begin{array}{l}\text { Amérique } \\
\text { latine } \\
\text { (8 pays) }\end{array}$ & $\begin{array}{c}\text { Asie de } \\
\text { l'Est } \\
\text { (6 pays) }\end{array}$ & Chine \\
\hline 1975 & 4894 & 367 & 604 & 20 & 21 & 6 & 9 & 5 & 0 \\
\hline 1980 & 5944 & 485 & 774 & 62 & 67 & 17 & 27 & 13 & 1 \\
\hline 1990 & 5795 & 722 & 1626 & 107 & 144 & 52 & 86 & 63 & 21 \\
\hline 2000 & 6704 & 1019 & 3940 & 298 & 433 & 249 & 360 & 253 & 193 \\
\hline 2006 & 7422 & 1306 & 6621 & 575 & 750 & 969 & 677 & 401 & 293 \\
\hline
\end{tabular}

Source: calculs effectués par les auteurs à partir des données des Indicateurs du développement dans le monde 2007 de la Banque mondiale, de la CNUCED et du FMI (Direction of Trade Statistics, 2007).

Tableau 2. Rapports échanges/PIB et exportations/PIB, 1970-2006 (en pourcentages)

\begin{tabular}{l|cccccc}
\hline Région & Ouverture & & 1980 & 1990 & $\mathbf{2 0 0 0}$ & $\mathbf{2 0 0 6}$ \\
\hline \multirow{3}{*}{ Amérique latine (8 pays) } & Échanges/PIB & 14.4 & 21.9 & 19.6 & 34.9 & 42.6 \\
\cline { 2 - 7 } & $\begin{array}{c}\text { Exportations/ } \\
\text { PIB }\end{array}$ & 6.9 & 10.3 & 10.9 & 17.4 & 23.2 \\
\hline \multirow{3}{*}{ Asie de l'Est (6 pays) } & Échanges/PIB & 47.1 & 71.1 & 88.2 & 137.3 & 154.9 \\
\cline { 2 - 7 } & $\begin{array}{c}\text { Exportations/ } \\
\text { PIB }\end{array}$ & 20.9 & 37.2 & 43.3 & 75.1 & 81.5 \\
\hline \multirow{3}{*}{ Chine } & Échanges/PIB & 3.2 & 19.4 & 26.5 & 38.7 & 69.9 \\
\cline { 2 - 7 } & $\begin{array}{c}\text { Exportations/ } \\
\text { PIB }\end{array}$ & 1.6 & 9.1 & 14.5 & 20.8 & 38.5 \\
\hline
\end{tabular}

Source: calculs effectués par les auteurs à partir des données des Indicateurs du développement dans le monde 2007 de la Banque mondiale et du FMI (Direction of Trade Statistics).

13. La meilleure tenue du solde extérieur en Asie de l'Est qu'en Amérique latine tient principalement au niveau plus concurrentiel et à la moindre instabilité des taux de change réels qui ont accompagné le processus de libéralisation des échanges. En Asie de l'Est, les banques centrales et les gouvernements ont réussi à éviter une surévaluation et de fortes fluctuations des monnaies nationales en maintenant l'inflation à un faible niveau, respectant une stricte discipline budgétaire et monétaire et limitant le montant de la dette intérieure et extérieure (Kokko, 2002). C'est la situation inverse qui a prévalu en Amérique latine jusqu'au début des années 2000. En effet, le processus de libéralisation des échanges des années 80 et 90 , examiné ci-après de façon plus approfondie, s'est déroulé dans plusieurs pays de la région dans un contexte d'appréciation du taux de change réel. Divers pays ont décidé d'ancrer leur taux de change nominal, ce qui est souvent allé de pair avec sa dépréciation effective à court terme. L'inflation persistante a toutefois très rapidement érodé ces dépréciations ponctuelles et s'est traduite, dans de nombreux cas, par une appréciation excessive à moyen terme ${ }^{5}$.

\section{B. Évolution des politiques relatives aux échanges}

14. À partir des années 80, les deux régions sont passées de politiques de remplacement des importations à des politiques davantage axées sur le marché et les exportations en réduisant les droits de douane et les obstacles non tarifaires dans le cadre de trois processus complémentaires, à savoir une libéralisation des échanges unilatérale, multilatérale et régionale/bilatérale. Dans cette section, nous examinerons tout d'abord l'évolution du rôle des politiques commerciales au fil du temps qui a vu celles-ci

\footnotetext{
${ }^{5}$ Voir, par exemple Agosin et Ffrench Davis (1995) et Ffrench Davis (2005).
} 
passer de politiques de remplacement des importations à des politiques axées sur les exportations. Nous considérerons ensuite les tendances des libéralisations unilatérale et multilatérale des échanges avant d'examiner les initiatives bilatérales et régionales visant à réduire les obstacles aux échanges avec les pays avoisinants et/ou les principaux marchés extérieurs. Nous évaluerons, pour terminer, l'évolution du niveau global de protection.

\section{L'abandon des politiques de remplacement des importations au profit de politiques de développement des exportations}

Amérique latine

15. Jusqu'aux années 80 , l'Amérique latine a mis en œuvre, sous l'impulsion des États, un modèle d'industrialisation fondée sur le remplacement des importations et tournée vers l'intérieur. Les politiques publiques favorisaient le développement des industries manufacturières nationales par le recours à des barrières commerciales élevées, des entreprises publiques et des subventions. Les barrières commerciales dressées étaient élevées pour les importations qui concurrençaient la production nationale mais basses pour certains moyens de production. Les pouvoirs publics privilégiaient la production des biens de consommation de base (chaussures, textiles et articles d'habillement, industrie alimentaire) et de certains biens durables et intermédiaires (produits pétrochimiques et sidérurgiques et matériel de transport) en faisant souvent appel à des entreprises publiques. Les exportations étaient lourdement taxées. Les politiques d'industrialisation fondée sur le remplacement des importations avaient une orientation nettement défavorable aux exportations qui revêtait différentes formes dont celles de droits de douane élevés, de contingents, d'interdictions d'importer, de l'absence ou du nombre limité d'exemptions tarifaires pour les secteurs d'exportation, d'impôts à l'exportation, de contrôles des prix ou d'une surévaluation du taux de change. Les pétrodollars ayant réduit le coût du crédit pendant les années 70 , les pouvoirs publics comme le secteur privé ont beaucoup emprunté et poussé à l'extrême les politiques d'industrialisation fondée sur le remplacement des importations, ce qui a entraîné une forte croissance industrielle et économique qui n'était toutefois pas durable.

16. Les politiques d'industrialisation fondée sur le remplacement des importations ont en effet conduit à d'importants déséquilibres économiques et déficits extérieurs. Quand les prix du pétrole ont baissé et que les taux d'intérêt ont augmenté, les lourdes dettes accumulées se sont avérées insoutenables, ce qui a provoqué la crise de la dette mexicaine en août 1982, suivie par des crises du même ordre dans d'autres pays de la région. La crise de la dette s'est traduite par une décennie «perdue », marquée par une faible croissance ${ }^{6}$, un chômage élevé, une aggravation de la pauvreté et des disparités de revenu, une hyperinflation et l'interruption temporaire des crédits extérieurs. Devant les divers problèmes résultant de la période d'industrialisation fondée sur le remplacement des importations, les hauts niveaux d'endettement et le manque d'efficience de nombreuses industries publiques, l'Amérique latine a été conduite à repenser sa stratégie de développement et à adopter une approche laissant davantage jouer les mécanismes du marché et plus nettement orientée vers l'extérieur et les échanges (Hofman, 1998).

17. Depuis les années 90, une meilleure intégration internationale et le développement des exportations sont les principaux objectifs de l'action menée par les pouvoirs publics pour favoriser la croissance économique. Cette intégration dépend en partie de l'accès aux marchés extérieurs et intérieurs. L'ouverture des marchés a été réalisée grâce à une libéralisation des échanges opérée aux niveaux unilatéral, multilatéral et régional/bilatéral. Entre la fin des années 80 et les années 90, le sous-ensemble de

\footnotetext{
${ }^{6}$ Les années 80 ont été la décennie de la période d'après-guerre au cours de laquelle les plus faibles résultats en matière de croissance ont été enregistrés. Le niveau des revenus par habitant avait régressé en 1990 par rapport à 1980 dans cinq des huit pays considérés. En outre, les recettes par habitant étaient inférieures encore en 2000 à ce qu'elles étaient en 1980 en Colombie et au Pérou.
} 
pays considéré a procédé à de fortes réductions unilatérales de ses droits de douane moyens et activement participé aux négociations d'Uruguay en s'engageant nettement à réduire les obstacles aux importations et à consolider pratiquement toutes ses lignes tarifaires. Plus récemment, les pays d'Amérique latine se sont montrés particulièrement résolus à conclure des accords commerciaux préférentiels bilatéraux et plurilatéraux avec des pays faisant ou non partie de la région. Cela s'explique par le fait qu'une libéralisation unilatérale ne garantit pas l'ouverture des marchés visés et que les négociations multilatérales ont peu progressé. La situation actuelle reflète le résultat des stratégies suivies par les pays pour se positionner sur les principaux marchés extérieurs de façon à ce que leurs produits (à valeur ajoutée) y aient plus largement et plus sûrement accès.

b)

Asie de l'Est

18. Les pays d'Asie de l'Est ont aussi mis en œuvre des politiques d'industrialisation fondée sur le remplacement des importations pour développer leur base manufacturière, mais le passage à une stratégie de croissance orientée vers l'exportation a été plus réussi que dans les pays d'Amérique latine du fait, en partie, qu'à la différence de ces derniers, les pays est-asiatiques ont adopté des mesures de promotion des exportations telles que des exonérations de droits de douane sur les intrants utilisés pour les exportations, des ristournes de droits de douane et des zones franches d'exportation ${ }^{7}$. De plus, pendant les années 80 , la deuxième génération de nouveaux pays industriels (NPI) d'Asie de l'Est (Indonésie, Malaisie et Thaillande) a bénéficié du redéploiement d'entreprises transnationales ${ }^{8}$ effectué au détriment des NPI de la première génération (Hong Kong, Corée, Singapour et Taipei Chinois) sous l'effet de trois tendances: (1) l'appréciation du yen et des monnaies des NPI du premier rang après l'accord du Plaza de 1985; (2) le retrait du bénéfice du système généralisé de préférences (SGP) aux NPI asiatiques en février 1988, et (3) les mesures répressives prises sur les marchés développés à l'encontre des importations en provenance de ces économies et du Japon. Les contingents alloués dans le cadre de l'Arrangement multifibres ont aussi exercé une influence dans le secteur des textiles et de l'habillement.

19. Les stratégies de développement des NPI de la première et de la deuxième génération différaient (Rasiah, 2002 ; Kuwayama et Durán, 2003). La stratégie des NPI de la deuxième génération était beaucoup plus tributaire de l'IDE orienté vers les exportations que celle des NPI de la première (Taipei chinois, Japon et Corée) qui privilégiaient le développement d'industries nationales, à commencer par des activités manufacturières à forte intensité de main-d'œuvre avant de passer ultérieurement à des activités plus pointues sur le plan technologique. Alors que la première stratégie de développement ne permet de renforcer que partiellement les capacités industrielles et technologiques endogènes et que l'absence de mesures appropriées n'a pas encouragé la production et l'utilisation de contenu local (Jomo, 2001), l'IDE a été le moteur de la croissance orientée vers les exportations. Dans ces pays, les entreprises sous contrôle étranger exportaient jusqu'à $90 \%$ de leur production alors que l'entreprise locale type exportait en moyenne moins de 10\% de ce qu'elle produisait (James et Ramstetter, 2005; Ramstetter 1999).

\section{Libéralisation unilatérale des échanges complétée par des accords multilatéraux}

20. Les obstacles au commerce ont été principalement réduits par une libéralisation unilatérale des échanges tant en Asie de l'Est qu'en Amérique latine. Cette réduction unilatérale des obstacles au commerce effectuée pendant les années 80 et 90 a constitué un aspect essentiel de la réforme approfondie des politiques d'industrialisation fondée sur le remplacement des importations qui a été mise en oeuvre dans les deux régions dans le but surtout de réduire le biais défavorable aux exportations résultant desdites

\footnotetext{
${ }^{7}$ Voir Bhattacharya et Linn (1988) pour plus de détails sur les mesures de promotion des exportations prises par les pays d'Asie de l'Est.

8 Par exemple, les principaux centres d'activité des industries informatiques complémentaires comme celles fabriquant des lecteurs de disques ont été transférés en Indonésie, Malaisie et Thaïlande (Rasiah, 1998).
} 
politiques. Ces réformes unilatérales ont souvent été entreprises en périodes de crise, fréquemment dans le cadre de programmes de prêts et/ou d'une concertation avec le FMI et la Banque mondiale sur les politiques à mener. De fait, $79 \%$ de l'ensemble des prêts à l'ajustement accordés par la Banque mondiale aux pays d'Amérique latine entre 1982 et 1989 ont été axés sur la libéralisation des échanges, de même qu'un tiers de tous les programmes assortis d'une forte conditionnalité mis en place par le FMI dans des pays d'Amérique latine entre 1983 et 1985 (Edwards, 1995). En outre, ces deux institutions se sont appuyées sur des études économiques montrant l'impact positif potentiel de la libéralisation des échanges sur l'emploi et l'économie, de manière générale, pour persuader les gouvernements d'entreprendre des réformes des échanges. On en a un exemple avec le Brésil où, à la suite d'une série d'études, de séminaires et de conférences organisés par la Banque mondiale à la fin des années 80 , les pouvoirs publics ont été en mesure de procéder à des réformes des échanges en $1990^{9}$.

21. Les négociations commerciales multilatérales ont complété la libéralisation unilatérale des échanges. En Amérique latine, les réductions unilatérales des droits effectivement appliqués ont précédé la plupart du temps les négociations du Cycle d'Uruguay alors qu'en Asie de l'Est, les réductions tarifaires unilatérales ont le plus souvent été effectuées après ce cycle de négociations. Les négociations multilatérales ont joué un plus grand rôle dans les réformes commerciales des pays qui ont adhéré au GATT et à l'OMC à partir du milieu des années 90. L'Équateur (1996), la Chine (2001) et le Vietnam (2006) ont dû réduire notablement leurs droits de douane et leurs obstacles non tarifaires aux échanges lorsqu'ils ont adhéré à l'OMC. Les conditions d'adhésion ont en effet été durcies après les années 90.

a)

Amérique latine

22. La plupart des pays d'Amérique latine ont commencé à libéraliser unilatéralement leurs échanges dans les années 80, avant le début du Cycle d'Uruguay. Le Chili s'est même engagé plus tôt dans cette voie puisqu'il a réduit ses barrières commerciales dès les années 70 . Ayant déjà sensiblement abaissé leurs droits de douane de façon unilatérale, les pays d'Amérique latine n'ont pas été poussés à procéder à de nouvelles réductions importantes dans le cadre du Cycle d'Uruguay. Il a été tenu compte de la libéralisation unilatérale des échanges effectuée par certains pays dans le cadre des lignes directrices informelles établies pour appliquer le principe de "l'égalité du sacrifice $»^{10}$. On en a pour preuve les réductions limitées de la protection de leur marché que ces pays ont «accordées » par rapport aux réductions plus importantes qu'ils ont «obtenues» de leurs partenaires commerciaux (tableau 3). L'Amérique latine a néanmoins utilisé le Cycle d'Uruguay pour affermir et "verrouiller» ses réformes commerciales unilatérales en consolidant presque tous ses tarifs douaniers. Le cycle de négociations a été utilisé pour approfondir les réformes et soutenir leur processus.

\footnotetext{
${ }^{9}$ D'après Edwards (1995), le FMI et la Banque mondiale ont joué un rôle important dans les réformes qui ont été mises en place en Amérique latine, mais elles $n$ 'en ont pas été les principaux moteurs. Les deux principaux facteurs déclenchants ont plutôt été l'échec des politiques orthodoxes et les enseignements tirés de l'expérience chilienne. Dans ce contexte, ces institutions basées à Washington ont influé sur l'évolution des points de vue à travers leurs études, leurs analyses macroécononiques et sectorielles, leurs programmes de concertation et de prêts et la condionnalité dont leurs programmes sont assortis.

${ }^{10}$ Alors que les réductions tarifaires ou les consolidations de droits de douane étaient généralement négociées sur la base des taux de droits en vigueur en 1988, ce sont les taux en vigueur au début des années 80 qui ont été utilisés pour les pays en développement pour récompenser notamment les efforts de libéralisation unilatérale (Finger et Winters, 2002). Il a en effet été tenu compte, au profit de nombreux pays d'Amérique latine, des réductions unilatérales déjà effectuées dans la réalisation de l'objectif « imposé » aux pays en développement de réduire leurs droits de douane de $25 \%$ (Finger, Reincke et Castro, 2002).
} 
Tableau 3. Amérique latine: libéralisation unilatérale et multilatérale

\begin{tabular}{|c|c|c|c|c|c|c|c|}
\hline \multirow{3}{*}{ Pays } & \multicolumn{2}{|c|}{ Libéralisation unilatérale } & \multicolumn{5}{|c|}{ Libéralisation multilatérale } \\
\hline & \multirow{2}{*}{$\begin{array}{l}\text { Premier programme } \\
\text { de libéralisation }\end{array}$} & \multirow{2}{*}{$\begin{array}{c}\text { Libéralisation } \\
\text { unilatérale } \\
\text { Réductions tarifaires } \\
\text { moyennes }^{\text {a }}\end{array}$} & \multirow{2}{*}{$\begin{array}{l}\text { Entrée } \\
\text { au } \\
\text { GATT }\end{array}$} & \multirow{2}{*}{$\begin{array}{l}\text { Entrée } \\
\text { à } \\
\text { I'OMC }\end{array}$} & \multirow{2}{*}{$\begin{array}{c}\text { Nombre de } \\
\text { cycles de } \\
\text { négociations } \\
\text { multilatérales } \\
\text { auxquels le } \\
\text { pays a pris } \\
\text { part b }\end{array}$} & \multicolumn{2}{|c|}{$\begin{array}{l}\text { Pourcentage de réduction } \\
\text { tarifaire dans le cadre du } \\
\text { Cycle d'Uruguay c }\end{array}$} \\
\hline & & & & & & Obtenu & Accordé \\
\hline Argentine & 1989 & 39.0 à 10.6 & 1967 & 1995 & 1 & 0.98 & 0.00 \\
\hline Brésil & 1990 & 51.0 à 12.2 & 1948 & 1995 & 7 & 1.37 & 0.00 \\
\hline Chili & 1975 & 94.0 tà 4.9 & 1949 & 1995 & 6 & 0.50 & 0.00 \\
\hline Colombie & 1990 & 44.0 à 11.4 & 1981 & 1995 & 1 & 1.25 & 0.02 \\
\hline Costa Rica & 1986 & 27.0 à 6.5 & 1990 & 1995 & 0 & $\ldots$ & $\cdots$ \\
\hline Équateur & 1988 & 40.0 à 11.4 & $\ldots$ & 1996 & 0 & $\ldots$ & $\ldots$ \\
\hline Mexique & 1985 & 24.0 à 18.1 & 1986 & 1995 & 1 & 0.16 & 0.00 \\
\hline Pérou & 1990 & 66.0 à 9.0 & 1951 & 1995 & 5 & 0.57 & 0.03 \\
\hline
\end{tabular}

Source: calculs effectués par les auteurs à partir de Ffrench Davis (1999); Durán (2001) et Finger et Winter (2002).

a Modification de la moyenne tarifaire entre la date du premier programme de libéralisation et 2005. Les tarifs douaniers initiaux sont pondérés par la production intérieure.

${ }^{5}$ Nombre de cycles de négociations auxquels chaque pays a participé: Genève (1947); Annecy (1949); Torquay (1951); Genève (1956); Dillon (1960-1961); Kennedy (1964-1967); Tokyo (1973-1979) et Uruguay (1986-1994).

c Modification moyenne pondérée, mesurée à l'aide de la formule $\mathrm{dT} /(1+\mathrm{t})^{*} 100$ dans laquelle $\mathrm{t}$ correspond à la moyenne des taux avant et après les modifications apportées, calculée pour l'ensemble des lignes tarifaires y compris celles n'ayant pas fait l'objet d'une réduction. Pour plus de détails, voir Finger, Ingco et Reincke (1996).

b) Asie de l'Est

23. En Asie de l'Est, la libéralisation unilatérale des échanges a surtout eu lieu après le Cycle d'Uruguay. Les pays de la région ont été invités à consentir des réductions tarifaires dans le cadre de ce cycle de négociations (tableau 4) et à porter leur taux de consolidation de moins de $10 \%$ à deux tiers dans la plupart des cas, malgré un niveau de taux déjà relativement élevé (Bora et Neufeld, 2001). Plusieurs pays est-asiatiques ont procédé à de nouvelles réductions tarifaires en vertu de l'Accord de 1997 sur les technologies de l'information.

Tableau 4. Asie de l'Est: libéralisation unilatérale et multilatérale

\begin{tabular}{|c|c|c|c|c|c|c|c|}
\hline \multirow[t]{3}{*}{ Pays } & \multicolumn{2}{|c|}{ Libéralisation unilatérale } & \multicolumn{5}{|c|}{ Libéralisation multilatérale } \\
\hline & \multirow{2}{*}{$\begin{array}{l}\text { Premier programme } \\
\text { de libéralisation }\end{array}$} & \multirow{2}{*}{$\begin{array}{l}\text { Libéralisation } \\
\text { unilatérale } \\
\text { Réductions } \\
\text { tarifaires } \\
\text { moyennes }^{\text {a }}\end{array}$} & \multirow{2}{*}{$\begin{array}{l}\text { Entrée } \\
\text { au } \\
\text { GATT }\end{array}$} & \multirow{2}{*}{$\begin{array}{l}\text { Entrée } \\
\text { à } \\
\text { l'OMC }\end{array}$} & \multirow{2}{*}{$\begin{array}{l}\text { Nombre de } \\
\text { cycles de } \\
\text { négociations } \\
\text { multilatérales } \\
\text { auxquels le } \\
\text { pays a pris } \\
\text { part b }\end{array}$} & \multicolumn{2}{|c|}{$\begin{array}{l}\text { Pourcentage de réduction } \\
\text { tarifaire dans le cadre du } \\
\text { Cycle d'Uruguay }{ }^{c}\end{array}$} \\
\hline & & & & & & Obtenu & Accordé \\
\hline Chine & 1990 & 40.3 à 9.0 & 2001 & 2001 & 0 & $\ldots$ & $\ldots$ \\
\hline Indonésie & 1987 & 31.5 à 4.3 & 1950 & 1995 & 5 & 0.87 & 0.25 \\
\hline Malaisie & 1988 & 13.0 à 7.5 & 1957 & 1995 & 4 & 1.46 & 1.97 \\
\hline Philippines & 1986 & 27.9 à 5.4 & 1979 & 1995 & 1 & 2.43 & 1.29 \\
\hline Singapour & 1985 & 0.0 & 1973 & 1995 & 1 & 1.96 & 0.85 \\
\hline Thaïlande & 1982 & 32.0 à 9.9 & 1982 & 1995 & 1 & 1.33 & 5.93 \\
\hline Vietnam & 1990 & ... à 13.4 & $\ldots \ldots$ & 2006 & 0 & $\ldots$ & $\ldots$ \\
\hline
\end{tabular}

Source: calculs effectués par les auteurs à partir de Warwick et autres (2000): Finger et Winter (2002); Rose (2002); CEPALC (2004) et Weimann et autres (2006).

${ }^{2}$ Modification de la moyenne tarifaire entre la date du premier programme de libéralisation et 2005.

${ }^{\mathrm{b}}$ Nombre de cycles de négociations auxquels chaque pays a participé: Genève (1947); Annecy (1949); Torquay (1951); Genève (1956); Dillon (19601961); Kennedy (1964-1967); Tokyo (1973-1979) et Uruguay (1986-1994).

c Modification moyenne pondérée, mesurée à l'aide de la formule $\mathrm{dT} /(1+\mathrm{t})^{\star} 100$ dans laquelle t correspond à la moyenne des taux avant et après les modifications apportées, calculée pour l'ensemble des lignes tarifaires y compris celles n'ayant pas fait l'objet d'une réduction. Pour plus de détails, voir Finger et autres (1996). 


\section{Libéralisation régionale et bilatérale des échanges}

24. L'Amérique latine pratique les accords de libre-échange depuis plus longtemps que l'Asie. Elle s'est lancée dans les accords commerciaux préférentiels et l'intégration régionale dès la fin des années 80 . Certains de ses pays (Chili et Mexique, par exemple) ont en outre négocié divers accords commerciaux bilatéraux avec des pays extérieurs à la région. Il a été conclu plus de 68 accords commerciaux intrarégionaux et 12 accords de libre-échange extrarégionaux qui ont instauré une coopération allant d'une coopération commerciale partielle à une coopération économique totale (CEPALC, 2007) (tableau 5). Les accords de libre-échange et l'intégration régionale sont un phénomène plus récent en Asie de l'Est. La négociation d'accords commerciaux préférentiels s'est intensifiée depuis peu dans les deux régions du fait notamment de la lenteur des progrès observés dans les négociations commerciales multilatérales (Kuwayama, Durán et Silva, 2005).

\section{Tableau 5. Amérique latine: préférences régionales et plurilatérales}

(accords commerciaux préférentiels existant en novembre 2007)

\begin{tabular}{|c|c|c|c|c|}
\hline Pays & $\begin{array}{l}\text { Accords commerciaux préférentiels } \\
\text { intrarégionaux }\end{array}$ & Accords commerciaux préférentiels extrarégionaux & Accords $^{c}$ & Pays $^{c}$ \\
\hline Argentine & $\begin{array}{l}\text { Mercosur (3)+ Communauté andine (5)+Chili } \\
(1)=9\end{array}$ & Mercosur - Union européenne ${ }^{a}$ & 4 & 9 \\
\hline Brésil & $\begin{array}{l}\text { Mercosur (3)+ Communauté andine (5)+Chili } \\
(1)=9\end{array}$ & Mercosur - Union européenne ${ }^{a}$ & 4 & 9 \\
\hline Chili & $\begin{array}{l}\text { Mercosur (4) + Communauté andine }(5)+ \\
\operatorname{MCCA}(5)+\text { Cuba }(1)+\text { Mexique }(1)=16\end{array}$ & $\begin{array}{c}\text { UE (25) +AELE (4) + États-Unis (1) + Canada (1) + } \\
\text { Corée (1) + Nouvelle-Zélande (1), Singapour (1) + } \\
\text { Brunei Darussalam (1) + Chine (1) + Inde (1) + } \\
\text { Japon (1) = } 38 \\
\text { Négociation en cours d'un accord de libre-échange } \\
\text { avec la Thaïlande, la Malaisie et l'Australie }\end{array}$ & 18 & 54 \\
\hline Colombie & $\begin{array}{c}\text { Communauté andine (4) + Mercosur (4) + } \\
\text { CARICOM (14) + Chili (1) + Mexique (1) = } 24\end{array}$ & États-Unis ${ }^{b}$ & 5 & 25 \\
\hline $\begin{array}{l}\text { Costa } \\
\text { Rica }\end{array}$ & $\begin{array}{c}\text { MCCA (4) + Chili (1) + Mexique (1) } \\
+ \text { République dominicaine (1) + Panama (1) + } \\
\text { Trinité-et-Tobago }(1)=9\end{array}$ & $\begin{array}{l}\text { États-Unis (CAFTA) (1) } \\
\quad+\text { Canada }(1)=2\end{array}$ & 8 & 11 \\
\hline Équateur & $\begin{array}{c}\text { Communauté andine (4) + Mercosur (4) + } \\
\text { Cuba (1) + Chili (1) }\end{array}$ & États-Unis ${ }^{\mathrm{b}}(1)$ & 5 & 11 \\
\hline Mexique & $\begin{array}{c}\text { ALENA (3) + Costa Rica (1) + Nicaragua (1) + } \\
\text { Chili (1) + Bolivie (1) + Uruguay (1) + Colombie } \\
(1)=9\end{array}$ & $\begin{array}{c}\text { Union européenne (25)+AELE (4) + ALENA (2) + } \\
\text { Israël (1) + Japon (1) =33 }\end{array}$ & 12 & 42 \\
\hline Nicaragua & $\begin{array}{l}\text { MCCA (4) + République dominicaine (1) + } \\
\text { Panama (1) + Mexique (1) + Chili (1) =8 }\end{array}$ & États-Unis (CAFTA) (1) + Taipei chinois $(1)=2$ & 7 & 10 \\
\hline Pérou & $\begin{array}{l}\text { Communauté andine (4)+Mercosur (4)+Chili } \\
\qquad(1)=9\end{array}$ & États-Unis ${ }^{\mathrm{b}}(1)+$ Thaïlande (1) $=2$ & 5 & 11 \\
\hline
\end{tabular}

Source: Kuwayama et autres, 2005, sur la base des instruments juridiques signés par les pays ou les blocs commerciaux : MERCOSUR Argentine, Brésil, Uruguay et Paraguay; Communauté andine -Bolivie, Colombie, Équateur et Pérou; MCCA (Marché commun centraméricain) - Costa Rica, Salvador, Guatemala, Honduras et Nicaragua; Communauté des Caraïbes (CARICOM) - Antigua-et-Barbuda, Barbade, Bélize, Dominique, Grenade, Guyana, Haïti, Jamaïque, Montserrat, Saint-Kitts-et-Nevis, Sainte-Lucie, Saint-Vincent-et-les-Grenadines, Suriname et Trinité-et-Tobago ; et Association latino-américaine d'intégration (ALADI) (www.aladi.org).

${ }^{a}$ Depuis 1999, le MERCOSUR négocie un accord de coopération interrégionale avec l'Union européenne.

${ }^{b}$ La Colombie et le Pérou ont signé un accord de libre-échange avec les États-Unis en 2006. L'accord avec le Pérou a été ratifié en novembre 2007, mais celui avec la Colombie ne l'a pas encore été.

c Le Mexique, la Colombie et le Venezuela avaient constitué une zone trilatérale de libre-échange appelée G-3. Le Venezuela s'en est retiré en 2006.

\section{a) Amérique latine}

25. Entre 1991 et 2005, la part des exportations préférentielles de l'Amérique latine et des Caraïbes est passée de $8 \%$ à $63 \%$, avec apparemment une plus grande ouverture commerciale dans le cadre des accords commerciaux préférentiels conclus avec des pays extérieurs à la région que dans celui des accords 
commerciaux préférentiels passés avec d'autres pays de la région (CEPALC, 2006) ${ }^{11}$. Les pays qui ont le mieux réussi à ouvrir des marchés extérieurs grâce à des accords de libre-échange sont le Mexique $(96 \%$ des exportations) ainsi que le Costa Rica et le Chili (trois quarts des exportations). Si le MERCOSUR et la Communauté andine parvenaient à conclure un accord de libre-échange avec l'UE et les États-Unis, les accords commerciaux préférentiels couvriraient $72 \%$ de l'ensemble des exportations.

b)

Asie de l'Est

26. Les pays d'Asie de l'Est manifestent, depuis peu, un intérêt croissant pour les accords de libreéchange et les accords de partenariat économique ${ }^{12}$. Les six pays de cette région considérés ici, à l'exclusion de la Chine, sont membres de l'AFTA, instituée en $1992^{13}$. Ses principaux objectifs étaient de rendre la région plus concurrentielle et plus attirante pour l'investissement direct étranger. Ses membres ont décidé, au départ, de rapprocher leur tarif douanier en vue d'instaurer un faible tarif préférentiel effectif commun en 2008. Les cinq membres initiaux de l'ANASE ont déjà introduit, en 2002, un tarif intérieur commun de 0 à $5 \%$ comportant toutefois un nombre considérable d'exceptions. D'autres membres se sont joints à eux par la suite ${ }^{14}$ et en 2010 la zone de libre-échange devrait inclure tous les pays de l'ANASE.

27. Après l'instauration de l'AFTA, aucun accord de libre-échange ou de partenariat économique n'a été négocié jusqu'en 2002 lorsque le Japon et Singapour ont signé un accord de partenariat économique. Depuis, d'autres économies de la région ont participé de plus en plus activement à des négociations pour la conclusion d'accords de libre-échange (Chine, Thaïlande et Singapour, par exemple) (voir le tableau 6). L'une des particularités de l'intégration régionale en Asie de l'Est est que la réalité a précédé le cadre juridique. Malgré l'AFTA, moins de $5 \%$ des échanges effectués au sein de l'ANASE bénéficient des préférences de cette zone de libre-échange (Haddad, 2007). Les pays d'Asie de l'Est ont signé plus de 14 accords intrarégionaux et 6 accords de libre-échange extrarégionaux. Plus d'une vingtaine d'accords sont actuellement en train d'être négociés.

\footnotetext{
${ }^{11}$ Ce calcul a été effectué en postulant que toutes les exportations destinées à des pays avec lesquels il a été passé un accord préférentiel sont des exportations préférentielles. Comme, en général, toutes les exportations ne bénéficient pas de tarifs préférentiels, la progression indiquée est vraisemblablement surévaluée.

${ }^{12}$ Un accord de partenariat économique est plus étendu qu'un accord normal de libre-échange qui ne porte que sur le commerce des biens et des services et l'investissement. Sa teneur varie selon les cas, mais il peut inclure des clauses de coopération portant, par exemple, sur une aide au développement, la circulation des travailleurs et les droits de propriété intellectuelle.

${ }^{13}$ L'Indonésie, la Malaisie, les Philippines et Singapour figurent parmi les membres fondateurs alors que le Vietnam les a rejoints plus tard. Les autres membres du groupe sont le Laos, le Myanmar et le Cambodge

${ }^{14}$ Le Vietnam a adhéré à l'AFTA en 2003, le Laos et le Myanmar en 2005 et le Cambodge devait les rejoindre en 2007.
} 
Tableau 6. Asie de l'Est: préférences régionales et plurilatérales

(accords commerciaux préférentiels existant et en cours de négociation en janvier 2008)

\begin{tabular}{|c|c|c|c|c|}
\hline Pays & Partenaires: Asie & Partenaires: reste du monde & $\begin{array}{c}\text { Nbre } \\
\text { d'accords C }\end{array}$ & $\begin{array}{c}\text { Nbre } \\
\text { de pays C }\end{array}$ \\
\hline Chine - Accords signés & $\begin{array}{c}\text { ANASE }(10)^{\text {a }}+\text { Pakistan (1) + Hong Kong RAS (1) + } \\
\text { Macao RAS (1) }=13\end{array}$ & Chili (1) & 5 & 14 \\
\hline Chine - Négociations en cours & $\begin{array}{c}\text { Australie (1) + Singapour (1) + Nouvelle-Zélande (1) } \\
=3\end{array}$ & $\begin{array}{c}\text { Conseil de coopération du Golfe }{ }^{a}(6)+ \\
\text { Pérou }(1)=7\end{array}$ & 5 & 10 \\
\hline Indonésie - Accords signés & $\begin{array}{c}\text { ANASE (9) +Chine }{ }^{b}(1)+\text { République de } \text { Corée }^{b}(1) \\
+ \text { Japon }(1)=12\end{array}$ & Aucun & 4 & 12 \\
\hline $\begin{array}{l}\text { Indonésie - Négociations en } \\
\text { cours }\end{array}$ & $\begin{array}{c}\text { Inde }^{c}(1)+\text { Australiec }^{c}(1)+\text { Nouvelle-Zélandec }(1)+ \\
\text { Pakistan (1) }=4\end{array}$ & Union européenne ${ }^{c}$ (27) & 5 & 31 \\
\hline Malaisie - Accords signés & $\begin{array}{c}\text { ANASE (9) + Chine (1)b + Japon (1) + République } \\
\text { de Corée }{ }^{b}(1)=12\end{array}$ & Aucun & 4 & 12 \\
\hline $\begin{array}{l}\begin{array}{l}\text { Malaisie - Négociations en } \\
\text { cours }\end{array} \\
\end{array}$ & $\begin{array}{c}\text { Australie (1) + Nouvelle- Zélande (1) + Pakistan (1) } \\
+\operatorname{Inde}^{c}(1)=4\end{array}$ & $\begin{array}{c}\text { États-Unis }=1+\text { Chili }(1)+\text { Union } \\
\text { européenne }^{c}(27)=29\end{array}$ & 7 & 33 \\
\hline Philippines - Accords signés & 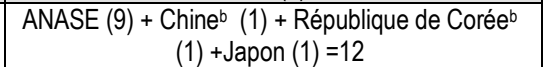 & Aucun & 4 & 12 \\
\hline $\begin{array}{l}\text { Philippines - Négociations en } \\
\text { cours }\end{array}$ & $\begin{array}{c}\text { Australiec }^{c}(1)+\text { Nouvelle-Zélandec }(1)+\operatorname{Inde}^{c}(1)= \\
3\end{array}$ & Union européenne $^{c}(27)$ & 4 & 30 \\
\hline Singapour - Accords signés & \begin{tabular}{|c|} 
ANASE (9) + Chine $^{b}(1)+$ République de \\
Coréeb $^{b}(1)+$ Australie $(1)+$ Nouvelle-Zélande \\
Japon (1) $(1)+14$
\end{tabular} & $\begin{array}{c}\text { États-Unis (1) + AELE (4) + } \\
\text { Jordanie (1) + Panama (1) + Chilid 1) } \\
=8\end{array}$ & 10 & 22 \\
\hline $\begin{array}{l}\text { Singapour - Négociations en } \\
\text { cours }\end{array}$ & Indec (1) + Pakistan (1) $=2$ & $\begin{array}{c}\text { CCG (6) + Canada (1) + Union } \\
\text { européenne }(27)+\text { Mexique (1) + Sri } \\
\text { Lanka (1) + Pérou (1) + Égypte (1) + } \\
\text { Ukraine (1) }=39\end{array}$ & 10 & 41 \\
\hline Thaillande - Accords signés & $\begin{array}{c}\text { ANASE (9) + Chine }(1)+\text { République de Coréeb }(1) \\
+ \text { Inde (1) + Bahreïn (1) + Australie (1) + Nouvelle- } \\
\text { Zélande (1) + Japon (1) }=16\end{array}$ & Ancun & 8 & 16 \\
\hline $\begin{array}{l}\text { Thaillande - Négociations en } \\
\text { cours }\end{array}$ & $\begin{array}{l}\text { Initiative de la baie du Bengale en matière de } \\
\text { coopération technique et économique } \\
\text { multisectorielle (BIMSTEC) } \\
(6)+\operatorname{Inde}^{c}(1)=7\end{array}$ & $\begin{array}{c}\text { Pérou (1) + États-Unis (1) +AELE (4) + } \\
\text { Union européennec }(27)=33\end{array}$ & 6 & 40 \\
\hline Vietnam - Accords signés & $\begin{array}{c}\text { ANASE (9) + } \text { Chine }^{b}(1)+\text { République de } \\
\text { Corée }^{b}(1)=11\end{array}$ & Aucun & 3 & 11 \\
\hline \begin{tabular}{|l}
$\begin{array}{l}\text { Vietnam - Négociations en } \\
\text { cours }\end{array}$ \\
\end{tabular} & 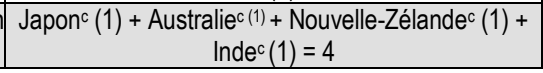 & Chili (1) + Union européennec $(27)=28$ & 6 & 32 \\
\hline
\end{tabular}

Source : tableau établi sur la base de CEPALC (2007), Latin America and the Caribbean in the World Economy 2006, 2007Trends, Indian Export Import portal (2007), - http://exim.indiamart.com/free-trade-agreement/ - ; Office of United States Trade Representative (2008) - http://www.ustr.gov/Trade Agreements/Bilateral/Section Index.html-; Kawai and Wignaraja (2007), ASEAN+3 or ASEAN (6) : Which Way Forward? ADB Institute Discussion Paper $N^{\circ} 77$; and ADB http://aric.adb.org.

${ }^{a}$ Les membres du Conseil de coopération du Golfe sont l'Arabie saoudite, le Bahreïn, les Émirats arabes unis, le Koweît, Oman et le Qatar. Les members de la BIMSTEC sont le Bangladesh, le Bhoutan, l'Inde, le Myanmar, le Népal, le Sri Lanka et la Thaïlande.

b Dans le cadre d'ALE plurilatéraux (ANASE-Chine) ; (ANASE- République de Corée)

c Dans le cadre d'ALE plurilatéraux en cours de négociation avec l'Australie, l'Inde, le Japon, la NouvelleZélande et l'Union européenne.

d Dans le cadre de l'ALE P4 entre Singapour, la Nouvelle-Zélande, Brunei et le Chili, qui compte comme un seul accord.

Note : Lorsqu'un pays (comme le Japon) a conclu un ALE avec un autre pays (comme la Malaisie), à la fois sur une base bilatérale et dans le cadre d'une région (comme l'ANASE), il n'est comptabilisé qu'une fois. 


\section{Protection tarifaire et non tarifaire globale}

28. L'Amérique latine et l'Asie de l'Est ont accompli des progrès considérables dans la réduction des droits de douane et des obstacles non tarifaires. Le droit de douane moyen (non pondéré) effectivement appliqué est tombé, en Amérique latine, de $40 \%$ en 1985 à $24 \%$ en 1990 et $14 \%$ en 2005, et en Asie de l'Est de 35\% à 7.4\% entre 1985 et 2005 (graphique 4). En 2005, les pays appliquant les plus faibles droits NPF étaient le Chili et le Costa Rica, en Amérique latine, et Singapour et l'Indonésie, en Asie de l'Est. Les pays qui appliquaient les droits NPF les plus élevés étaient le Mexique et le Vietnam. Le niveau des droits est encore plus faible lorsque l'on tient compte des droits préférentiels consentis en vertu des accords de libre-échange régionaux, bilatéraux et plurilatéraux, en supposant (pour simplifier) que tout accord de libre-échange se traduit immédiatement par la suppression des droits de douane entre ses signataires ${ }^{15}$.

\section{Graphique 4. Droit de douane moyen effectivement appliqué par chaque pays et moyenne régionale}

(pourcentages non pondérés)

\section{Amérique latine (8 pays)}

Asie de l'Est (7 pays)
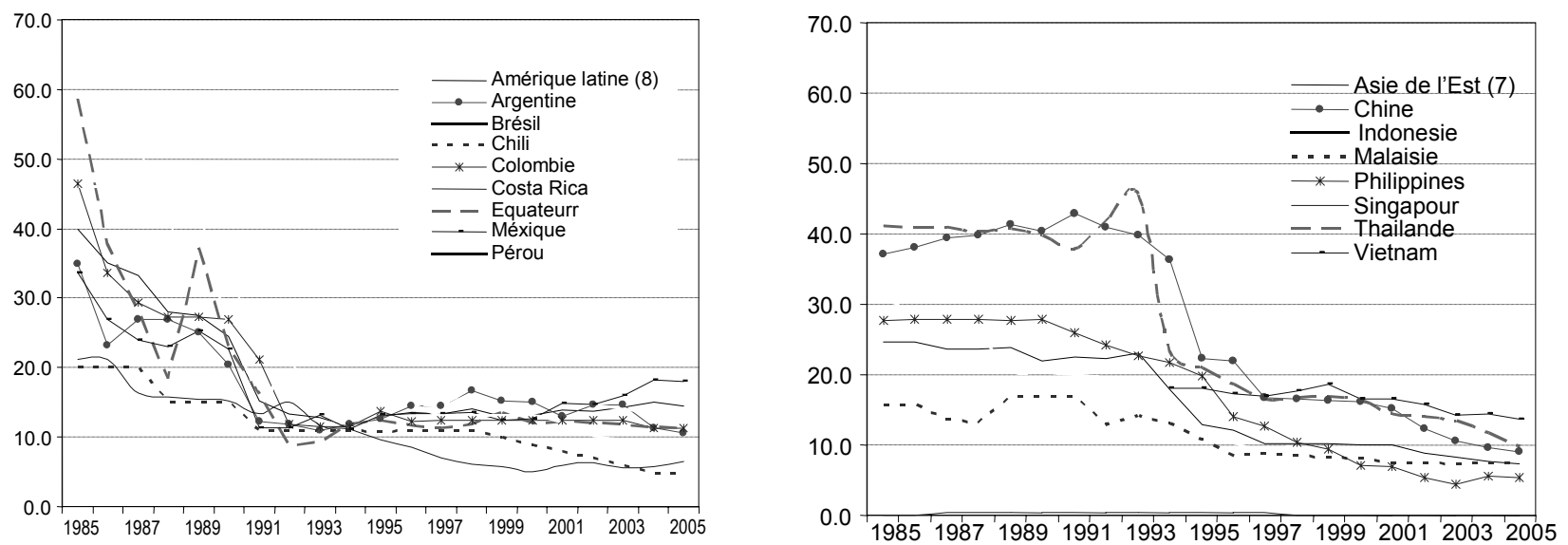

Source: calculs effectués par les auteurs à partir des données de la Banque mondiale (http://econ.worldbank.org/) et du système d'analyse et d'informations commerciales (TRAINS) de la CNUCED.

\footnotetext{
a Le chiffre régional est la moyenne pondérée des droits nationaux calculée en utilisant comme coefficient de pondération la part des importations de chaque pays dans le total des importations régionales pendant l'année considérée.

${ }^{b}$ Ce droit de douane a été calculé en utilisant le pourcentage des importations totales couvert par un accord de libre-échange ou un accord régional, pondéré par le droit de douane moyen, soit $t^{*}=t^{*}(1-\% P T A)$, avec $t^{*}=$ la variable représentative du droit de douane effectivement appliqué; $t=$ le droit de douane moyen et \%PTA = la part de l'ensemble des importations provenant de partenaires commerciaux avec lesquels un accord commercial préférentiel a été conclu. On suppose que les échanges entre les pays liés par un accord commercial sont exempts de droits à partir de l'année de la signature dudit accord.
}

\footnotetext{
${ }^{15}$ Ce simple calcul suppose que tous les échanges effectués au sein de la zone de libre-échange sont immédiatement exempts de droits pour l'ensemble des produits, que les échanges effectués à l'intérieur comme à l'extérieur de la zone présentent la même structure et que toutes les préférences prévues par l'accord de libre-échange sont exploitées. Le chiffre obtenu doit, de ce fait, être considéré comme le niveau «minimal» du taux appliqué pour plusieurs raisons. Premièrement, tous les accords de libre-échange prévoient une période de démarrage au cours de laquelle les droits de douane sont réduits par étapes sur plusieurs années. Deuxièmement, la structure des échanges effectués à l'intérieur et à l'extérieur de la zone de libre-échange diffère. Troisièmement, toutes les préférences prévues par l'accord de libre-échange peuvent ne pas être exploitées si, par exemple, il s'avère difficile de respecter les règles d'origine fixées.
} 
29. Les droits de douane étaient, au départ, plus faibles en Asie de l'Est qu'en Amérique latine, au milieu des années 80. Cette situation s'est inversée à la fin des années 80 du fait que les réductions tarifaires ont été plus lentes dans la première que dans la deuxième région. On a assisté à un nouveau retournement de la situation au milieu des années 90 sous l'effet du relèvement des droits NPF dans certains pays d'Amérique latine (Argentine et Mexique, notamment). Toutefois, lorsque l'on tient compte des accords de libre-échange, les droits de douane ont continué de baisser après le milieu des années 90 , ce qui indique une convergence vers le bas des niveaux de protection douanière (graphique 5).

Graphique 5. Droits de douane moyens effectivement appliqués en Amérique latine et en Asie de l'Est. ${ }^{a}$
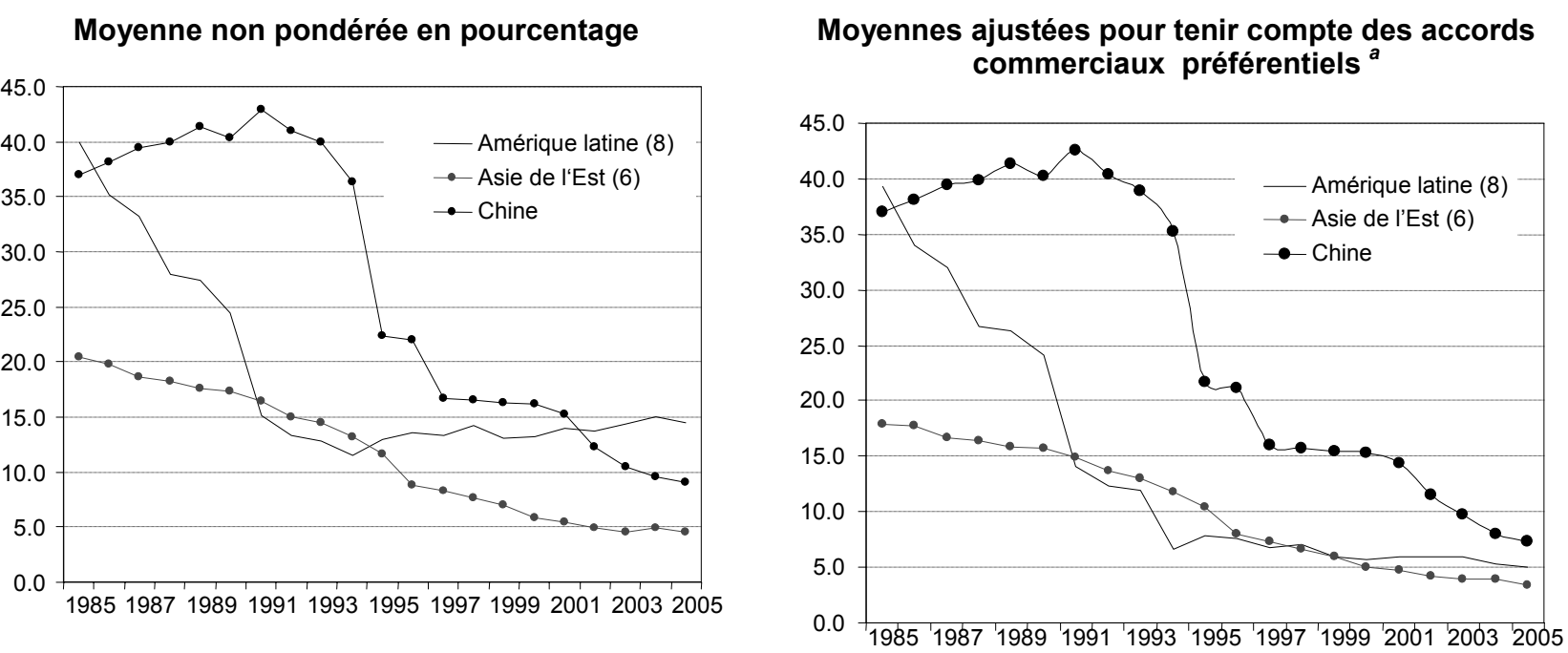

Source: calculs effectués par les auteurs à partir des données de la Banque mondiale (http://econ.worldbank.org/) et du système d'analyse et d'informations commerciales (TRAINS) de la CNUCED.

30. Une ventilation des droits de douane appliqués, par sections à un chiffre de la CTCI (Rév.2), montre qu'en 2005 ceux-ci étaient loin d'être homogènes dans les différents secteurs tant en Amérique latine qu'en Asie de l'Est. Des pays d'Asie de l'Est appliquaient des droits atteignant jusqu'à 70\% (boissons) alors que les droits de douane étaient généralement plus élevés dans les pays d'Amérique latine sans qu'aucun groupe de produits particulier ne se singularise (tableau 7). 
Tableau 7. Droits de douane moyens effectivement appliqués en Amérique latine et en Asie de l'Est, par pays, en 2005

(pourcentages non pondérés)

\begin{tabular}{|c|c|c|c|c|c|c|c|c|c|c|c|c|c|c|c|c|}
\hline \multirow{2}{*}{\multicolumn{2}{|c|}{ Régions }} & \multicolumn{8}{|c|}{ Amérique latine (8 pays) } & \multicolumn{7}{|c|}{ Asie de l'Est (7 pays) } \\
\hline & & 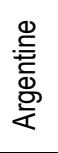 & $\begin{array}{l}\bar{\Phi} \\
\bar{\Phi}\end{array}$ & 言 & $\frac{\text { 응 }}{\text { 응 }}$ & 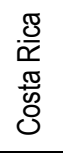 & 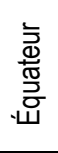 & 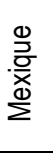 & 홇 & $\frac{\mathscr{\Phi}}{\frac{\text { C }}{U}}$ & $\begin{array}{l}\frac{\mathscr{U}}{\mathscr{\Phi}} \\
\text { 응 } \\
\text { 으 }\end{array}$ & $\frac{\frac{\mathscr{D}}{\mathscr{D}}}{\frac{\vec{D}}{\mathbb{N}}}$ & 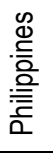 & 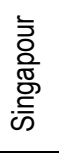 & 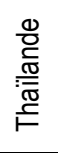 & 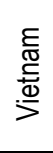 \\
\hline 0 & $\begin{array}{l}\text { Produits alimentaires et animaux } \\
\text { vivants }\end{array}$ & 3.9 & 3.2 & 1.8 & 12.3 & 12.5 & 11.3 & 4.5 & 7.9 & 11.4 & 5.0 & 3.0 & 6.2 & 0.0 & 8.6 & 14.2 \\
\hline 1 & Boissons et tabacs & 9.8 & 16.6 & 3.5 & 13.1 & 18.1 & 17.3 & 7.0 & 12.7 & 12.2 & 18.2 & 19.8 & 8.5 & 0.0 & 39.6 & 70.1 \\
\hline 2 & Matières brutes & 1.0 & 2.9 & 1.3 & 5.8 & 1.5 & 4.2 & 0.6 & 7.7 & 3.5 & 1.5 & 1.1 & 3.0 & 0.0 & 4.1 & 1.7 \\
\hline 3 & $\begin{array}{l}\text { Combustibles minéraux etc. } \\
\text { Huiles, graisses et cires d'origine }\end{array}$ & 0.6 & 0.2 & 3.4 & 6.7 & 3.7 & 1.0 & 1.1 & 11.4 & 1.6 & 2.4 & 1.2 & 4.6 & 0.0 & 0.6 & 15.5 \\
\hline 4 & animale ou végétale & 6.2 & 7.6 & 1.9 & 16.7 & 9.0 & 15.5 & 4.0 & 3.2 & 12.3 & 3.4 & 2.1 & 4.1 & 0.0 & 10.9 & 9.6 \\
\hline 5 & $\begin{array}{l}\text { Produits chimiques } \\
\text { Articles manufacturés classés }\end{array}$ & 5.2 & 6.2 & 3.7 & 6.8 & 2.8 & 6.1 & 1.2 & 6.3 & 7.3 & 6.1 & 4.9 & 4.3 & 0.0 & 5.9 & 3.3 \\
\hline 6 & d'après la matière première & 6.2 & 10.2 & 3.7 & 10.6 & 4.8 & 9.5 & 2.9 & 8.3 & 6.4 & 8.2 & 15.5 & 5.7 & 0.0 & 5.1 & 17.1 \\
\hline 7 & Machines et matériel de transport & 5.2 & 9.9 & 4.6 & 9.9 & 1.9 & 10.1 & 3.1 & 7.0 & 4.0 & 5.8 & 2.8 & 1.5 & 0.0 & 5.4 & 11.7 \\
\hline 8 & Articles manufacturés divers & 9.7 & 13.1 & 5.2 & 12.4 & 8.8 & 14.5 & 5.5 & 11.2 & 7.6 & 9.4 & 4.8 & 5.3 & 0.0 & 9.6 & 20.4 \\
\hline 9 & $\begin{array}{l}\text { Articles et transactions. non } \\
\text { classés ailleurs }\end{array}$ & 6.3 & 17.3 & 4.7 & 18.3 & 5.3 & 18.4 & 0.7 & 11.9 & 4.8 & 0.7 & 0.1 & 2.6 & 0.0 & 0.2 & 6.6 \\
\hline
\end{tabular}




\section{Amérique latine (8 pays), Asie de l'Est (6 pays) et Chine, moyenne simple des droits de douane effectivement appliqués, par secteurs: 2005}

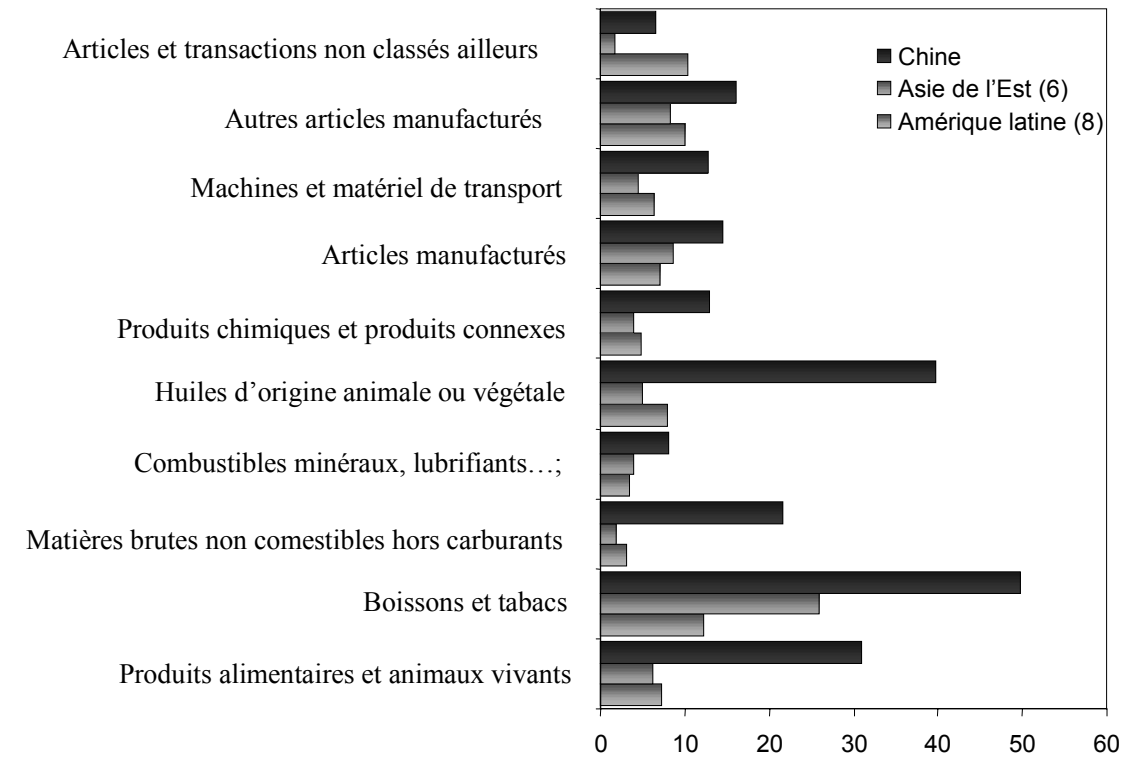

Source: calculs effectués par les auteurs à partir de la base de données COMTRADE et du système TRAINS des Nations Unies.

31. Les obstacles non tarifaires (ONT) ont aussi été assez sensiblement réduits à la faveur d'initiatives unilatérales et d'engagements pris dans le cadre de l'intégration régionale, c'est-à-dire plusieurs unions douanières en Amérique latine et la déclaration de Bogor de 1994 pour les pays de $1^{\prime} A P E C{ }^{16}$. L'incidence des ONT a diminué au fil des ans avec une réduction de leurs niveaux mais on observe en général une plus forte incidence des ONT dans les pays appliquant des droits de douane plus élevés. La trajectoire de la réduction des ONT a différé de celle des réductions tarifaires dans la mesure où l'abaissement des ONT semble avoir été dans l'ensemble plus rapide en Asie de l'Est qu'en Amérique latine malgré d'importantes variations d'un pays à l'autre (tableau 8). Le Brésil, la Chine et la Thaïlande ont assez fréquemment recours aux ONT. Une ventilation par secteur indique que ces mesures atteignent leurs plus forts taux de fréquence en Chine, en Malaisie, en Thaïlande et au Vietnam, surtout pour les produits manufacturés (tableau 9).

\footnotetext{
${ }^{16}$ La déclaration de Bogor de l'APEC préconise une libéralisation totale des échanges et de l'investissement direct étranger d'ici à 2010 pour les pays membres développés et d'ici à 2020 pour les pays membres en développement. Chaque membre élabore et met en œuvre un plan annuel d'action individuel (IAP), c'est-à-dire un inventaire des mesures de libéralisation et d'ouverture des échanges et de l'investissement prises pour respecter cet engagement. Les membres fixent leur propre calendrier et leurs propres objectifs et prennent ces initiatives de leur plein gré et sur une base non contraignante. Ils rendent compte de l'action menée dans quinze domaines: droits de douane, ONT, services, investissements, normes et conformité, procédures douanières, propriété intellectuelle, politique de la concurrence, marchés publics, déréglementation/réexamen de la réglementation, obligations de l'OMC (règles d'origine comprises), règlement des différends, mobilité des gens d'affaires, et collecte et analyse d'informations. Chaque année, plusieurs membres se portent volontaires pour que leur IAP soit examiné par des experts et le conseil consultatif des gens d'affaires de l'APEC (ABAC) qui est un organisme privé indépendant.
} 
Tableau 8. Taux de couverture des obstacles non tarifaires aux échanges, 1984-2001

\begin{tabular}{|c|c|c|c|c|}
\hline & $1984-1987$ & $1988-1990$ & $1991-1993$ & $\mathbf{2 0 0 1}$ \\
\hline $\begin{array}{c}\text { Pays d'Amérique latine } \\
\text { retenus: }\end{array}$ & & & & \\
\hline Argentine & 31.9 & 16.1 & 0.2 & n.d. \\
Brésil & 35.3 & 3.2 & 1.5 & 3.9 \\
Chili & 10.1 & 10.6 & 0.1 & 0.4 \\
Colombie & 73.2 & 73.8 & 1.7 & n.d. \\
Costa Rica & 0.8 & n.d. & n.d. & n.d. \\
Équateur & 59.3 & 63.6 & n.d. & n.d. \\
Mexique & 12.7 & 6.3 & 3.9 & 1.2 \\
Pérou & 53.4 & n.d. & n.d. & 0.2 \\
\hline Pays d'Asie de l'Est retenus: & & & & \\
\hline Chine & 10.6 & 23.2 & 11.3 & 7.6 \\
Indonésie & 94.7 & 9.4 & 2.7 & 1.8 \\
Malaisie & 3.7 & 2.8 & 2.1 & 2.5 \\
Philippines & 44.9 & n.d. & n.d. & 1.7 \\
Singapour & 14.7 & 1.0 & 0.3 & 0.2 \\
Thaillande & 12.4 & 8.8 & 5.5 & 4.0 \\
Vietnam & n.d. & n.d. & n.d. & n.d. \\
\hline
\end{tabular}

Source : calculs effectués par les auteurs à partir de Bijit Bora, Aki Kuwahara et Sam Laird (2002).

Note: n.d. = non disponible.

Tableau 9. Taux de fréquence des obstacles non tarifaires (ONT) par produits dans les pays retenus, 2001

\begin{tabular}{|c|c|c|c|c|c|c|c|c|c|c|c|}
\hline Catégories de produits (CTCl) & $\begin{array}{l}\overline{\overline{\mathscr{Q}}} \\
\stackrel{\overline{\mathscr{\omega}}}{\bar{m}}\end{array}$ & 言 & $\begin{array}{l}\frac{0}{\partial} \\
\cdot \frac{0}{x} \\
\stackrel{0}{\Sigma}\end{array}$ & 밈 & $\frac{\mathscr{E}}{\frac{\text { C }}{\mathrm{U}}}$ & 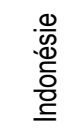 & $\frac{\frac{0}{N}}{\frac{0}{\frac{N}{T}}}$ & 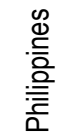 & 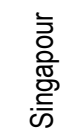 & 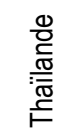 & 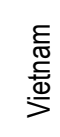 \\
\hline Produits primaires $(0-4,68)$ & 3.5 & 1.2 & 2.4 & 0.9 & 6.5 & 4.4 & 3.0 & 0.7 & 0.6 & 6.3 & 0.4 \\
\hline Agriculture $(0-2,4)$ & 3.8 & 1.4 & 2.5 & 1.0 & 7.3 & 3.4 & 3.5 & 0.8 & 0.7 & 6.7 & 0.4 \\
\hline Industries extractives $(3,68)$ & 2.5 & n.d. & 1.7 & n.d. & 1.5 & 10.8 & n.d. & 0.6 & n.d. & 4.2 & 0.5 \\
\hline Produits manufacturés (5-8,moins 68$)$ & 3.9 & 0.2 & 0.8 & n.d. & 8.0 & 1.1 & 2.4 & 1.9 & 0.1 & 3.3 & 1.2 \\
\hline Produits sidérurgiques (67) & 0.5 & n.d. & n.d. & n.d. & 44.9 & 1.9 & 8.0 & n.d. & n.d. & n.d. & 21.7 \\
\hline $\begin{array}{l}\text { Produits chimiques }(5) \\
\text { Autres produits semi-manufacturés }(61 \text { - }\end{array}$ & 0.9 & n.d. & 0.1 & n.d. & 3.9 & 1.6 & 0.8 & 4.7 & n.d. & 0.2 & 0.1 \\
\hline $64,66,69)$ & 2.2 & n.d. & 0.1 & n.d. & 1.4 & 1.2 & 0.9 & 0.6 & n.d. & 1.5 & 0.4 \\
\hline Machines et matériel de transport (7) & 8.1 & 0.7 & 2.3 & 0.1 & 14.0 & 1.9 & 4.3 & 1.9 & 0.6 & 1.4 & n.d. \\
\hline Textiles et habillement $(65,84)$ & 5.4 & n.d. & n.d. & 0.1 & 2.9 & n.d. & 0.3 & n.d. & n.d. & 13.5 & n.d. \\
\hline $\begin{array}{l}\text { Autres biens de consommation } \text { (81- } \\
83,85,87-89)\end{array}$ & 6.9 & n.d. & 1.6 & n.d. & 5.1 & n.d. & 4.3 & 2.7 & n.d. & n.d. & n.d. \\
\hline Autres produits (9) & n.d. & n.d. & n.d. & n.d. & n.d. & n.d. & n.d. & 8.3 & n.d. & n.d. & n.d. \\
\hline Ensemble des produits $(0-9)$ & 3.9 & 0.4 & 1.2 & 0.2 & 7.6 & 1.8 & 2.5 & 1.7 & 0.2 & 4.0 & 1.0 \\
\hline
\end{tabular}

Source : Bijit Bora, Aki Kuwahara et Sam Laird (2002).

Note : n.d. = non disponible. 


\section{Indicateurs des échanges et de l'investissement direct étranger}

32. Les réformes commerciales décrites à grands traits plus haut ont eu un effet notable sur les échanges internationaux et les entrées d'investissement direct étranger (IDE). À de nombreux égards, les échanges ont davantage contribué à la croissance économique en Chine et en Asie de l'Est qu'en Amérique latine en raison de leur plus grand dynamisme, de leur plus large diversification et de leur adaptation plus rapide au progrès technologique. Cette différence entre les deux régions s'explique notamment par la plus forte orientation vers l'exportation des économies est-asiatiques pendant la période d'industrialisation fondée sur le remplacement des importations, le rôle déterminant joué par l'IDE dans la création de nouveaux avantages comparatifs pour les produits de moyenne et haute technicité et la persistance d'un biais défavorable aux exportations en Amérique latine malgré de profondes réformes commerciales.

\section{Diversification des exportations}

33. Les exportations de l'Asie de l'Est se sont davantage diversifiées que celles de l'Amérique latine et ont, de ce fait, davantage contribué à la croissance économique et à la réduction de son instabilité. La diversification des exportations stimule la croissance économique de deux façons (Agosin, 2007). D'une part par l'effet de portefeuille selon lequel des exportations plus diversifiées produisant des recettes plus stables, la croissance économique est elle aussi moins variable. D'autre part, la diversification s'accompagne d'effets dynamiques puisque la productivité augmente quand les pays diversifient leurs exportations et leur base de production. Ce processus est lié à l'accumulation de compétences, à l'apprentissage par la pratique et aux externalités associées à la production d'intrants ne faisant pas l'objet d'échanges internationaux. Agosin montre qu'avec des taux plus élevés d'investissement fixe, la plus grande diversification des exportations explique, pour l'essentiel, les différences observées au niveau de la croissance économique entre l'Asie de l'Est et l'Amérique latine. La diversification ou la concentration des exportations est mesurée ici à l'aide de l'indice de Herfindahl Hirschman $(\mathrm{IHH})^{17}$ et calculée en utilisant les positions à cinq chiffres de la Classification type pour le commerce international (CTCI, rév.2). Plus le IHH est faible, moins les exportations sont concentrées ou plus elles sont diversifiées.

34. Dans l'ensemble, les exportations sont plus diversifiées en Asie de l'Est qu'en Amérique latine hormis plusieurs exceptions. Les niveaux de diversification des exportations diffèrent fortement d'un pays à l'autre et doivent être compris dans le contexte des facteurs nationaux qui contribuent à réduire la concentration des exportations (revenu par habitant, taille du pays, part des produits manufacturés dans les exportations et ouverture commerciale, par exemple) et de ceux qui ont l'effet opposé (dotation en ressources naturelles, par exemple) ${ }^{18}$. Ces facteurs semblent expliquer relativement bien la position des

${ }^{17}$ On mesure la diversification des exportations à l'aide de l'indice de Herfindahl-Hirschman (IHH), dans lequel la
part de chaque produit dans l'ensemble des exportations d'un pays est pondérée de façon à ce qu'une exportation de
faible valeur n'influe que légèrement sur l'indicateur. On utilise pour cela le carré des parts de marché des divers
produits pour chaque pays. L'IHH se calcule normalement comme suit: $H H=\frac{\left(\sum_{j=1}^{n} p_{j}^{2}-\frac{1}{n}\right)}{1-\frac{1}{n}}$ où $p_{j=X_{I J} / X T_{I}}$ correspond à la part de marché du produit j dans l'ensemble des exportations mondiales du pays $i$, c'est-à-dire $X T i$.
Plus l'indice est proche de l'unité, plus le panier d'exportations est concentré. Un indice supérieur à 0.18 est considéré comme correspondant à une « concentration moyenne ».

${ }^{18}$ La concentration des exportations diminue avec l'augmentation du revenu par habitant jusqu'à un seuil d'environ 20000 USD internationaux (PPA), aux prix de 1995, après quoi le niveau de concentration augmente à nouveau. Cette courbe en U a été confirmée par Klinger et Lederman (2006). 
pays situés aux deux extrémités de la concentration des exportations (graphique 6). En effet, les plus grandes économies des deux régions considérées, la Chine et le Brésil, sont aussi celles dont les exportations sont le plus diversifiées. À l'inverse, des pays largement dotés en ressources naturelles, comme l'Équateur et le Chili, ont une gamme d'exportations relativement concentrée. Dans ces deux pays d'Amérique latine, peu de produits représentent plus de $90 \%$ des exportations (40 et 75 produits sur plus de 1000 groupes de produits de la CTCI, respectivement). La position relative des pays se situant entre ces deux extrêmes est plus difficile à comprendre. Par exemple, la diversification des exportations observée en Thaillande, au Mexique, en Malaisie et au Costa Rica peut tenir à l'existence de bases industrielles étendues tandis que la position de la Colombie et de la Thaïlande s'explique peut-être par la faiblesse de la part des produits manufacturés dans les exportations.

35. On a observé une diversification des exportations dans 9 des 15 pays considérés, entre 1980 et 2006, parallèlement à un accroissement du revenu par habitant, une libéralisation des échanges et un renforcement du rôle joué par les produits manufacturés dans les exportations. Les niveaux de concentration des exportations ont surtout diminué pendant les années 80 lorsque de nombreux pays ont commencé à libéraliser leur commerce. Ce mouvement de déconcentration des exportations a été particulièrement marqué en Indonésie, au Mexique et en Colombie. On a assisté, à l'inverse, à une concentration des exportations au fil du temps aux Philippines, à Singapour et au Pérou. Dans le cas de Singapour, les exportations se sont de nouveau concentrées sur les domaines dans lesquels le pays jouit d'un avantage comparatif.

Graphique 6. Diversification des exportations, 1990-2005

(Indices de Herfindahl-Hirschman)

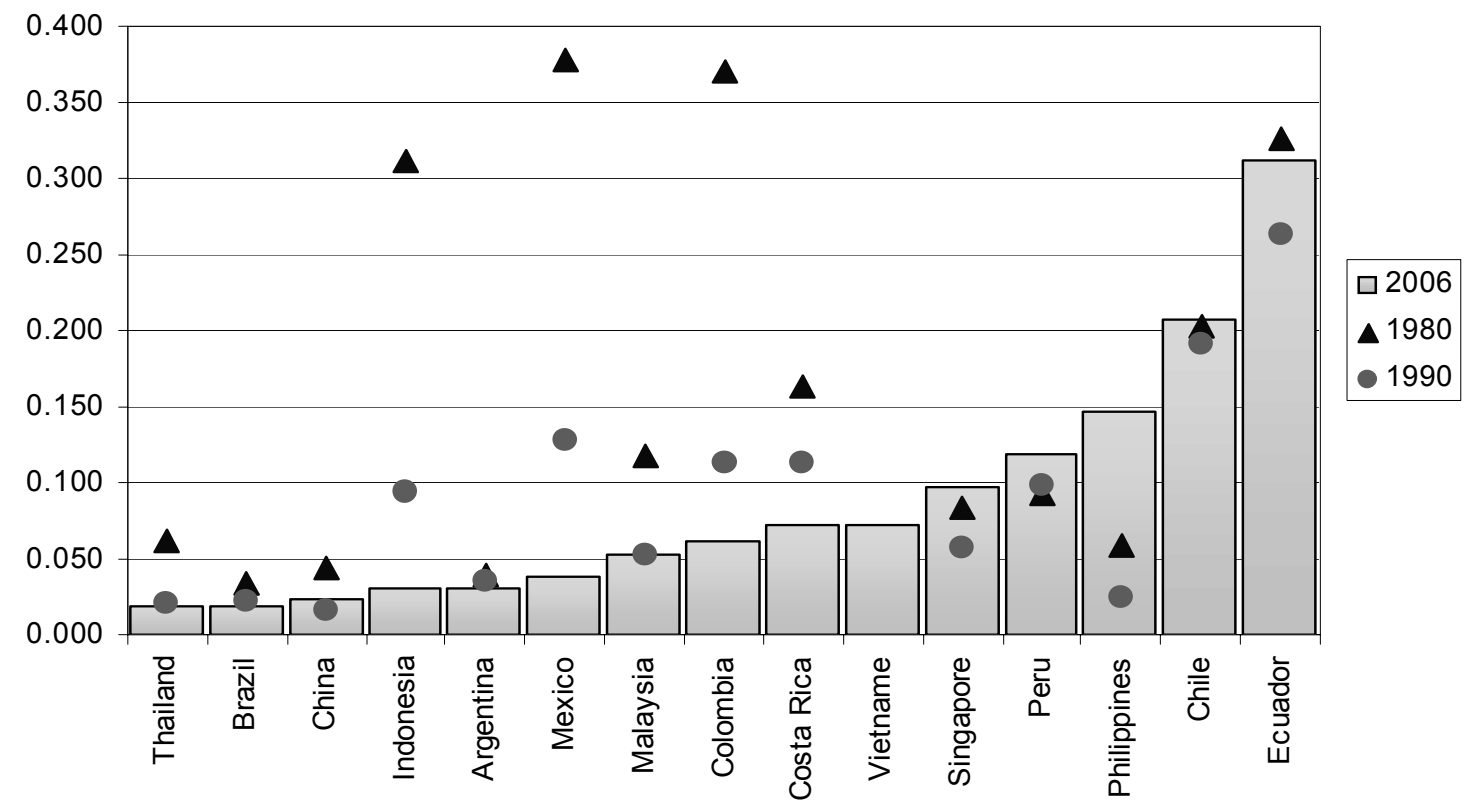

Source: calculs effectués par les auteurs à partir de la base de données COMTRADE.

36. Si les exportations sont moins concentrées en Asie de l'Est qu'en Amérique latine, c'est aussi en partie parce que le contexte est plus favorable au développement de nouveaux types d'exportations dans la première région. Avant la libéralisation des échanges, les politiques d'industrialisation fondée sur le remplacement des importations avaient une orientation nettement plus défavorable aux exportations en Amérique latine (voir plus haut) puisqu'en Asie de l'Est la protection du marché intérieur était liée à des mesures d'encouragement des exportations. Le contexte était aussi plus favorable aux exportations en Asie 
de l'Est en raison notamment d'un meilleur accès aux intrants nécessaires à la production de biens exportables aux prix mondiaux, de taux de change réels plus concurrentiels et d'une plus grande facilité d'obtention de crédits bonifiés (Weiss, 2005).

37. Parmi les facteurs précédemment mentionnés, le fait que les taux de change étaient plus concurrentiels en Asie de l'Est qu'en Amérique latine est probablement la principale raison pour laquelle la diversification des exportations a été mieux réussie dans la première que dans la deuxième région. Il existe une nette corrélation négative en Amérique latine entre le niveau et l'instabilité des taux de change et l'accroissement du rapport entre les biens de consommation durables et les diffuseurs de progrès technique, d'une part, et l'ensemble des exportations, d'autre part, entre 1970 et 2003 (CEPALC, 2006b). Les importations de biens d'équipement ont en outre eu un effet positif sur ce rapport. Celui-ci est censé représenter le processus de diversification des exportations selon lequel les exportations de produits de base cèdent progressivement la place à des exportations de produits manufacturés à moyenne ou forte intensité technologique.

\section{Rôle des exportations de produits manufacturés de moyenne et haute technicité}

38. Les produits de moyenne et haute technicité sont les produits manufacturés qui sont les plus susceptibles d'avoir un effet positif sur la croissance et la productivité. Ils favorisent la croissance économique non seulement parce que les échanges internationaux dont ils font l'objet augmentent plus rapidement du fait de leur forte élasticité par rapport aux revenus, mais aussi parce qu'ils créent une nouvelle demande et qu'ils remplacent plus rapidement les anciens produits. Ils permettent aussi davantage d'incorporer de nouvelles connaissances scientifiques au niveau surtout de leur conception. La production de nombre d'entre eux nécessite des infrastructures technologiques élaborées, de hauts niveaux de compétences techniques spécialisées et d'étroites interactions entre entreprises et entre entreprises et universités. Dans certains cas, toutefois, comme dans celui de l'électronique, les biens sont produits dans le cadre de systèmes de production intégrés au niveau international qui séparent les divers processus et les répartissent géographiquement en fonction des différences de coûts salariaux, de la présence de maind'œuvre qualifiée et des infrastructures existantes en matière de R-D. Lorsque seul le montage final est effectué dans des pays à bas salaires, l'effet des exportations de produits de moyenne et haute technicité sur la croissance économique peut être plus restreint.

39. Dans les années 70, les ressources naturelles et les produits manufacturés à partir d'elles représentaient environ $80 \%$ des exportations des deux régions considérées ici. Au cours des trente dernières années, celles-ci ont réduit la part des produits de base dans leurs exportations et augmenté celle des produits de haute technicité (graphique 7). Cette mutation structurelle a toutefois été plus marquée en Asie de l'Est et en Chine qu'en Amérique latine. En 2004-2006, la part des produits de moyenne et haute technicité était plus élevée d'environ 10 points en Asie de l'Est et en Chine qu'en Amérique latine. Une ventilation régionale par pays montre que c'est au Costa Rica et aux Philippines que l'accroissement de la part de ces produits a été le plus spectaculaire (graphique 8). 


\section{Graphique 7. Composition des exportations selon leur degré d'intensité technologique, années $\mathbf{7 0}$-années 2000}

(en pourcentage de l'ensemble des exportations)

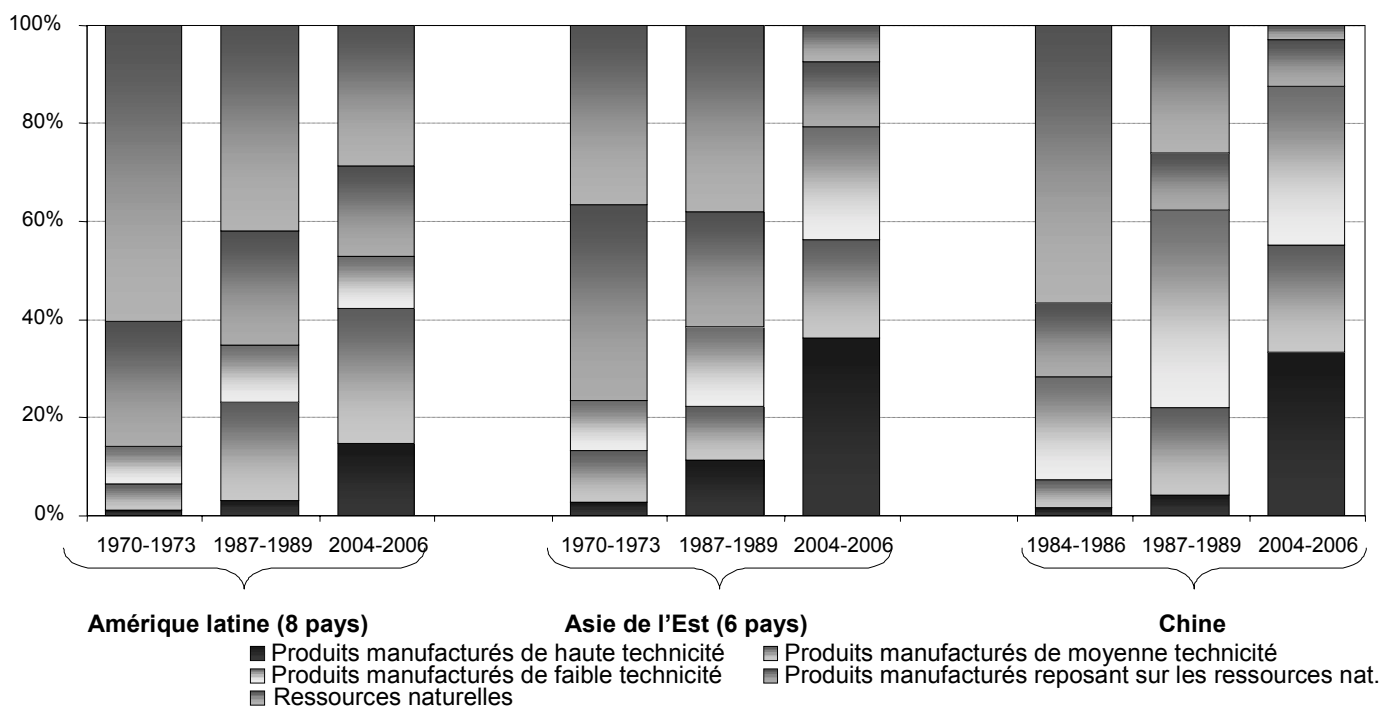

Source: calculs effectués par les auteurs à partir de la base de données COMTRADE.

Graphique 8. Part des produits de moyenne et haute technicité dans les exportations, 1993 et 2003

(en pourcentage)

Exportations

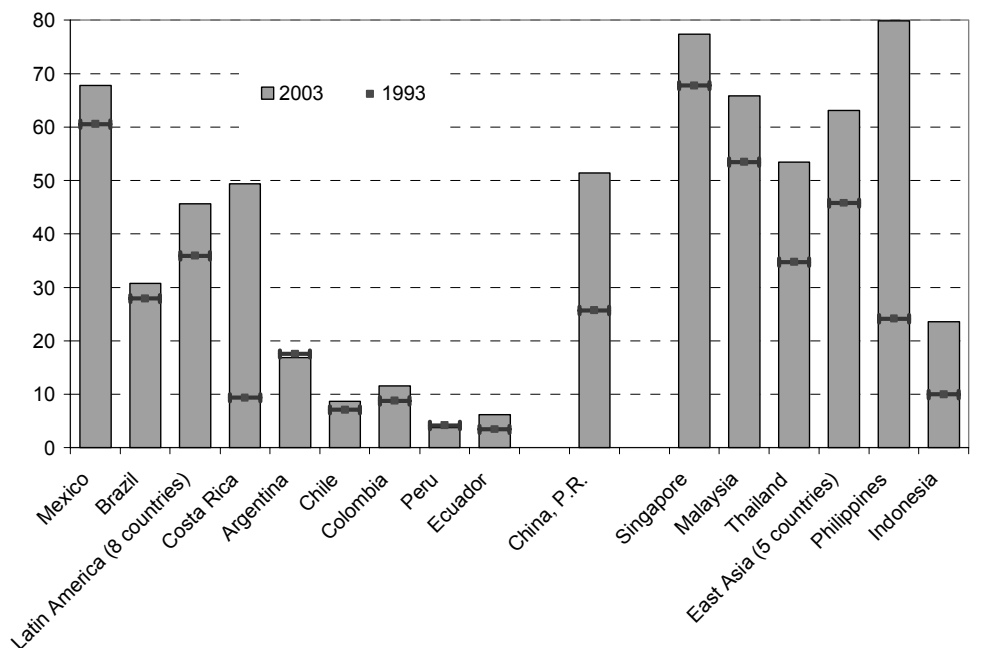

Source: calculs effectués par les auteurs à partir de Industrial Scoreboard 2007 de l'ONUDI.

40. Cette modification de la composition des exportations s'est aussi reflétée dans l'évolution des balances commerciales par catégories de produits (tableau 10). À la fin des années 80, l'Asie comme l'Amérique latine enregistraient un excédent commercial pour les produits de base et un déficit pour les produits de haute technicité. Au fil du temps, la Chine et l'Asie de l'Est ont cessé d'être des exportateurs nets de produits de base pour en devenir des importateurs nets et d'être des importateurs nets de produits de haute technicité pour en devenir des exportateurs nets. En revanche, l'Amérique latine a accentué la 
position traditionnelle de sa balance commerciale en dépit de la nette amélioration technologique de ses exportations: l'excédent commercial enregistré pour les produits de base et les produits manufacturés à partir des ressources naturelles a augmenté tandis les déficits accusés pour les produits manufacturés de moyenne et haute technicité se sont aggravés.

41. La ventilation par pays montre que chaque région continue d'être assez hétérogène. En Amérique latine, le Mexique et le Costa Rica ainsi que - dans une moindre mesure - le Brésil, se distinguent par la façon dont ils ont valorisé leurs exportations au fil du temps (tableau 11). Aujourd'hui, près des deux tiers des exportations mexicaines se composent de produits de moyenne ou haute technicité. En revanche, les autres pays de la région restent fortement tributaires, pour leurs exportations, des produits de base ou des produits manufacturés qui en contiennent une forte proportion. En Asie de l'Est, on a assisté partout à une valorisation considérable des exportations, mais l'Indonésie et le Vietnam sont en partie restés spécialisés dans les ressources naturelles (tableau 12).

Tableau 10. Exportations, importations et balance commerciale par niveau d'intensité technologique, 1987-1989 et 2004-2006

(milliards d'USD)

\begin{tabular}{|c|c|c|c|c|c|c|c|c|c|c|}
\hline \multirow{2}{*}{\multicolumn{2}{|c|}{ Régions (pays retenus) }} & \multicolumn{3}{|c|}{$\begin{array}{c}\text { Amérique latine } \\
\text { (8 pays) }\end{array}$} & \multicolumn{3}{|c|}{$\begin{array}{c}\text { Asie de l'Est (5 pays) } \\
\text { (Vietnam exclu) }\end{array}$} & \multicolumn{3}{|c|}{ Chine } \\
\hline & & Export. & Import. & Solde & Export. & Import. & Solde & Export. & Import. & Solde \\
\hline \multirow{6}{*}{ 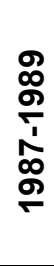 } & Produits de base & 32.9 & 12.4 & 20.6 & 24.0 & 15.4 & 8.6 & 11.6 & 5.3 & 6.3 \\
\hline & Prod.manuf. à partir de RN & 18.5 & 10.9 & 7.6 & 24.6 & 17.1 & 7.5 & 5.2 & 7.3 & -2.0 \\
\hline & Faible technicité & 9.3 & 5.1 & 4.2 & 11.4 & 11.9 & -0.4 & 18.0 & 10.7 & 7.3 \\
\hline & Moyenne technicité & 15.6 & 19.8 & -4.2 & 13.1 & 33.2 & -20.1 & 7.9 & 23.5 & -15.6 \\
\hline & Haute technicité & 2.5 & 7.7 & -5.2 & 18.8 & 20.9 & -2.1 & 1.9 & 6.3 & -4.4 \\
\hline & Total & 78.8 & 55.8 & 22.9 & 92.0 & 98.5 & -6.5 & 44.6 & 53.1 & -8.4 \\
\hline \multirow{6}{*}{ 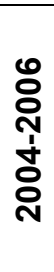 } & Produits de base & 1328 & 45.1 & 87.7 & 648 & 716 & -68 & 238 & $109 ?$ & -853 \\
\hline & Prod.manuf. à partir de RN & 86.3 & 65.7 & 20.6 & 112.4 & 87.5 & 24.9 & 73.3 & 86.5 & -13.2 \\
\hline & Faible technicité & 49.0 & 55.1 & -6.1 & 62.9 & 44.6 & 18.2 & 249.1 & 52.2 & 196.9 \\
\hline & Moyenne technicité & 126.5 & 151.6 & -25.2 & 115.0 & 127.1 & -12.1 & 170.6 & 182.4 & -11.8 \\
\hline & Haute technicité & 68.4 & 90.0 & -21.6 & 245.4 & 198.8 & 46.6 & 257.6 & 239.1 & 18.5 \\
\hline & Total & 462.9 & 407.5 & 55.4 & 600.6 & 529.6 & 70.9 & 774.5 & 669.4 & 105.1 \\
\hline
\end{tabular}

Source: calculs effectués par les auteurs à partir de la base de données COMTRADE des Nations Unies et du système en ligne SIGCI de la Division de l'intégration et du commerce internationaux (http://www.eclac.cl/comercio/).

${ }^{a}$ Classification des échanges en cinq groupes suivant Lall (2000): Groupe 1.- Produits de base (inclut des produits comme les fruits frais, la viande, le riz, le cacao, le thé, le café, le bois, le charbon, le pétrole brut, le gaz et les métaux de base); Groupe 2.- Produits manufacturés à partir de ressources naturelles (inclut les produits reposant sur les ressources agricoles et forestières et d'autres ressources naturelles tels que: les concentrés de minerais, les produits pétroliers et les produits dérivés du caoutchouc, le ciment, les pierres précieuses taillées, le verre): Groupe 3.- Produits de faible technicité inclut les textiles et les vêtements, les grès, les éléments/structures métalliques simples, les meubles, les bijoux, les jouets et les produits en matières plastiques; Groupe 4.Produits de moyenne technicité inclut les produits de l'industrie automobile, les produits reposant sur des procédés de transformation de moyenne technicité (fibres synthétiques, produits chimiques et peintures, engrais, matières plastiques, fer, tuyaux et tubes) et les produits des industries mécaniques de moyenne technicité comme les moteurs, les machines industrielles, les pompes, les boîtes de vitesse, les navires et les montres; et Groupe 5.- Produits de haute technicité inclut les produits électroniques et électriques (matériel de bureau, de traitement des données et de télécommunication, téléviseurs, transistors, turbines, matériel nécessaire à la production d'électricité) et d'autres produits de haute technicité comme les produits pharmaceutiques, les aéronefs, les instruments d'optique et de mesure, les appareils photographiques. Ces groupes correspondent aux groupes à trois chiffres de la CTCI, rév. 2 . 
Tableau 11. Amérique latine (8 pays): évolution de la composition des exportations, 1987-2006

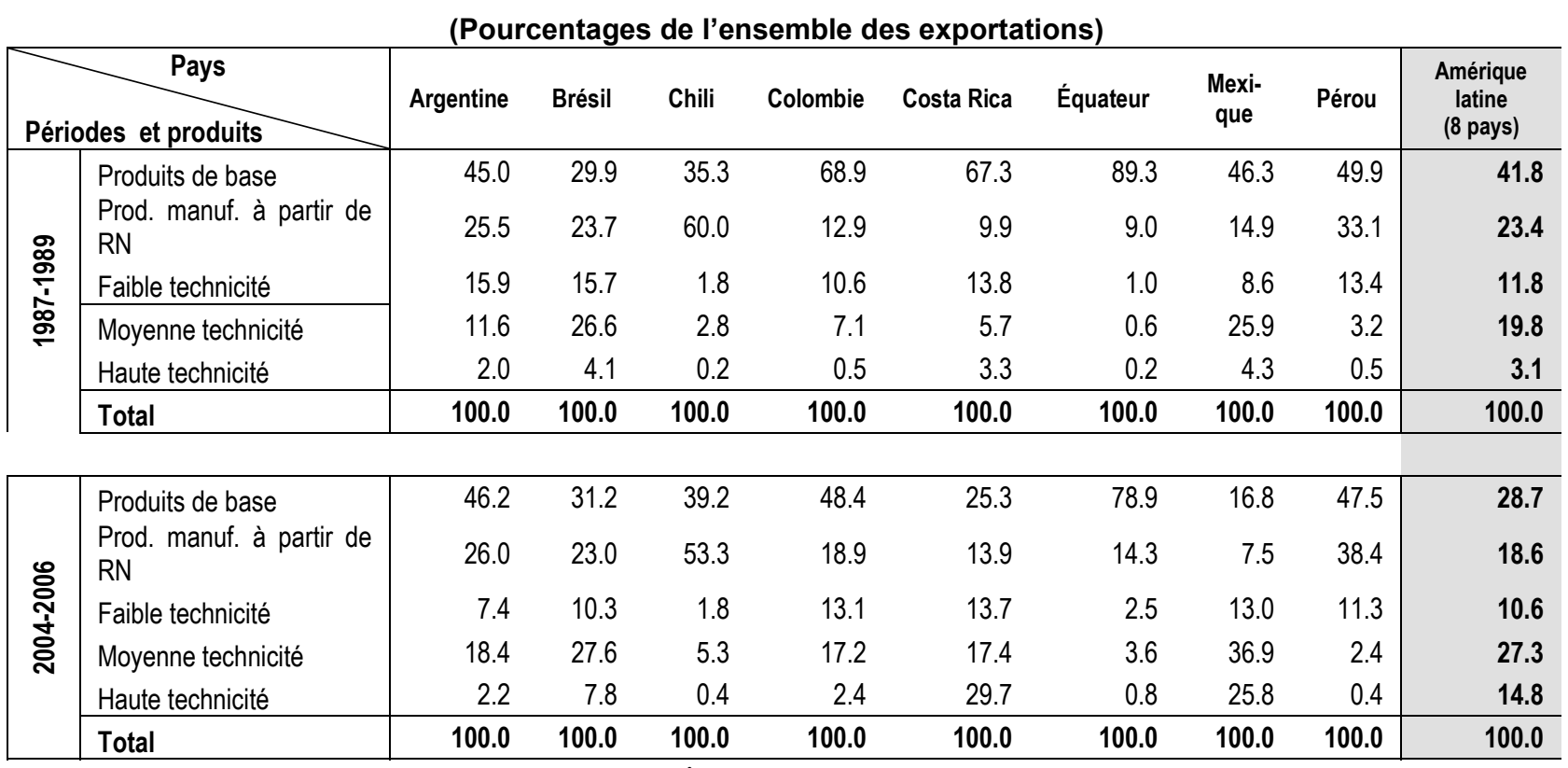

Source : calculs effectués par les auteurs à partir de la base de données statistiques des Nations Unies sur le commerce des marchandises (COMTRADE) et de la base de données en ligne de la Division de l'intégration et du commerce internationaux - système SIGCI (http://www.eclac.cl/comercio/).

Tableau 12. Asie de l'Est (7 pays): évolution de la composition des exportations, 1987-2006

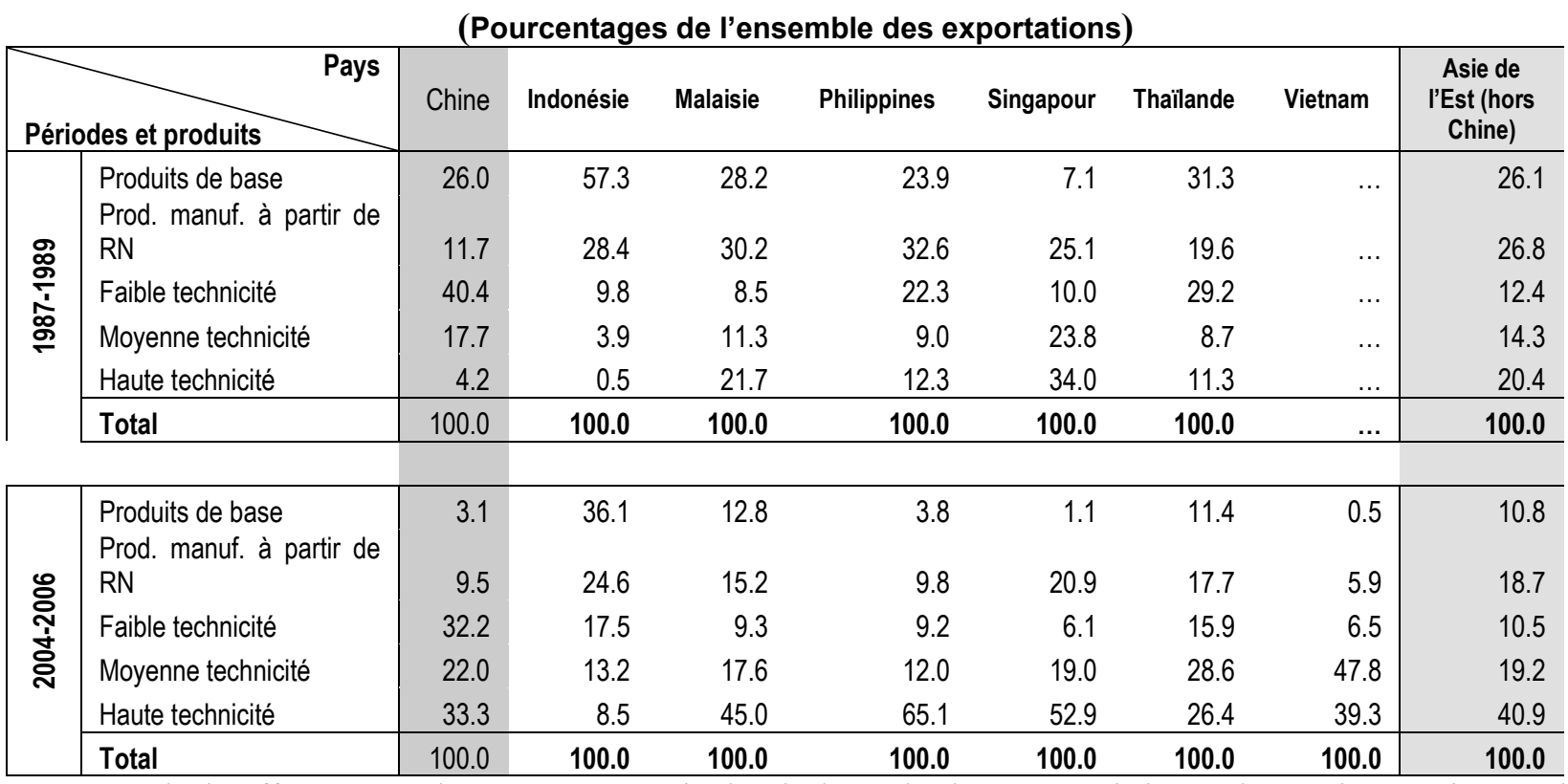

Source: calculs effectués par les auteurs à partir de la base de données statistiques des Nations Unies sur le commerce des marchandises (COMTRADE) et de la base de données en ligne SIGCI de la CEPALC (http://www.eclac.cl/comercio/).

42. L'Asie de l'Est a également mieux réussi que l'Amérique latine à créer de nouveaux avantages comparatifs dynamiques pour ses exportations au fil du temps, avec des retombées considérables pour la croissance économique (tableau 13). On peut étudier ce phénomène à l'aide du cadre d'analyse de 
l'avantage comparatif révélé (RCA) proposé par Balassa ${ }^{19}$. Un chiffre supérieur à l'unité indique que la part d'un pays dans les exportations mondiales d'un produit est plus grande que sa part globale dans les exportations mondiales. Dans les années 60 et 70, l'Amérique latine comme l'Asie jouissaient d'avantages comparatifs pour des produits comme les denrées alimentaires, les matières brutes et les huiles animales et végétales. L'Amérique latine est restée très spécialisée, au fil des ans, dans les produits de base et les produits manufacturés en contenant une forte proportion, comme on peut l'attendre d'une région richement dotée en ressources naturelles telles, entre autres, que des produits pétroliers, des produits minéraux et des terres. Certains estiment que les ressources naturelles ont peut-être en fait constitué un " handicap » pour le développement de la région du fait que la forte rentabilité de leur exploitation, qui ne nécessite qu'un faible apport technologique, a freiné la valorisation des exportations (Kuwayama et Durán, 2003). L'histoire de l'Asie de l'Est est différente, surtout depuis l'année 2000: la région a réduit l'avantage comparatif dont elle jouissait pour les denrées alimentaires et les matières premières ${ }^{20}$ tout en augmentant notablement ses avantages pour les produits manufacturés (catégories 5, 6 et 7 de la CTCI, rév.1).

Tableau 13. Avantage comparatif révélé: 1962-2005

(sur la base de la valeur des exportations)

\begin{tabular}{|c|c|c|c|c|c|c|c|c|c|c|c|c|c|}
\hline \multirow{2}{*}{\multicolumn{2}{|c|}{$\begin{array}{ll} & \text { Régions } \\
\text { Secteurs } & \\
\end{array}$}} & \multicolumn{6}{|c|}{ Amérique latine (8) } & \multicolumn{6}{|c|}{ Asie de l'Est (5) } \\
\hline & & 1962 & 1970 & 1980 & 1990 & 2000 & 2005 & $1962^{\mathrm{a}}$ & $1970^{a}$ & 1980 & 1990 & 2000 & 2005 \\
\hline \multicolumn{2}{|r|}{$\begin{array}{ll}\text { Produits alimentaires et animaux } \\
\text { vivants }\end{array}$} & 3.9 & 4.4 & 3.9 & 3.1 & 2.5 & 2.8 & 1.1 & 1.5 & 1.2 & 1.3 & 0.9 & 0.7 \\
\hline \multirow{4}{*}{\multicolumn{2}{|c|}{$\begin{array}{ll}1 & \text { Boissons et tabacs } \\
2 & \text { Matières brutes non comestibles } \\
3 & \text { Combustibles minéraux, lubrifiants } \\
& \text { Huiles et graisses d'origine animale } \\
4 & \text { et végétale }\end{array}$}} & 0.5 & 0.5 & 1.0 & 1.1 & 1.3 & 1.5 & 0.9 & 0.7 & 0.4 & 0.6 & 0.5 & 0.3 \\
\hline & & 1.7 & 1.9 & 2.1 & 2.5 & 2.4 & 3.3 & 4.1 & 4.6 & 2.6 & 1.5 & 0.8 & 0.7 \\
\hline & & 0.3 & 0.2 & 0.7 & 2.0 & 0.9 & 1.2 & 1.7 & 1.8 & 1.7 & 2.0 & 0.8 & 0.7 \\
\hline & & 3.5 & 2.8 & 3.9 & 4.8 & 3.0 & 3.4 & 2.3 & 6.3 & 5.3 & 4.3 & 3.0 & 2.6 \\
\hline \multirow{2}{*}{5} & Produits chimiques & 0.3 & 0.3 & 0.5 & 0.6 & 0.5 & 0.5 & 0.2 & 0.1 & 0.4 & 0.5 & 0.5 & 0.5 \\
\hline & Produits manufacturés & 0.5 & 1.0 & 0.9 & 1.3 & 1.0 & 1.0 & 0.5 & 0.5 & 0.6 & 0.8 & 0.8 & 0.9 \\
\hline 7 & Machines et matériel de transport & 0.0 & 0.1 & 0.3 & 0.4 & 0.9 & 0.8 & 0.1 & 0.1 & 0.3 & 0.7 & 1.1 & 1.2 \\
\hline 8 & Articles manufacturés divers & 0.0 & 0.2 & 0.4 & 0.4 & 0.8 & 0.7 & 0.2 & 0.2 & 0.9 & 1.4 & 1.7 & 1.7 \\
\hline 9 & $\begin{array}{l}\text { Articles et transactions non classés } \\
\text { ailleurs }\end{array}$ & 0.2 & 0.3 & 0.3 & 0.4 & 0.3 & 0.1 & 1.0 & 1.2 & 2.7 & 1.2 & 0.3 & 0.3 \\
\hline
\end{tabular}

Source: calculs effectués par les auteurs à partir de la base de données COMTRADE.

${ }^{a}$ Hors Chine et Vietnam.

43. Là encore, l'analyse détaillée par pays fait apparaître une situation hétérogène. En Amérique latine, seuls le Mexique et, dans une moindre mesure, le Costa Rica ont réussi à déplacer le centre de gravité de leur spécialisation des produits de base vers les produits manufacturés (en particulier les groupes 7 et 8). En Asie de l'Est, l'Indonésie, la Thaïlande et le Vietnam continuent d'avoir des avantages comparatifs révélés pour les groupes 0,2 et 3, et l'Indonésie et la Malaisie pour le groupe 4 , de même que l'Amérique latine (tableau 14).

${ }^{19}$ L'indice de Balassa se calcule comme suit: $I B=\frac{X_{i j} / X_{i w}}{x_{i w} / x_{w}}$ où $x_{i j}$ correspond aux exportations du produit $i$ vers le pays $j, X_{i w}$ à l'ensemble des exportations mondiales du produit $i$ et $X_{w}$ total aux exportations mondiales. Si l'indice est supérieur à l'unité, cela signifie que le pays en question jouit d'un avantage comparatif relatif pour le produit $i$.

${ }^{20}$ Les huiles et graisses d'origine animale et végétale sont le seul segment dans lequel la région a maintenu un avantage. 
Tableau 14. Avantage comparatif révélé: 1980 à 2005

Calculé sur la base de la valeur des exportations en utilisant la CTCI, rév. 1

\begin{tabular}{|c|c|c|c|c|c|c|c|c|c|c|c|c|c|c|c|c|}
\hline \multirow[b]{2}{*}{$\begin{array}{l}\text { \&ै } \\
\text { ठㅇ }\end{array}$} & \multirow[b]{2}{*}{$\begin{array}{l}\text { Product Names/Regions \& } \\
\text { Countries }\end{array}$} & \multicolumn{8}{|c|}{ Latin America (8 countries) } & \multicolumn{7}{|c|}{ East Asian (7 countries) } \\
\hline & & 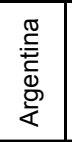 & $\begin{array}{c}\overline{\bar{N}} \\
\frac{\pi}{\bar{\omega}} \\
\end{array}$ & $\stackrel{\varrho}{\frac{\varrho}{\bar{U}}}$ & 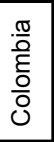 & 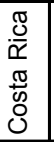 & 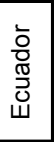 & $\begin{array}{l}\frac{0}{x} \\
\stackrel{0}{x}\end{array}$ & $\begin{array}{l}\frac{2}{0} \\
0 \\
0\end{array}$ & $\frac{\pi}{\frac{\pi}{C}}$ & $\begin{array}{l}\frac{\pi}{\infty} \\
\stackrel{0}{0} \\
\stackrel{0}{0} \\
\frac{0}{0} \\
\underline{\Xi}\end{array}$ & $\begin{array}{l}\frac{\pi}{0} \\
\frac{\pi}{\pi} \\
\frac{\pi}{20}\end{array}$ & 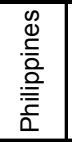 & $\begin{array}{l}0 \\
\stackrel{0}{7} \\
\frac{2}{0} \\
\stackrel{0}{0} \\
\stackrel{5}{\omega}\end{array}$ & 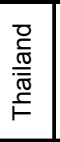 & 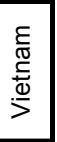 \\
\hline & 1980 & & & & & & & & & & & & & & & \\
\hline 0 & Food and live animals & 5.3 & 4.1 & $\overline{1.4}$ & 7.5 & 6.7 & 3.4 & 1.2 & 1.6 & 1.3 & 0.6 & 0.4 & 2.6 & 0.5 & 4.7 & \\
\hline 1 & Beverages and tobacco & 0.5 & 1.5 & 0.5 & 0.7 & 0.1 & 0.1 & 0.8 & 0.0 & 0.4 & 0.3 & 0.1 & 0.5 & 0.4 & 1.0 & \\
\hline 2 & Crude materials, inedible & 2.4 & 2.4 & 3.5 & 0.8 & 0.2 & 0.2 & 0.9 & 3.7 & 1.6 & 2.6 & 5.2 & 4.0 & 1.8 & 2.3 & \\
\hline 3 & Mineral fuels, lubricants & 0.2 & 0.1 & 0.1 & 0.1 & 0.0 & 3.2 & 3.4 & 1.0 & 1.6 & 3.6 & 1.3 & 0.0 & 1.3 & 0.0 & \\
\hline 4 & Animal and vegetable oils & 10.3 & 5.6 & 1.3 & 0.0 & 0.0 & 0.2 & 0.1 & 0.3 & 0.7 & 2.1 & 18.1 & 16.2 & 4.3 & 0.3 & \\
\hline 5 & Chemicals & 0.6 & 0.5 & 0.5 & 0.3 & 0.9 & 0.0 & 0.4 & 0.3 & 0.6 & 0.0 & 0.1 & 0.2 & 0.9 & 0.1 & \\
\hline 6 & Manufact goods classified & 0.6 & 0.8 & 3.2 & 0.5 & 0.7 & 0.1 & 0.3 & 1.8 & 1.2 & 0.2 & 0.8 & 0.5 & 0.5 & 1.3 & \\
\hline 7 & Machinery-transport eq. & 0.2 & 0.6 & 0.1 & 0.1 & 0.2 & 0.0 & 0.2 & 0.1 & 0.2 & 0.0 & 0.4 & 0.1 & 1.0 & 0.2 & \\
\hline 8 & Other manufactures & 0.4 & 0.5 & 0.0 & 0.7 & 0.7 & 0.0 & 0.2 & 0.6 & 1.8 & 0.1 & 0.3 & 1.3 & 0.8 & 0.8 & \\
\hline \multirow[t]{2}{*}{9} & Commodities-other trans. & 0.0 & 0.6 & 0.3 & 0.3 & 2.6 & 0.0 & 0.0 & 0.0 & 2.6 & 0.1 & 0.1 & 6.9 & 3.2 & 1.7 & \\
\hline & 1990 & & & & & & & & & & & & & & & \\
\hline 0 & Food and live animals & 5.2 & 2.8 & 3.0 & 4.3 & 7.7 & 5.8 & 1.4 & 2.8 & $\overline{1.4}$ & $\overline{1.2}$ & 0.6 & 1.7 & 0.4 & 3.8 & \\
\hline 1 & Beverages and tobacco & 0.9 & 1.8 & 0.6 & 0.4 & 0.1 & 0.2 & 0.9 & 0.0 & 0.5 & 0.4 & 0.1 & 0.6 & 1.2 & 0.3 & \\
\hline 2 & Crude materials, inedible & 2.5 & 3.4 & 4.4 & 1.0 & 1.3 & 0.3 & 0.9 & 5.4 & 1.3 & 1.7 & 3.2 & 1.5 & 0.7 & 1.3 & \\
\hline 3 & Mineral fuels, lubricants & 1.0 & 0.3 & 0.1 & 4.7 & 0.1 & 6.6 & 4.8 & 1.3 & 1.1 & 5.6 & 2.3 & 0.3 & 2.3 & 0.1 & \\
\hline 4 & Animal and vegetable oils & 23.1 & 3.9 & 0.5 & 0.0 & 1.1 & 0.2 & 0.1 & 1.3 & 0.6 & 4.1 & 17.7 & 11.4 & 2.0 & 0.1 & \\
\hline 5 & Chemicals & 0.7 & 0.7 & 0.4 & 0.4 & 0.5 & 0.0 & 0.7 & 0.2 & 0.7 & 0.3 & 0.2 & 0.3 & 0.7 & 0.2 & \\
\hline 6 & Manufact goods classified & 1.0 & 1.5 & 2.9 & 0.6 & 0.6 & 0.1 & 0.6 & 2.1 & 1.2 & 1.3 & 0.5 & 0.6 & 0.4 & 0.8 & \\
\hline 7 & -transport eq. & 0.2 & 0.5 & 0.0 & 0.0 & 0.1 & 0.0 & 0.7 & 0.0 & 0.5 & 0.0 & 0.9 & 0.3 & 1.3 & 0.5 & \\
\hline 8 & Othe & 0.2 & 0.4 & 0.1 & 0.8 & 0.7 & 0.1 & 0.3 & 0.4 & 2.1 & 0.8 & 0.9 & 1.2 & 0.9 & 2.1 & \\
\hline \multirow[t]{2}{*}{9} & Commodities-other trans. & 0.1 & 0.6 & 0.7 & 0.4 & 4.0 & 0.0 & 0.0 & 0.0 & 1.0 & 0.0 & 0.2 & 16.4 & 0.7 & 0.6 & \\
\hline & 2000 & & & & & & & & & & & & & & & \\
\hline 0 & Food al & 6.1 & 3.2 & 4.0 & 3.4 & 5.5 & 6.7 & 0.7 & 5.4 & 0.9 & 1.1 & 0.3 & 0.6 & 0.2 & 2.6 & 4.6 \\
\hline 1 & es and tobacco & 1.4 & 1.9 & 3.8 & 0.4 & 0.2 & 0.2 & 1.1 & 0.3 & 0.3 & 0.4 & 0.4 & 0.2 & 0.9 & 0.3 & 0.1 \\
\hline 2 & Crude materials, inedible & 2.5 & 5.2 & 9.1 & 1.7 & 1.1 & 1.4 & 0.4 & 5.7 & 0.6 & 2.4 & 0.9 & 0.5 & 0.2 & 1.3 & 0.9 \\
\hline 3 & ricants & 1.8 & 0.2 & 0.1 & 4.3 & 0.1 & 5.0 & 1.0 & 0.7 & 0.3 & 2.5 & 1.0 & 0.1 & 1.0 & 0.3 & 2.7 \\
\hline 4 & d vegetable oils & 20.4 & 2.8 & 0.2 & 1.2 & 2.6 & 1.3 & 0.1 & 4.8 & 0.2 & 9.4 & 11.3 & 4.1 & 0.5 & 0.4 & 1.4 \\
\hline 5 & Chem & 0.8 & 0.7 & 0.6 & 1.1 & 0.6 & 0.3 & 0.3 & 0.3 & 0.5 & 0.5 & 0.4 & 0.1 & 0.7 & 0.7 & 0.1 \\
\hline 6 & Manu & 0.7 & 1.5 & 2.5 & 0.8 & 0.5 & 0.3 & 0.6 & 2.2 & 1.2 & 1.4 & 0.5 & 0.3 & 0.3 & 0.8 & 0.4 \\
\hline 7 & Mach & 0.3 & 0.7 & 0.1 & 0.1 & 0.9 & 0.0 & 1.4 & 0.0 & 0.7 & 0.4 & 1.4 & 1.8 & 1.6 & 1.0 & 0.2 \\
\hline 8 & Other & 0.2 & 0.5 & 0.1 & 0.6 & 1.1 & 0.1 & 1.1 & 0.8 & 2.8 & 1.4 & 0.8 & 0.9 & 0.7 & 1.2 & 2.1 \\
\hline \multirow[t]{2}{*}{9} & Commodities-other trans. & 0.5 & 0.8 & 0.9 & 0.0 & 0.0 & 0.0 & 0.0 & 0.0 & 0.1 & 0.0 & 0.3 & 0.0 & 0.3 & 1.1 & 1.3 \\
\hline & 2005 & & & & & & & & & & & & & & & \\
\hline 0 & Food and li & 6.4 & 3.9 & 3.5 & 3.4 & 5.8 & 5.6 & 0.9 & 4.0 & 0.6 & 1.1 & 0.4 & 0.8 & 0.2 & 2.3 & 4.8 \\
\hline 1 & Beverages and tobacco & 1.6 & 1.7 & 2.7 & 0.5 & 0.4 & 0.3 & 1.3 & 0.1 & 0.2 & 0.4 & 0.4 & 0.5 & 0.6 & 0.3 & 0.6 \\
\hline 2 & Crude materials, inedible & 3.3 & 5.5 & 10.9 & 1.9 & 1.2 & 1.5 & 0.5 & 10.1 & 0.3 & 3.6 & 0.9 & 0.6 & 0.2 & 1.7 & 1.0 \\
\hline 3 & Mineral fuels, lubricants & 1.6 & 0.6 & 0.2 & 4.0 & 0.0 & 5.8 & 1.5 & 1.1 & 0.2 & 2.7 & 1.3 & 0.2 & 1.2 & 0.4 & 2.1 \\
\hline 4 & Animal and vegetable oils & 22.3 & 3.6 & 0.3 & 1.7 & 3.2 & 2.0 & 0.1 & 3.2 & 0.1 & 16.3 & 12.9 & 4.7 & 0.3 & 0.4 & 0.3 \\
\hline 5 & Chemicals & 0.7 & 0.6 & 0.5 & 0.7 & 0.7 & 0.2 & 0.3 & 0.3 & 0.4 & 0.5 & 0.5 & 0.1 & 1.0 & 0.7 & 0.1 \\
\hline 6 & Manufact goods classified & 0.7 & 1.3 & 2.6 & 0.9 & 0.7 & 0.2 & 0.6 & 1.8 & 1.2 & 1.2 & 0.5 & 0.3 & 0.3 & 0.9 & 0.5 \\
\hline 7 & Machinery-transport eq. & 0.3 & 0.7 & 0.0 & 0.2 & 0.8 & 0.1 & 1.3 & 0.0 & 1.1 & 0.4 & 1.3 & 1.9 & 1.5 & 1.1 & 0.2 \\
\hline 8 & Other manufactures & 0.2 & 0.3 & 0.1 & 0.7 & 1.5 & 0.1 & 1.1 & 0.8 & 2.4 & 1.1 & 0.8 & 0.9 & 0.6 & 1.1 & 2.8 \\
\hline 9 & Commodities-other trans. & 0.5 & 0.0 & 0.6 & 0.0 & 0.0 & 0.0 & 0.1 & 0.0 & 0.1 & 0.1 & 0.4 & 0.0 & 1.1 & 0.5 & 0.2 \\
\hline
\end{tabular}

Source: Authors' calculations based on UN - COMTRADE.

Revealed comparative advantage increasing from $<1$ to $>1$ relative to previous period.

Revealed comparative advantage falling from $>1$ to $<1$ relative to previous period. 


\section{Rôle de l'investissement direct étranger et des réseaux régionaux de production}

44. Au cours des deux dernières décennies, les entrées d'IDE ont augmenté tant en Amérique latine qu'en Asie de l'Est (tableau 15). Le stock d'IDE en pourcentage du PIB a nettement plus augmenté en Amérique latine. La situation varie toutefois considérablement d'un pays à l'autre dans les deux régions, Singapour et le Chili enregistrant proportionnellement les plus fortes entrées d'IDE et la Chine et l'Indonésie les plus faibles.

Tableau 15. Évolution de l'IDE, 1970-2006

(Moyennes annuelles en millions d'USD et pourcentage du PIB)

\begin{tabular}{|c|c|c|c|c|c|c|}
\hline & \multicolumn{4}{|c|}{ Flux } & \multicolumn{2}{|c|}{ Stock } \\
\hline & $1970-1979$ & $1980-1989$ & 1991-1999 & $2000-2006$ & Stock 1990 & Stock 2006 \\
\hline & \multicolumn{4}{|c|}{ Millions d'USD } & \multicolumn{2}{|c|}{$\% d u P I B$} \\
\hline Amérique latine (8 pays) & 2272 & 5806 & 32557 & 55817 & 8.8 & 29.6 \\
\hline Argentine & 131 & 584 & 6629 & 4203 & 6.2 & 30.4 \\
\hline Brésil & 1270 & 1721 & 9823 & 19138 & 8.1 & 25.7 \\
\hline Chili & 59 & 438 & 3181 & 5334 & 31.9 & 65.1 \\
\hline Colombie & 53 & 479 & 1757 & 4061 & 8.7 & 33.8 \\
\hline Costa Rica & 44 & 70 & 335 & 746 & 23.2 & 32.0 \\
\hline Équateur & 68 & 85 & 459 & 1396 & 15.7 & 40.8 \\
\hline Mexique & 602 & 2387 & 8801 & 19066 & 8.5 & 27.2 \\
\hline Pérou & 45 & 41 & 1572 & 1873 & 5.1 & 23.1 \\
\hline Asie de l'Est (6 pays) & 984 & 3929 & 19932 & 27903 & 9.2 & 11.8 \\
\hline Indonésie & 196 & 326 & 2048 & 1116 & 7.7 & 7.4 \\
\hline Malaisie & 326 & 965 & 4555 & 3524 & 23.4 & 36.7 \\
\hline Philippines & 80 & 214 & 1255 & 1357 & 7.4 & 14.3 \\
\hline Singapour & 301 & 1907 & 7841 & 15343 & 82.6 & 160.1 \\
\hline Thaïlande & 80 & 510 & 2925 & 4966 & 9.7 & 32.0 \\
\hline Vietnam & 1 & 7 & 1307 & 1598 & 25.5 & 59.4 \\
\hline Chine & 0 & 1619 & 28694 & 56621 & 5.8 & 14.3 \\
\hline
\end{tabular}

Source: calculs effectués par les auteurs à partir des données de la CNUCED.

45. Les secteurs destinataires de l'IDE n'étaient pas du tout les mêmes dans les deux régions: en Asie de l'Est, l'IDE a surtout bénéficié aux industries manufacturières alors qu'en Amérique latine, il a principalement été destiné aux services (infrastructures) et, dans une moindre mesure, aux secteurs des ressources naturelles (graphique 9). La part du secteur secondaire dans l'IDE avoisine ou excède $40 \%$ en Asie de l'Est et dépasse 60\% en Chine. Elle se maintient aux alentours de 20\% en Amérique latine, sauf au Mexique et au Costa Rica et, à un moindre degré, au Brésil. La plupart des multinationales de cette région fournissent des produits finaux et des services aux marchés locaux et suivent une stratégie plus traditionnelle de recherche de ressources naturelles ou d'accès aux marchés nationaux (ou régionaux). L'IDE a été principalement destiné aux industries extractives (cuivre au Pérou et au Chili, pétrole en Équateur, par exemple) et aux secteurs des services comme les activités bancaires, l'électricité et les télécommunications et beaucoup moins aux industries manufacturières. L'IDE a en grande partie résulté d'opérations de privatisation et de fusion-acquisition d'entreprises publiques, qui ont souvent constitué un phénomène ponctuel. 
Graphique 9: composition du stock d'IDE par secteur, 2005

(pourcentage du total, classement en fonction de la part occupée dans le secteur secondaire)
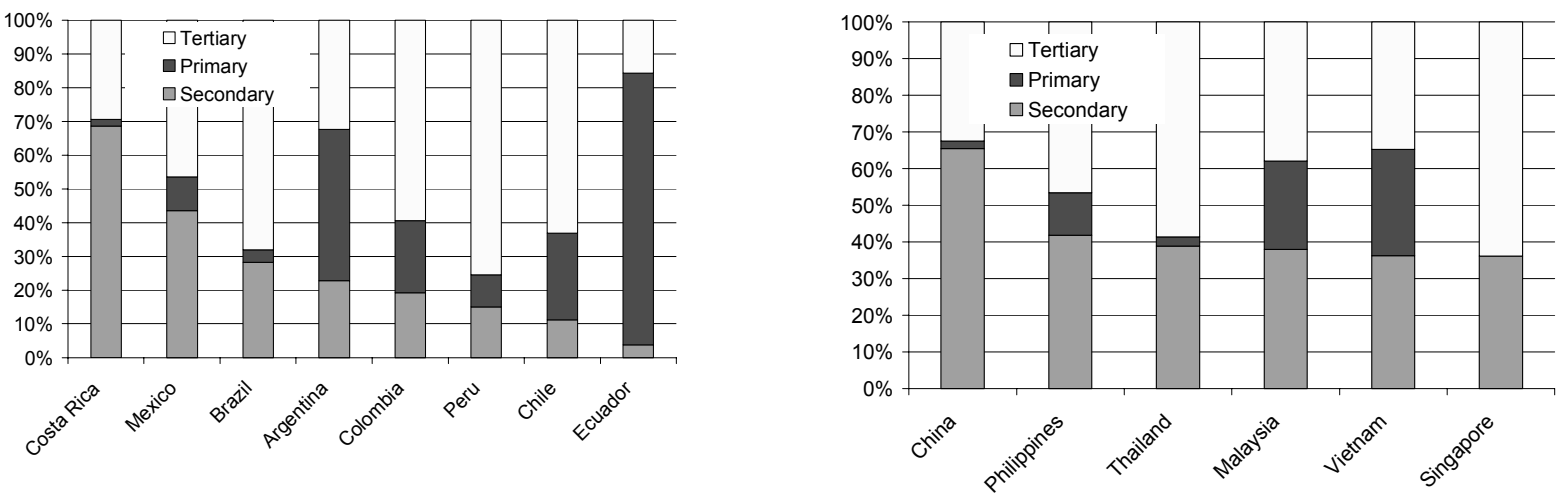

Source : calculs effectués par les auteurs à partir des données du site www.investmentmap.org et de la CNUCED.

46. Le Costa Rica et le Mexique constituent des exceptions en Amérique latine puisque leurs industries manufacturières (pièces détachées d'automobiles, électronique et textile-habillement, par exemple) ont aussi attiré beaucoup d'IDE. Les retombées en ont toutefois été limitées du fait que l'IDE a surtout été concentré dans les zones franches pour l'industrie d'exportation (ou «maquilas ») de ces deux pays sans créer beaucoup de liens avec le reste de l'économie puisque la plus grande partie du capital et des entrées intermédiaires était importée et que très peu d'activités étaient sous-traitées localement. L'Asie de l'Est compte aussi des zones franches pour l'industrie d'exportation mais plusieurs pays (Singapour et Chine, par exemple) ont mieux réussi à établir des liens avec le reste de l'économie ${ }^{21}$.

47. D'après Zhang (2001), l'IDE a eu un effet plus positif sur la croissance économique en Asie de l'Est qu'en Amérique latine du fait de la stratégie d'encouragement des exportations de la première région, de l'amélioration de son capital humain et de sa stabilité macroéconomique. Poon et Thompson (1998) estiment que l'IDE des industries manufacturières japonaises a eu un effet positif sur les taux de croissance des pays d'Asie ${ }^{22}$ et que l'hypothèse selon laquelle l'IDE manufacturier qui exploite l'avantage comparatif du pays d'accueil renforce la croissance est confirmée dans le cas de l'Asie de l'Est.

48. L'IDE manufacturier réalisé en Asie de l'Est diffère de celui effectué en Amérique latine du fait que dans la première région, les entreprises multinationales ont mis en place des réseaux régionaux de

${ }^{21}$ Ce succès dépend de façon décisive de l'efficacité d'acteurs publics et privés importants. À Singapour, le conseil de développement économique (EDB) a incité des entreprises transnationales à investir dans des fournisseurs locaux, ce qui les a aidés à respecter des normes internationales comme celles de l'ISO et à augmenter leur productivité et leur valeur ajoutée (Nagel, 2005). D’après Lall (2004), on peut considérer que la politique menée par Singapour pour attirer l'IDE a consisté à « cibler et sélectionner agressivement les entreprises transnationales des secteurs d'activité à forte valeur ajoutée ». En Chine, l'IDE est surtout orienté vers le secteur des exportations. Les autorités encouragent l'IDE à l'aide de deux types de coentreprises. Celles-ci ne représentent que 3\% du nombre total d'entreprises mais près de $30 \%$ de la valeur ajoutée et un cinquième des recettes fiscales (Rosales et Kuwayama, 2007). Voir aussi Engman et autres (2007).

${ }^{22}$ La même étude conclut que ce n'est pas le cas pour l'investissement direct japonais en Amérique latine. Le fait que des résultats similaires ne sont pas constatés dans les pays latino-américains compromet sérieusement la généralisation de l'idée que les industries manufacturières japonaises stimulent nécessairement «mieux» la croissance. 
production alors que dans la seconde, cette tendance a été quasiment inexistante en dehors du Mexique et du Costa Rica qui ont conclu des accords bilatéraux de partage de la production avec les États-Unis. En Asie de l'Est, l'IDE a surtout été effectué pour des raisons d'efficience en visant à créer des plates-formes régionales d'exportation. Ces plates-formes ont été renforcées dans cette région suite aux efforts déployés par les pouvoirs publics pour accroître les compétences technologiques (Narula, 2002).

49. Le partage régional de la production a joué un rôle déterminant dans l'amélioration technologique des exportations en Asie de l'Est. Ando et autres (2006) observent que la part des échanges intrarégionaux de produits manufacturés dans l'ensemble des échanges a considérablement augmenté dans cette région. La part de ces produits dans les importations de la région est passée de $50 \%$ à $70 \%$ alors qu'elle est restée relativement stable, aux alentours de 10\%, en Amérique latine (graphique 10). Le commerce international des pièces détachées a également tendance à prendre de l'importance par rapport aux échanges de produits finaux (graphique 11). Cette tendance reflète le plus grand rôle joué par les réseaux internationaux de production. En Asie de l'Est, par exemple, l'accroissement total des exportations intrarégionales observé entre 1990 et 2003 tient pour moitié à l'intensification des échanges intrarégionaux de pièces et composants de machines.

\section{Graphique 10. Part des échanges intrarégionaux de produits manufacturés dans les échanges avec le monde entier}

(en pourcentage)
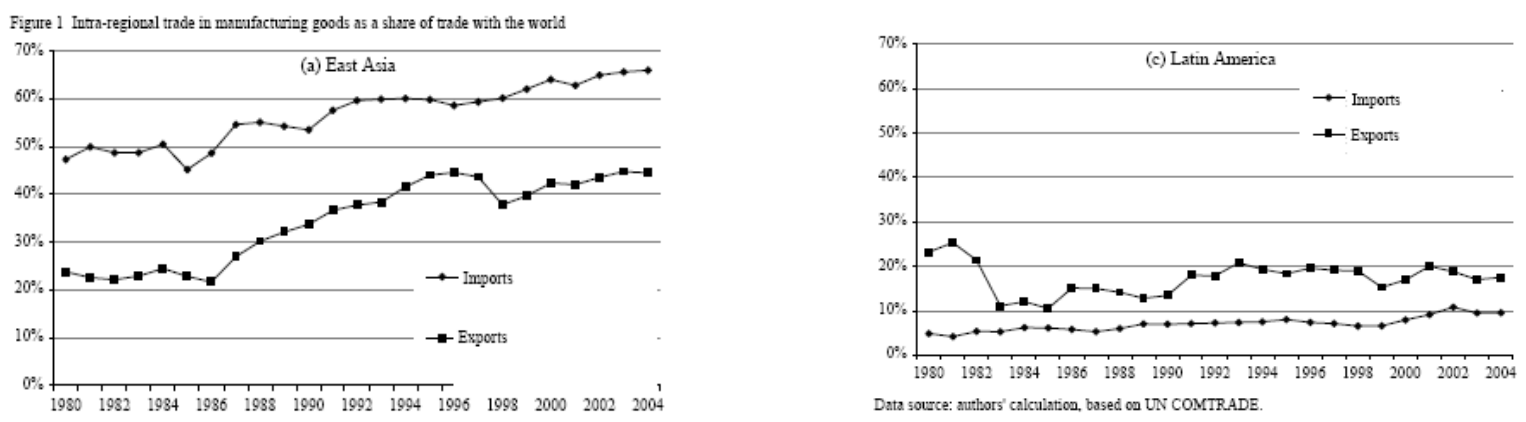

Source des données: calculs effectués par les auteurs à partir de la base de données COMTRADE des Nations Unies Source : Ando et autres (2006).

Graphique 11. Part des échanges de pièces et composants de machines dans l'ensemble des échanges de machines: échanges intrarégionaux et échanges avec le monde entier

(en pourcentage)
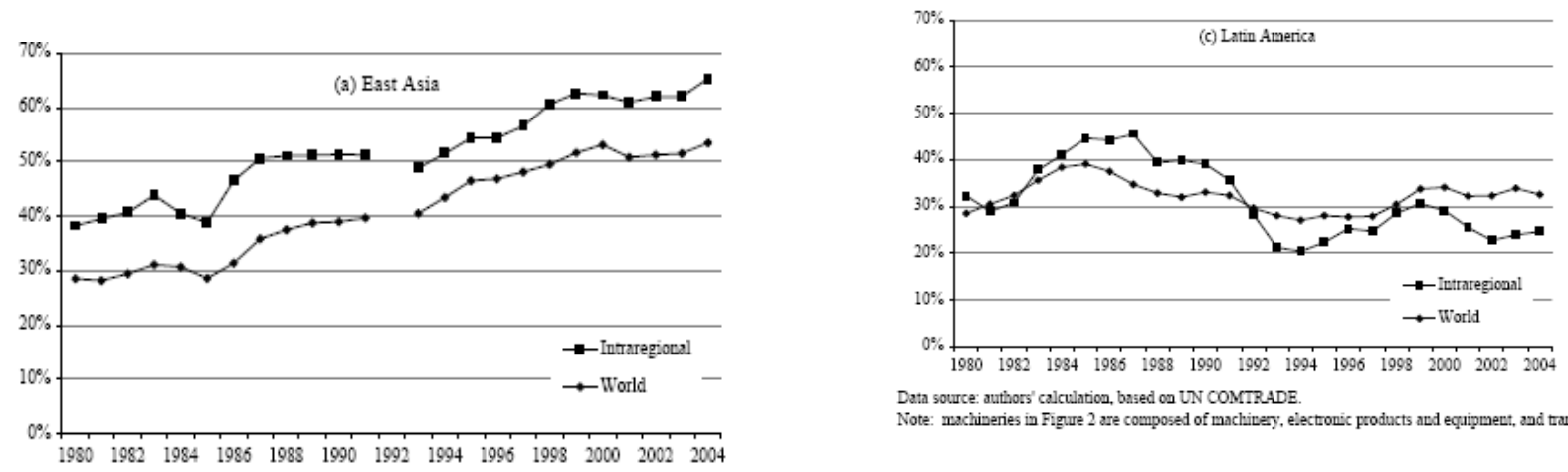

Data source: authors' calculation, based on UN COMTRADE.

Note: machiveries in Figure 2 are composed of machivery, electronic products and equigraett, and transportal

Source: Ando et autres (2006). 
50. La libéralisation générale et intrarégionale des échanges a certes contribué à stimuler les échanges régionaux (voir plus haut), mais d'autres évolutions ont aussi grandement contribué à ce processus. En Asie de l'Est, l'intégration régionale de fait, dont témoignent les flux commerciaux, a progressé beaucoup plus rapidement que l'intégration régionale de droit, résultant d'accords commerciaux. L'établissement de réseaux de production a été notablement favorisé par les flux d'IDE venant du Japon et des nouvelles économies industrielles d'Asie et destinés aux autres pays asiatiques qui ont nettement repris après la dépréciation du dollar et des monnaies liées à lui, consécutive à l'Accord du Plaza de 1985. L'introduction d'une politique plus favorable à l'IDE dans de nombreux pays d'Asie de l'Est ainsi que d'importants progrès techniques dans les transports et les technologies de l'information et des communications (TIC) qui ont fortement réduit le coût du transport des marchandises et de la transmission d'informations, ont aussi facilité le processus.

\section{L'ajustement structurel dans les deux régions}

Dans cette section du document, nous examinons les divers aspects de l'ajustement structurel au niveau de la production et de l'emploi en Chine, en Asie de l'Est et en Amérique latine, qui sont en partie liés à l'évolution des échanges et de l'investissement direct étranger afin d'étudier comment ils ont contribué aux résultats en matière de croissance.

\section{I. $\quad$ Le rôle joué par les industries manufacturières dans le PIB}

51. La composition sectorielle du PIB s'est considérablement modifiée dans les deux régions: la part de l'agriculture a diminué tandis que celle des services a augmenté. Toutefois, seule l'Asie de l'Est a réussi à renforcer, au fill des ans, le rôle joué dans l'économie par le secteur manufacturier (tableau 16) alors que la part de celui-ci dans le PIB a diminué en Chine et en Amérique latine. Dans le cas de la Chine, cette évolution doit être interprétée avec circonspection puisque dans les années 80, beaucoup d'entreprises manufacturières (publiques) fournissaient de nombreux services (scolaires et hospitaliers notamment) qui ont été externalisés par la suite. En Amérique latine, la désindustrialisation peut être en partie attribuée à des facteurs endogènes (par exemple, une évolution structurelle en direction des industries de services lorsque les économies mûrissent sous l'effet de l'évolution de la composition de la demande et d'une faible progression de la productivité). Des facteurs exogènes semblent toutefois avoir joué un rôle encore plus important, notamment la réorientation des politiques de remplacement des importations qui étaient axées sur le développement de l'industrie. Certains estiment que l'abandon du programme d'industrialisation a renvoyé la région à ses avantages comparatifs traditionnels liés à sa base de ressources habituelle (Palma, 2004). 
Tableau 16. Parts des différents secteurs dans le PIB, 1980-2006 (moyennes pondérées, pourcentages)

\begin{tabular}{|c|c|c|c|}
\hline & 1980 & 1990 & 2006 \\
\hline & \multicolumn{3}{|c|}{ Amérique latine (8 pays) } \\
\hline Agriculture & 10.3 & 8.9 & 6.0 \\
\hline Industrie & 38.9 & 35.0 & 31.7 \\
\hline Activités manuf. & 28.1 & 24.2 & 18.4 \\
\hline \multirow[t]{2}{*}{ Services } & 50.8 & 56.1 & 62.3 \\
\hline & \multicolumn{3}{|c|}{ Chine } \\
\hline Agriculture & 30.1 & 27.0 & 11.9 \\
\hline Industrie & 48.5 & 41.6 & 47.0 \\
\hline Activités manuf. & 40.5 & 32.9 & 30.9 \\
\hline \multirow[t]{2}{*}{ Services } & 21.4 & 31.3 & 41.1 \\
\hline & \multicolumn{3}{|c|}{ Asie de l'Est (6 pays) } \\
\hline Agriculture & 24.8 & 18.5 & 11.7 \\
\hline Industrie & 37.0 & 36.7 & 41.8 \\
\hline Activités manuf. & 20.3 & 23.0 & 28.1 \\
\hline Services & 38.1 & 44.8 & 46.5 \\
\hline
\end{tabular}

Source: calculs effectués par les auteurs à partir des données des Indicateurs du développement dans le monde de la Banque mondiale.

Note: les chiffres régionaux sont la moyenne pondérée des parts des différents pays calculée en utilisant comme coefficients de pondération les PIB sectoriels des pays en PPA.

52. Le contraste entre le recul (Amérique latine) et la progression (Asie de l'Est) de la part des activités manufacturières dans le PIB explique peut-être en partie la disparité des résultats observés dans les deux régions en matière de croissance puisque ces activités peuvent avoir d'importantes retombées au niveau non seulement du capital humain et physique, mais aussi de la croissance économique et de l'amélioration de la productivité du fait de leur plus forte intensité en savoir et en capital humain et physique (Nagel, 2005).

\section{II. Évolution de la structure de la valeur ajoutée et de l'emploi manufacturiers}

53. Nous allons maintenant nous intéresser de plus près à l'évolution sectorielle de la valeur ajoutée et de l'emploi dans les industries manufacturières. Ce secteur est l'un des principaux moteurs de la croissance économique du fait qu'il est l'un des plus riches en innovations et retombées pour le reste de l'économie et celui qui est le plus orienté vers l'exportation dans la plupart des pays.

\section{a) Valeur ajoutée}

54. Les modifications subies par la structure de la valeur ajoutée manufacturière ont été beaucoup plus importantes en Asie de l'Est et en Chine qu'en Amérique latine et elles ont été plus conformes à l'amélioration technologique des exportations (graphique 12). En Asie de l'Est et en Chine, des industries comme celles des machines électriques (textiles) ont progressé (reculé) de plus de 10 points alors qu'en Amérique latine le secteur qui a le plus progressé (reculé), le secteur alimentaire (textile), n'a progressé (reculé) que de deux à trois points. La différence constatée dans l'ampleur des effets des échanges sur les structures de production au niveau de la valeur ajoutée peut s'expliquer par la plus grande intégration régionale existant en Asie sous l'effet de l'abandon des processus antérieurs de production nationale au 
Graphique 12. Évolution de la structure de la valeur ajoutée manufacturière, 2003 et 1990 par rapport à $1980^{\text {a }}$ (variation de l'ensemble de la valeur ajoutée en points de pourcentage) ${ }^{\mathrm{b}}$

Latin America (8 countries)

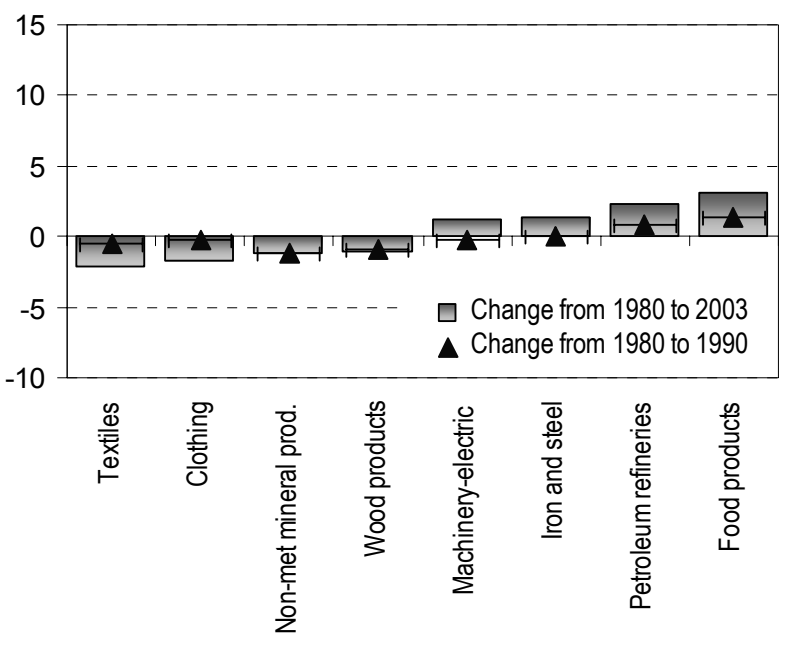

MEXICO

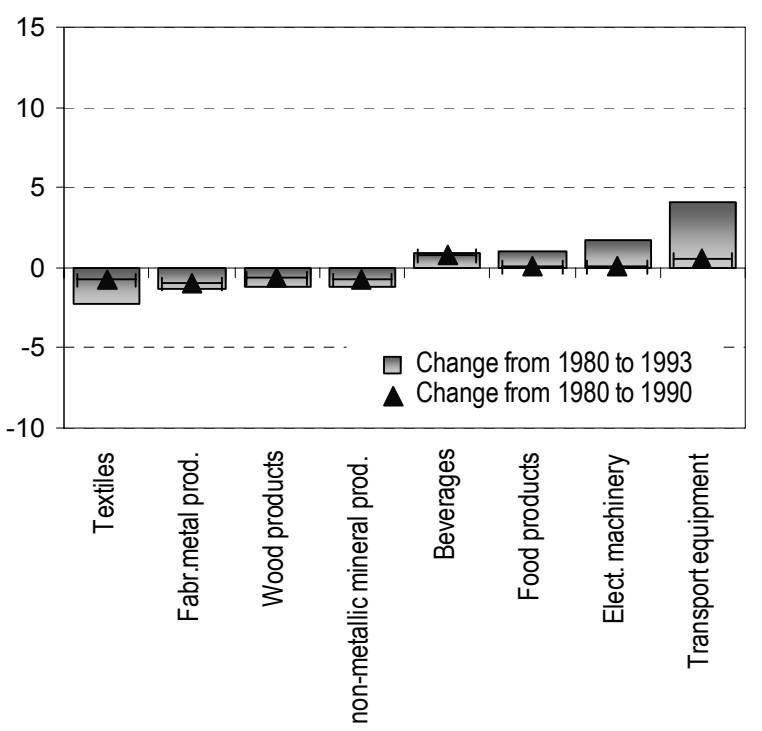

East Asia (5 countries)

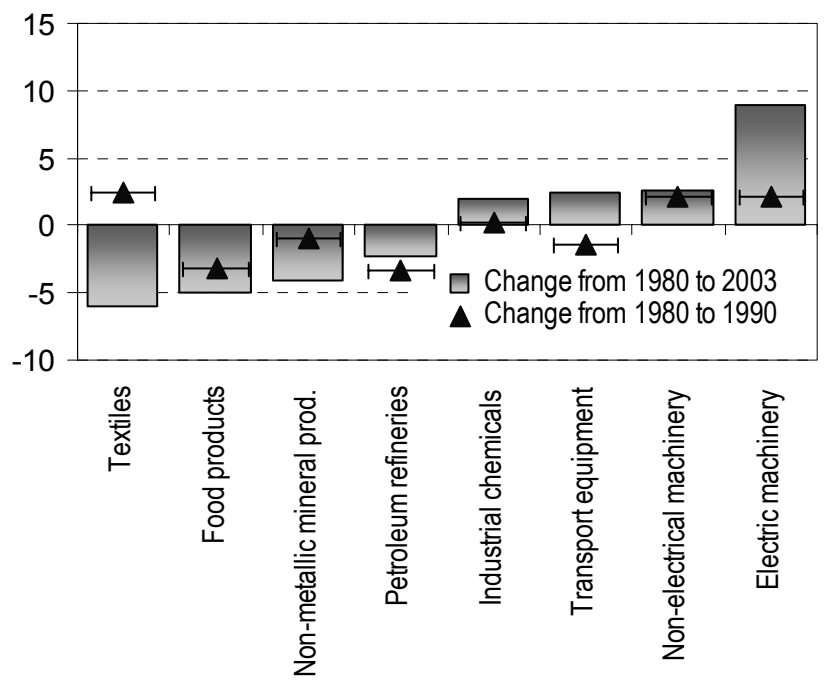

CHINA

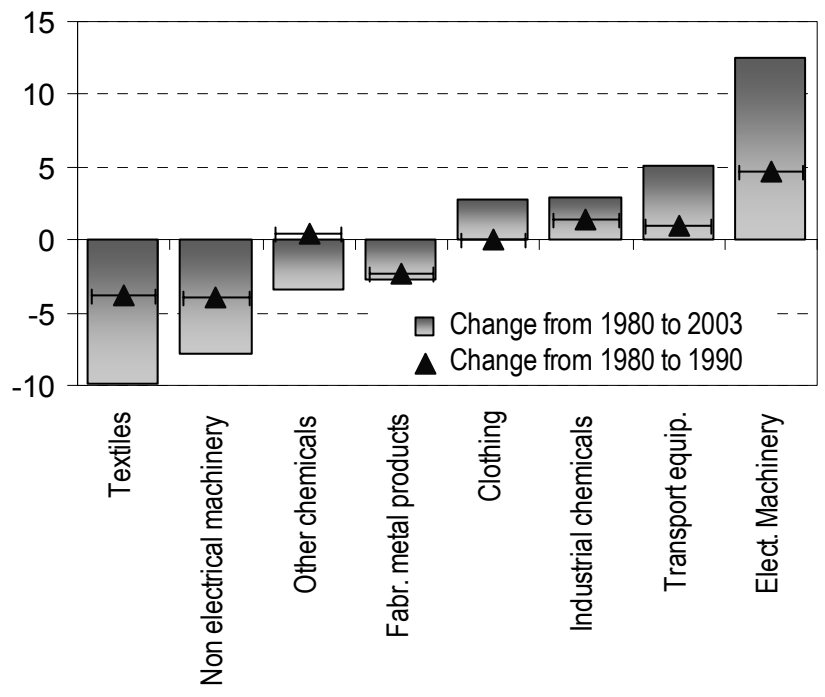

Source: calculs effectués par les auteurs à partir de la base de données de l'ONUDI et du Programme d'analyse de la dynamique industrielle (PADI) de la CEPALC.

Notes: ces chiffres correspondent aux secteurs dont la contribution à l'ensemble de la valeur ajoutée manufacturière a le plus progressé ou reculé. Les points de pourcentage représentent la différence absolue entre les contributions en 1980 et 2003 et 1980 et 1990.

${ }^{a}$ La modification régionale de la structure repose sur les moyennes pondérées des résultats obtenus par les différents pays, calculées en utilisant comme coefficients de pondération la valeur ajoutée sectorielle en USD courants.

${ }^{\mathrm{b}}$ Asie de l'Est hors Vietnam.

profit d'un réseau de production régionale dans les le cadre duquel la production est disséminée dans les endroits de la région qui permettent d'obtenir les plus faibles prix de revient ${ }^{23}$. Les changements absolus

${ }^{23}$ Ce processus a été facilité par la libéralisation unilatérale du commerce des pièces et composants sur lesquels portent principalement les échanges intrarégionaux en Asie de l’Est. Bien que les réductions tarifaires aient été non 
les plus importants observés dans la contribution des différents secteurs à la valeur ajoutée sont survenus pendant la deuxième sous-période (1990 à 2003) en Asie de l'Est et en Chine. En Amérique latine, les changements ont été limités tant dans les années 80 que dans les années 90.

55. Les évolutions observées au sein des régions sont assez hétérogènes. En Amérique latine, la structure de l'industrie a évolué vers les secteurs reposant sur les ressources naturelles dans six des huit pays de la région. Au Mexique, elle a évolué vers les secteurs de moyenne et haute technicité - les produits chimiques, y compris les matières plastiques; les machines électriques et le matériel de transport. La part dans la valeur ajoutée des industries de main-d'œuvre comme celles du cuir et de la chaussure ont diminué (voir l'annexe). En Asie, la principale tendance constatée est l'augmentation de l'importance relative des secteurs de moyenne et haute technicité. C'est ce qui ressort nettement de l'examen de la part dans le PIB des industries manufacturières à moyenne et forte intensité technologique (graphique 13). Bien que la part des exportations de biens produits par ces industries ait augmenté dans les deux régions (graphique 8), l'Amérique latine a moins réussi à accroître la part des secteurs de moyenne et haute technicité dans l'économie du fait qu'elle est restée tributaire des ressources naturelles et des industries qui reposent sur elles.

Graphique 13. Part des secteurs de moyenne et haute technicité dans le PIB, 1993 et 2003

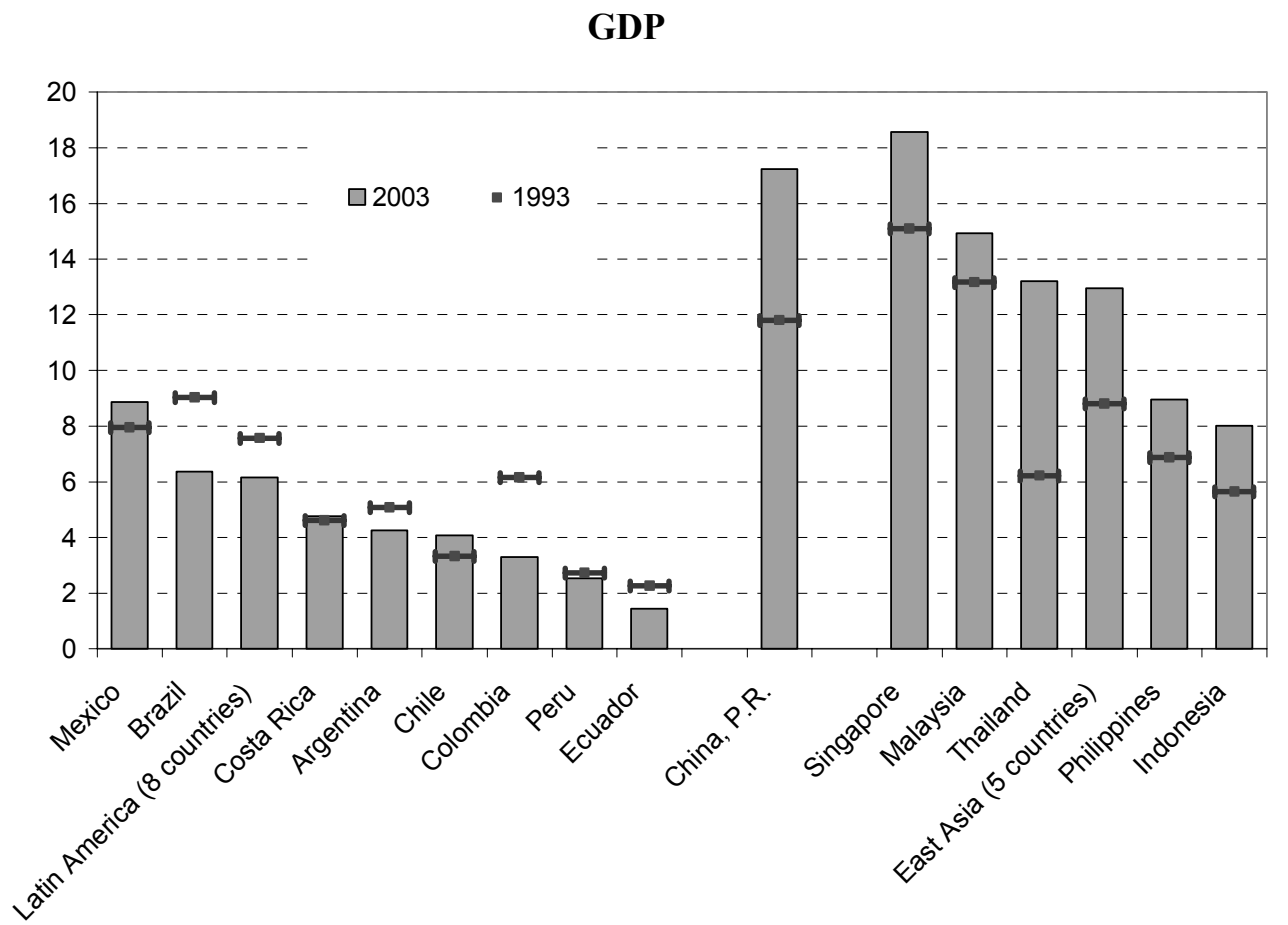

Source: Authors' calculations based on UNIDO, Industrial Scoreboard.

Source: calculs effectués par les auteurs à partir des données de l'Industrial Developement Scoreboard de l'ONUDI.

discriminatoires, elles ont eu un effet régional du fait des réseaux établis par les entreprises multinationales de la Corée, du Japon et du Taipei chinois (CEPALC, 2007). 
b)

Emploi

56. L'évolution de l'emploi manufacturier diffère notablement entre les deux régions (graphique 14a). En Asie de l'Est, l'emploi manufacturier a progressé entre le milieu des années 80 et le milieu des années 90 mais il a provisoirement reculé dans le contexte de la crise asiatique avant de retrouver son niveau d'avant la crise en 2003. En Amérique latine, il a diminué presque constamment depuis le milieu des années 80 sous l'effet des tendances exogènes et endogènes indiquées plus haut.

\section{Graphique 14a. Évolution de l'emploi dans le secteur manufacturier, 1985 à 2003}

(millions de personnes occupées)
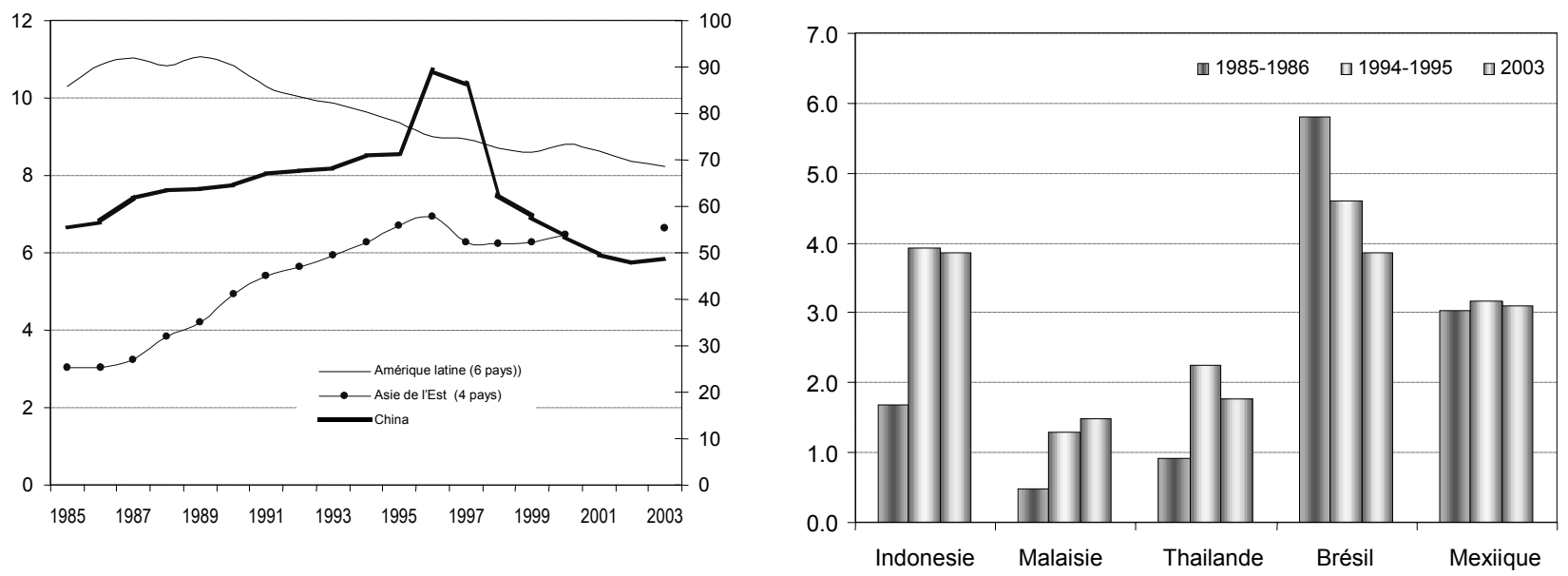

Source: calculs effectués par les auteurs à partir des bases de données de l'ONUDI et PADI de la CEPALC ainsi que de Szirmai et autres (2005).

Graphique 14b. Évolution des niveaux d'emploi dans les industries manufacturières, 1985 à 2003 (millions de personnes occupées)
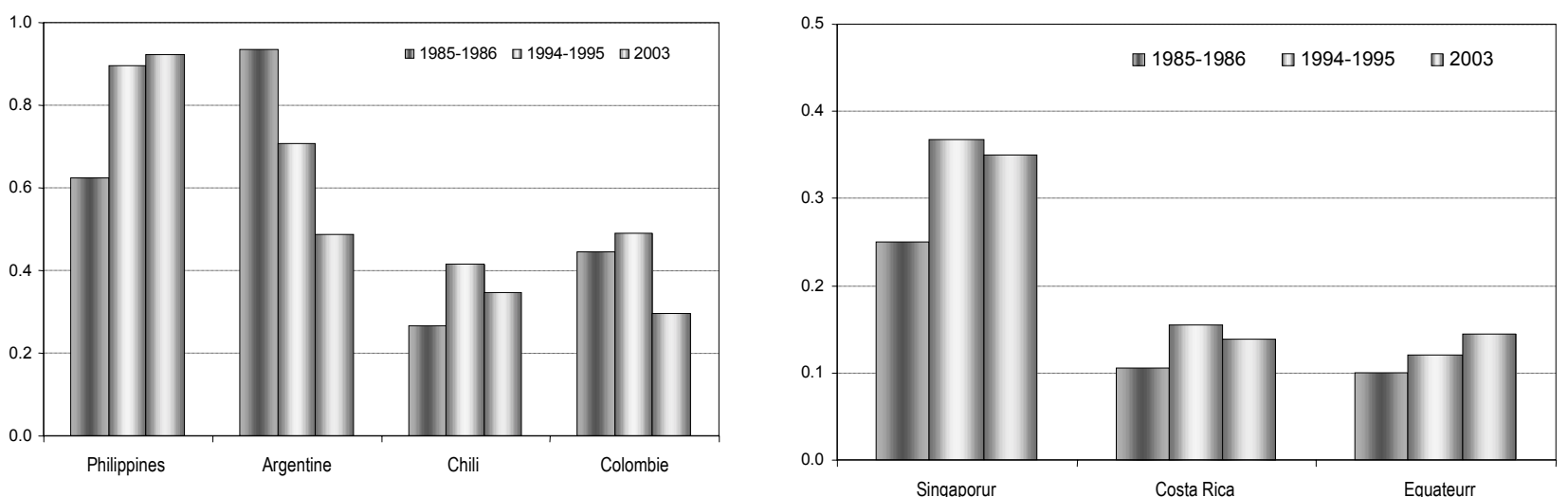

Source: calculs effectués par les auteurs à partir de la base de données de l'ONUDI et du Programme d'analyse de la dynamique industrielle (PADI) de la CEPALC ainsi que de Szirmai et autres (2005). 
57. Les tendances observées dans les pays d'Amérique latine sont plus hétérogènes que celles constatées en Asie de l'Est (graphique 2 de l'annexe). Les pays de taille moyenne comme l'Indonésie, la Malaisie et la Thaïlande ont vu leur emploi manufacturier augmenter sur le long terme alors que ce type d'emploi a diminué au Brésil et s'est stabilisé au Mexique.

58. Certains des changements survenus dans les structures de l'emploi ont suivi ceux observés dans la composition de la valeur ajoutée et des exportations. En Asie de l'Est, surtout, la part du secteur des machines électriques dans l'emploi a augmenté parallèlement à l'accroissement de sa contribution à la valeur ajoutée et aux exportations. En Amérique latine, les produits alimentaires ont enregistré une expansion comparable dans les trois structures. Les deux régions ont en commun d'avoir vu la part de leur industrie textile diminuer (graphique 15). Elles présentent toutefois des différences importantes qui reflètent les différentes évolutions des avantages comparatifs dans chacune d'elles. La situation varie considérablement entre les pays qui les composent (tableau 2 de l'annexe). Une décomposition des données en deux sous-périodes montre que l'ajustement de l'emploi s'est surtout opéré après 1990. 


\section{Graphique 15. Évolution de la structure de l'emploi dans les industries manufacturières, 2003 (ou année la plus récente) et 1990 par rapport à $1985^{\mathrm{a}}$}

(variation en points de pourcentage de la part dans l'emploi total) ${ }^{\mathrm{b}}$

Latin America (7 countries)

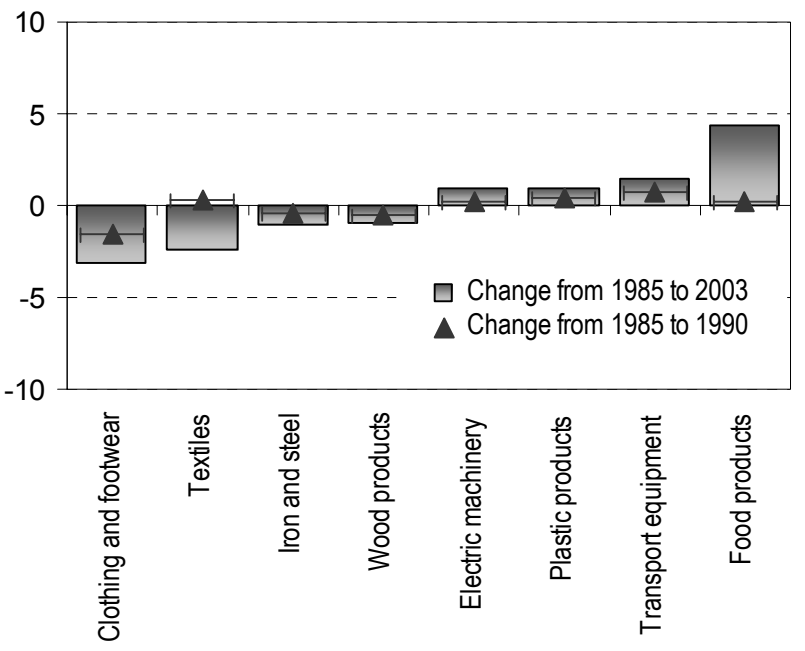

MEXICO

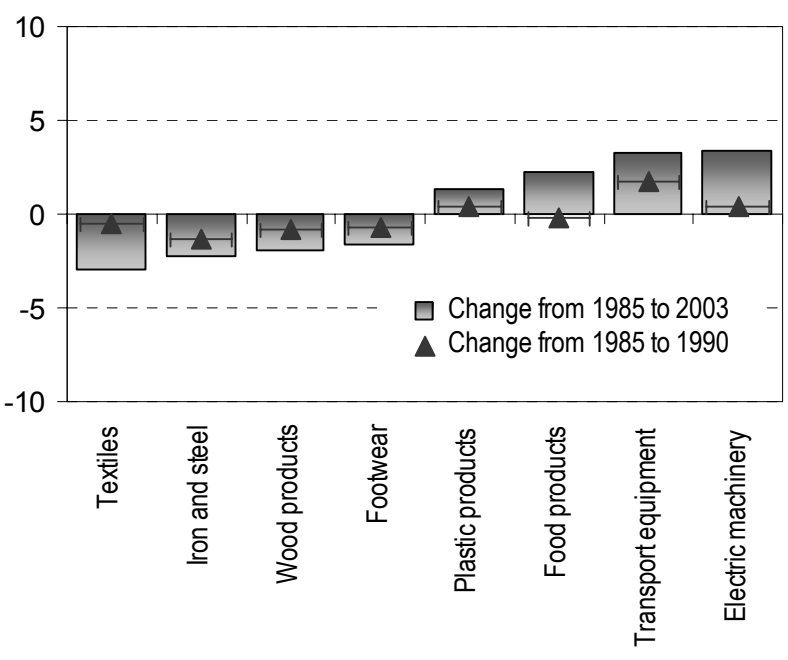

East Asia ( 5 countries)

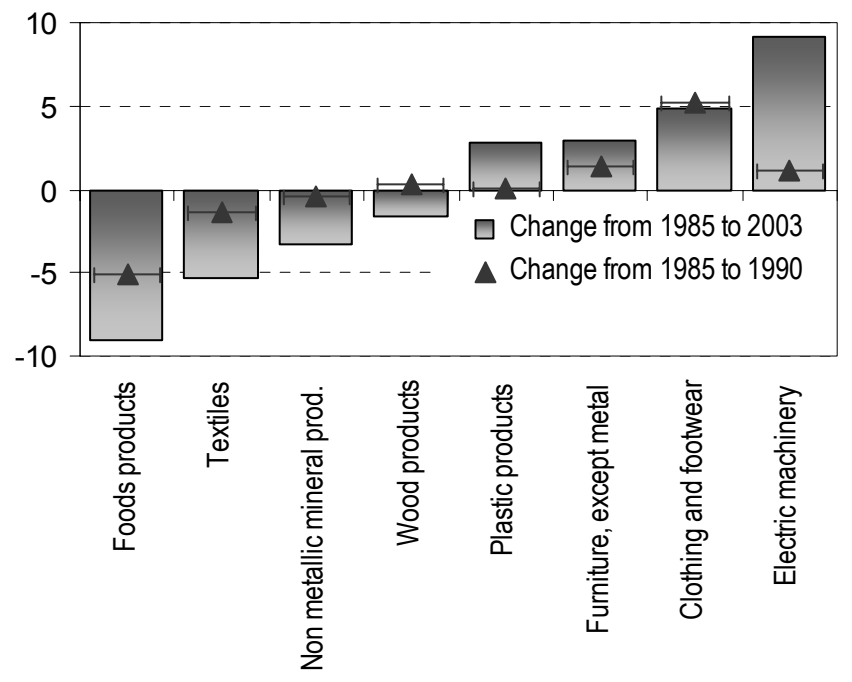

CHINA

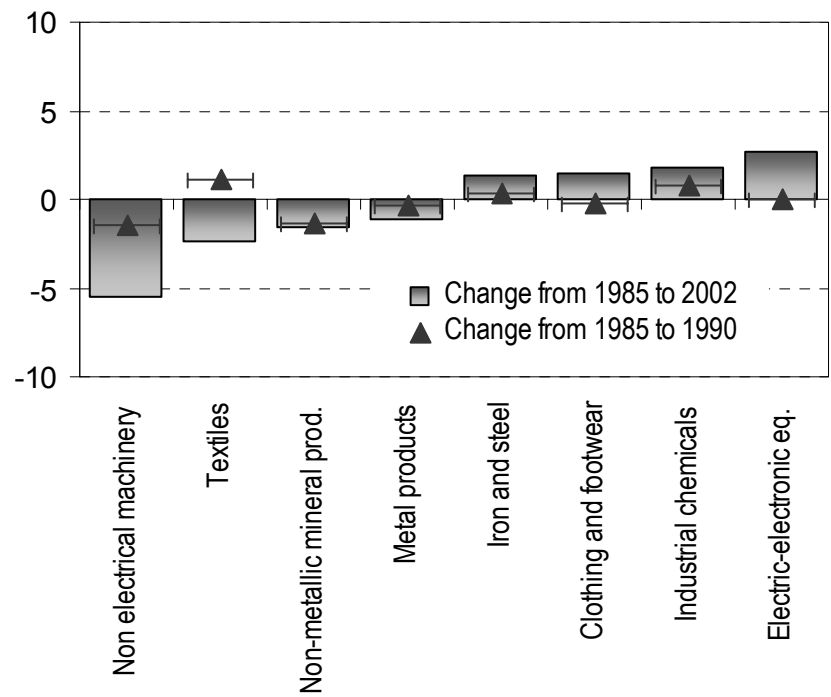

Source: calculs effectués par les auteurs à partir de la base de données de l'ONUDI et du Programme d'analyse de la dynamique industrielle (PADI) de la CEPALC ainsi que de Szirrmai et autres (2005) pour la Chine.

Notes: ces chiffres correspondent aux secteurs dont la participation à l'ensemble de l'emploi manufacturier a le plus progressé ou reculé. Les points de pourcentage représentent la différence absolue entre les participations en 2003 et 1985 et 1990 et 1985.

${ }^{a}$ Les modifications régionales de la structure reposent sur les moyennes pondérées des résultats obtenus par les différents pays, calculées en utilisant l'emploi sectoriel comme coefficient de pondération. ${ }^{b}$ Asie de l'Est: hors Vietnam et Chine; l'Amérique latine 7 exclut le Pérou. 


\section{E. Conclusions}

59. Les pays d'Amérique latine et d'Asie de l'Est considérés ici présentaient des points communs aux alentours de 1980: ils exportaient principalement des ressources naturelles et des produits à forte intensité de main-d'oeuvre et leurs politiques commerciales orientées vers le remplacement des importations se caractérisaient par l'application de droits de douane élevés et progressifs et de nombreux obstacles non tarifaires. Au cours des décennies suivantes, les deux régions ont progressivement abandonné leur politique de remplacement des importations au profit d'une action orientée vers l'exportation laissant davantage jouer les mécanismes du marché. L'Asie de l'Est a obtenu de meilleurs résultats tant en ce qui concerne la croissance que l'intégration dans l'économie mondiale. La progression rapide et plus régulière de son PIB par habitant lui a permis de combler en grande partie son écart de revenu avec l'Amérique latine. Si l'on considère certains des principaux points communs et différences entre les deux régions, on constate que:

- L'Amérique latine et l'Asie de l'Est ont réduit leurs tarifs douaniers et leurs obstacles non tarifaires au cours du dernier quart de siècle parvenant ainsi à instaurer des niveaux de protection comparables, d'après les droits de douanes et les obstacles non tarifaires effectivement appliqués.

- La libéralisation tarifaire a été essentiellement effectuée de façon unilatérale. La libéralisation multilatérale des échanges réalisée dans le cadre du Cycle d'Uruguay a surtout joué un rôle complémentaire en permettant de verrouiller la libéralisation des échanges déjà opérée dans le cas de l'Amérique latine et d'améliorer la prévisibilité des échanges grâce à des taux de consolidation plus élevés dans le cas de l'Asie de l'Est. Dans cette dernière région, l'accord de 1997 sur les technologies de l'information a donné un élan supplémentaire à la réduction des obstacles. Les accords régionaux et bilatéraux de libre-échange jouent un rôle de plus en plus important dans les réformes des échanges du fait, en partie, de la lenteur des progrès enregistrés dans les négociations commerciales multilatérales.

- Malgré leurs droits de douane plus élevés, les économies d'Asie de l'Est ont mieux réussi à s'intégrer dans l'économie mondiale que celles économies d'Amérique latine si l'on en juge par la part des échanges dans le PIB. La contribution des exportations et du solde extérieur à la croissance est nettement plus importante dans les pays d'Asie de l'Est que dans ceux d'Amérique latine.

- L'Asie de l'Est a mieux réussi à diversifier ses exportations et à créer de nouveaux avantages comparatifs dynamiques pour les produits à forte valeur ajoutée. À l'inverse, l'Amérique latine est restée très spécialisée dans les produits de base et les produits manufacturés en contenant une forte proportion.

- La restructuration des industries manufacturières a été plus marquée en Asie de l'Est qu'en Amérique latine. L'accroissement des exportations des secteurs de moyenne et haute technicité a eu pour effet d'augmenter notablement la contribution de ces secteurs à la valeur ajoutée manufacturière en Asie de l'Est. Cette augmentation a atteint jusqu'à 10 points dans cette région contre 2 à 3 points en Amérique latine. Il est permis de penser que ce décalage reflète les différences constatées dans l'évolution des avantages comparatifs dans les deux régions et dans l'aptitude des industries à s'adapter à la réforme des échanges.

60. Le succès relatif avec lequel les pays d'Asie de l'Est ont accru leurs exportations et restructuré leurs économies découle du plus net succès avec lequel ils ont suscité une réaction plus forte et plus large 
des exportations, ce qui leur a permis de s'intégrer davantage dans l'économie mondiale en augmentant leurs importations. Les raisons fondamentales des meilleures performances économiques et commerciales de l'Asie de l'Est continuent de faire l'objet de nombreuses études. Il est certain que de nombreux facteurs peuvent expliquer pourquoi cette région est mieux parvenue à s'adapter aux réformes commerciales que l'Amérique latine tels, entre autres, que des institutions, un capital humain et des infrastructures de meilleure qualité ainsi que des différences dans les politiques mises en œuvre à l'égard de la main-d'œuvre et des marchés financiers et dans l'étendue de la libéralisation des services effectuée. Le présent document conclut que du point de vue de la libéralisation des échanges et de l'investissement, de la structure des exportations et de l'ajustement structurel, si l'Asie de l'Est a réussi son ajustement, c'est peut-être en raison:

- de différences dans l'ordre de succession des mesures de réforme commerciale (mesures tarifaires et obstacles non tarifaires) et dans leur contenu (grand nombre d'exemptions tarifaires, ristournes de droits de douane et autres dispositifs qui ont abaissé les droits de douane effectifs et corrigé le biais défavorable aux exportations)

- de la stabilité macroéconomique

- de la prévention d'une surévaluation des taux de change ; et

- du rôle joué par l'IDE et les réseaux de production.

61. Si l'Amérique latine s'est engagée plus tôt que l'Asie de l'Est dans la voie de la libéralisation tarifaire, la réduction des obstacles non tarifaires a été plus rapide dans la deuxième que dans la première région. La plupart des pays d'Amérique latine ont diminué leurs droits de douane entre le milieu des années 80 et le début des années 90 alors que ceux d'Asie de l'Est l'ont fait entre le milieu et la fin des années 90. En revanche, les pays d'Asie de l'Est ont ramené le taux de couverture de leurs obstacles non tarifaires à moins de $10 \%$ dès la fin des années 80 alors que de nombreux pays d'Amérique latine ont maintenu le leur à un niveau qui pouvait atteindre $60 \%$ au début des années 90 . Cela peut donner à penser que le retard avec lequel les obstacles non tarifaires ont été réduits a diminué les effets de la réforme des échanges, ce qui s'est traduit par un moindre ajustement structurel.

62. Le contexte macroéconomique était beaucoup plus favorable au développement de nouvelles activités d'exportation en Asie de l'Est qu'en Amérique latine. L'Asie de l'Est a réussi à obtenir une croissance économique forte et stable avec un taux de change réel compétitif et des taux d'inflation et d'intérêt relativement faibles. À l'inverse, la croissance a été faible et irrégulière en Amérique latine avec des taux de change durablement surévalués et des taux d'inflation et d'intérêt élevés. La surévaluation des taux de change a peut-être réduit les effets de la réforme commerciale et contribué ainsi à maintenir les distorsions défavorables aux exportations. La diversification des exportations peut avoir elle-même contribué à renforcer la croissance économique en Asie de l'Est en réduisant l'instabilité.

63. Alors que les deux régions ont reçu des niveaux comparables d'IDE, l'Asie de l'Est a mieux su attirer l'IDE dans le secteur manufacturier. Une plus forte proportion de l'IDE y était motivée par la recherche d'efficience et orientée vers l'exportation qu'en Amérique latine, ce qui a contribué à l'accroissement des exportations. De ce fait, l'Asie de l'Est ainsi que le Costa Rica et le Mexique, qui constituent des exceptions en Amérique latine, ont mieux réussi à s'intégrer dans les réseaux mondiaux de production, ce qui leur a permis de moderniser leurs exportations. Certaines des différences observées dans les flux d'IDE peuvent certes tenir à des raisons géographiques et historiques, mais les pays d'Amérique latine peuvent peut-être rendre plus favorable l'environnement des réseaux de production en axant 
davantage leur action sur le coût des services utilisés pour lier entre eux les blocs de production fragmentés et en améliorant les infrastructures et la gouvernance relatives à ces services dans toute la région ${ }^{24}$.

64. Les ressources naturelles sont considérées depuis longtemps comme un handicap pour le développement de l'Amérique latine. On est effectivement conduit à le penser lorsque l'on voit comment les activités manufacturières ont permis aux pays d'Asie de l'Est de bénéficier d'une plus forte croissance, dans le passé. Il y a toutefois de plus en plus de raisons de croire qu'avec des politiques appropriées, la richesse naturelle peut aussi incorporer de la valeur ajoutée et du savoir (voir Lederman et Maloney, 2007, et Banque mondiale, 2007). Les pays en développement qui entreprendront à l'avenir une réforme des échanges jugeront sans doute utile de ne pas perdre de vue les enseignements tirés des expériences passées décrites plus haut et de faire en sorte que l'envolée actuelle des prix des produits de base conduise à un développement durable à terme.

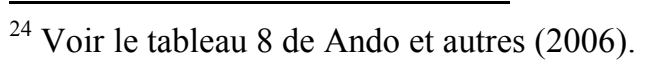




\section{BIBLIOGRAPHIE}

Agosin, M.R. (2007), «Trade and Growth: Why Asia Grows Faster than Latin America », in R. FfrenchDavis et J.L. Machinea (éd.), Economic Growth with Equity: Challenges for Latin America, Palgrave MacMillan, New York, NY.

Agosin, Manuel R et R. Ffrench-Davis (1995), «Trade liberalization and growth: Recent experiences in Latin America », Journal of Interamerican Studies and World Affairs (automne 1995).

Ando, M., S.W. Arndt et F. Kimura (2006), « Production Networks in East Asia: Strategic Behaviour by Japanese and U.S. firms ", document présenté à une conférence organisée à Tokyo par le Japan Center for Economic Research sur le thème: "Multinational Firms'Strategies in East Asia: A Comparison of Japanese, U.S., European and Korean Firms », le $1^{\text {er }}$ juin 2006.

Banque mondiale (2007), Rapport sur le développement dans le monde 2008: L'agriculture au service du développement, Banque mondiale, Washington, DC.

Bender, S. et K.W. Li (2002), « The Changing Trade and Revealed Comparative Advantages of Asian And Latin American Manufacture Exports ", Center Discussion Paper, $\mathrm{n}^{\circ}$ 843, Economic Growth Center, Université Yale.

Bhattacharya, A. et J. F. Linn (1988), «Trade and industrial policies in the developing countries of East Asia », document de synthèse de la Banque mondiale ${ }^{\circ}$ 27, Banque mondiale, Washington D.C.

Bora, B., A. Kuwahara et S. Laird, (2002), «Quantification on Non-Tariff Measures », UNCTAD Policy Issues in International Trade and Commodities Study Issue, $\mathrm{n}^{\circ} 18$.

Bora, B. et I.N. Neufeld (2001), "Tariffs and the East Asian Financial Crisis », Policy Issues jn International Trade and Commodities, Study Series, $\mathrm{n}^{\circ}$ 13, CNUCED.

CEPALC (Commission économique pour l'Amérique latine et les Caraïbes) (2004), Latin America and the Caribbean in the World Economy, 2002-2003, CEPALC, Santiago.

CEPALC (2005), Latin America and the Caribbean in the World Economy, 2004. Trends 2005, CEPALC, Santiago.

CEPALC (2006a), Latin America and the Caribbean in the World Economy 2005-2006, CEPALC, Santiago.

CEPALC (2006b), «The role of the real exchange rate and investment in export diversification », chapitre VI in Economic Survey of Latin America and the Caribbean, CEPALC, Santiago.

CEPALC (2007), Latin America and the Caribbean in the World Economy 2006. Trends 2007, CEPALC, Santiago.

CNUCED (2006), Rapport sur l'investissement dans le monde, CNUCED, Genève. 
De Gregorio, J. et J.W. Lee (2003), « Growth and Adjustment in East Asia and Latin America », Central Bank of Chile Working Papers ${ }^{\circ} 245$, Banque centrale du Chili.

Durán, J.E. (2001), Economía Chilena: 120 Años de Historia Económica (1880-2000), Universidad Católica Raúl Silva Henríquez. Santiago du Chili.

Edwards, S. (1995), Crisis and Reform in Latin America: From Despair to Hope, Oxford University Press, New York, NY.

Engman, M., O. Onodera et E. Pinali (2007), «Zones franches d'exportation : leur rôle passé et futur dans les échanges et le développement», document de travail de l'OCDE sur la politique commerciale $n^{\circ} 53$, OCDE.

Estevadeordal A. et C. V. Martincus (2007), «Trade Policy and Sectoral Manufacturing Specialization », document présenté à la réunion LACEA 2007 à Bogota, Colombie.

Ffrench Davis, R. (1999), Macroeconomía, Comercio y Finanzas para Reformar las Reformas en América Latina, Editorial McGraw Hill, CEPALC.

Ffrench Davis, R. (2005), "Reforming Latin America's Economies: After Market Fundamentalism », Palgrave MacMillan, Basingstoke.

Finger J. M. et L.A. Winter (2002), « Reciprocity in the WTO » in Bernard Hoekman, Aaditya Matto., et Philip English (éd.) (2002), Développement, commerce et OMC, Banque mondiale, Washington, DC.

Finger, J.M., U. Reincke et A. Castro (2002), « Market Access Bargaining in the Uruguay Round: Rigid or Relaxed Reciprocity », in J.N. Bhagwati (éd.), Going Alone: The Case for Relaxed Reciprocity in Freeing Trade, MIT Press, Cambridge, Mass.

Haddad, M. (2007), « Overview Rules of Origin in East Asia: How are They Working in Practice? » in Trade Issues in Asia: Preferential Rules of Origin - Policy Research Report, Asie de l'Est et Pacifique, Unité Réduction de la pauvreté et gestion économique, Banque mondiale, Washington D.C.

Hofman, A. (1998), «Latin American Economic Development: A Casual Analysis in Historical Perspective », Monograph Series, $\mathrm{n}^{\circ}$ 3. Groningen Growth and Development Centre, Groningue.

James et E,D. Ramstetter, E.D. (1999), « Comparisons of Foreign Multinationals and Local Firms in Asian manufacturing over Time » Asian Economic Journal, vol. 12, n 2, pp. 163-203.

James et E.D. Ramstetter, E.D. (2005), «Identifying the Sources and Destinations of Foreign Direct Investment: Some Asian examples ». Document présenté à la réunion d'experts sur le renforcement des capacités dans le domaine de l'IDE, « Data Compilation and Policy Formulation in Developing Countries », Genève, 12-14 décembre.

Jomo, K.S. (2001), « Growth After the Asian Crisis: What Remains of the East-Asian Model », documents de travail - Série G-24 n 10, mars, CNUCED et Center for International Development, Université Harvard.

Jomo, K.S. (2002), « State and Market in Economic Development: Southeast-Asian Industrial Policy in Comparative East-Asian Perspective », document présenté au séminaire intitulé «Promoting Growth 
and Welfare: The Role of Institutions and Structural Change in Asia », Santiago, Chili, 29-30 avril, CEPALC, IDE-JETRO and Instituto de Economía, UFRJ.

Klinger, B. et D. Lederman (2006), « Innovation and export portfolios », document de travail consacré à la recherche sur les politiques, $\mathrm{n}^{\circ}$ 3983, Banque mondiale, Washington, DC.

Kokko, A. (2002), «Export-Led Growth in East-Asia: Lessons for Europe's Transition Economies », Working Paper, $\mathrm{n}^{\circ} 142$, The European Institute of Japanese Studies, Stockholm School of Economics.

Kuwayama, M. et J. Durán Lima (2003), « La Calidad de la Inserción Internacional de América Latina y el Caribe en el Comercio Mundial », Serie Comercio Internacional, n²6, CEPALC, Santiago.

Kuwayama, M., J. Durán Lima y V. Silva (2005), «Bilateralism and Regionalism: Re-establishing the Primacy of Multilateralism: A Latin American and Caribbean Perspectiva ", Serie Comercio Internacional, $\mathrm{n}^{\circ}$. 58. CEPALC, Santiago.

Lall, S. (2000) «The Technological Structure and Performance of Developing Country Manufactured Exports, 1985-98 », Oxford Development Studies, vol. 28, n 3, pp. 337-369.

Lederman, D. et W. Malony (2006), Natural Resources: Neither Curse Nor Destiny, Banque mondiale et Stanford University Press, Stanford, CA.

Nagel, J.C. (2005), «Un Marco para la Formulación de Políticas Sectoriales en la Región Andina », in Castilla, L.M., O. Manzano et J. Nagel (éd.), Políticas Sectoriales en la Región Andina. Lecciones y Propuestas, Corporación Andina de Fomento (CAF), Caracas.

Narula, R. (2002), «Switching from Import Substitution to the 'New Economic Model' in Latin America: A case of not learning from Asia », document de travail $n^{\circ} 4$, Latin America/Caribbean and Asia/Pacific Economics and Business Association.

Nelson, R. et H. Pack (1997), « The Asian Miracle and Modern Growth Theory », Université Columbia et Université de Pennsylvanie, document non publié, octobre.

OCDE (2005), Les échanges et l'ajustement structurel: Les enjeux de la mondialisation, OCDE, Paris

Palma, J G (2004), «Four Different Sources of De-industrialisation and a New Concept of the Dutch Disease », in J A Ocampo (éd.) New Challenges for Latin American Development, Stanford University Press (CEPALC - World Bank series).

Poon, J.P.H. et E.R. Thompson (1998), «Foreign Direct Investment and Economic Growth: Evidence from Asia and Latin America », Journal of Economic Development, vol.23, $\mathrm{n}^{\circ}$ 2, Economic Research Institute, Université Chung Ang, Séoul, Corée.

Rasiah, R. (1998), «The Export Manufacturing Experience of Indonesia, Malaysia and Thailand: Lessons for Africa », Documents de travail de la CNUCED, n 137 . CNUCED, Genève.

Rasiah, R. (2002), «Systemic coordination and Human Capital Development: Knowledge Flows in Malaysia's MNC-Driven Electronic Clusters », Discussion Paper Series, n 2002-7, Université des Nations Unies (UNU/INTECH ), Institut pour la nouvelle technologie. 
Rosales, O. et M. Kuwayama (2007), « América Latina y China e India: Hacia una Nueva Alianza de Comercio e Inversión », Serie Comercio Internacional, n 81, CEPALC, Santiago du Chili.

Rose, A.K. (2002), « Do WTO Members Have a More Liberal Policy? », NBER Working Paper, n 9347, novembre.

Szirmai, A., R. Rouen et M. Bai (2005), "Chinese Manufacturing Performance in Comparative Perspective, 1980-2002», Center Discussion Paper, $n^{\circ}$ 920, Economic Growth Center, Université Yale.

Warwick J., McKibbin et KK. Tang (2000), « Trade and Financial Reform in China: Impacts on the World Economy », The World Economy, vol. 3, n 8.

Weimann, J., H. Effner, S. Grammling, K. Henke, C. Kammer: et L. Muhlich (2006), «Vietnam - The 150th WTO-Member. Implications for Industrial Policy and Export Promotion », Studies, ${ }^{\circ} 23$, German Development Institute, Bonn.

Weiss, J. (2005), «Export Growth and Industrial Policy: Lessons from the East Asian Miracle Experience », ADB Institute Discussion Paper, $\mathrm{n}^{\circ} 26$, ADB Institute, Tokyo.

Zhang, K.H. (2001), « Does Foreign Direct Investment Promote Economic Growth? Evidence from East Asia and Latin America », Contemporary Economic Policy, vol. 19, n 2, pp. 175-185. 
Annexe: restructuration des industries manufacturières, résultats par pays pour la valeur ajoutée et l'emploi

\section{Graphique 1a de l'annexe. Amérique latine: évolution de la structure de production des industries} manufacturières, 2003 (ou année la plus récente) par rapport à 1980
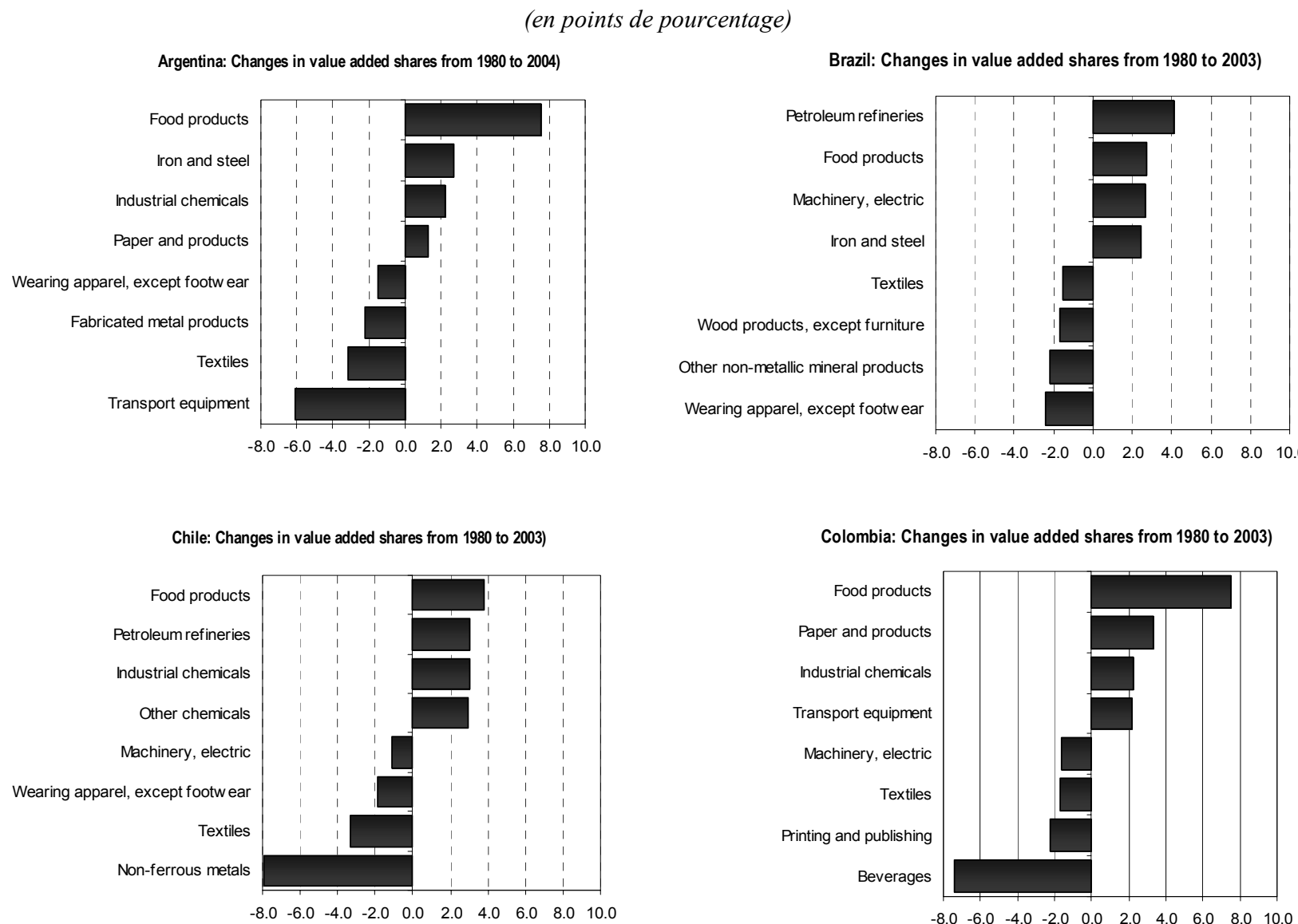

Source: calculs effectués par les auteurs à partir de la base de données PADI et des informations de l'ONUDI dans le cas de l'Équateur et du Costa Rica. 
Graphique 1a de l'annexe (suite). Amérique latine: évolution de la structure de production des industries manufacturières, 2003 (ou année la plus récente) par rapport à 1980

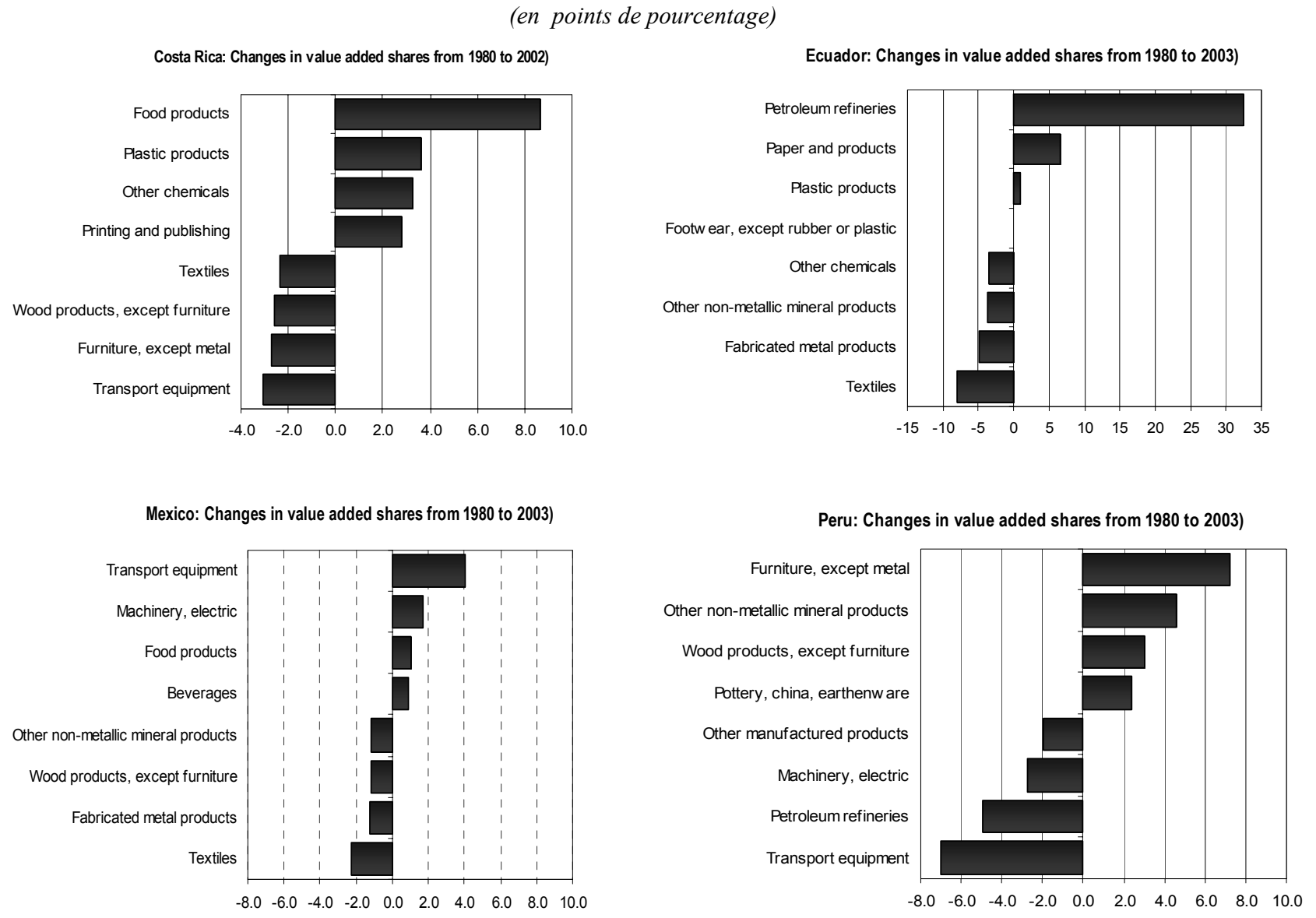

Source: calculs effectués par les auteurs à partir des informations de l'ONUDI et de la base de données PADI. 
Graphique 1b de l'annexe. Asie de l'Est: évolution de la structure de production des industries manufacturières, 2003 (ou année la plus récente) par rapport à 1980

(en points de pourcentage)

China: Changes in value added shares from 1980 to 2003)

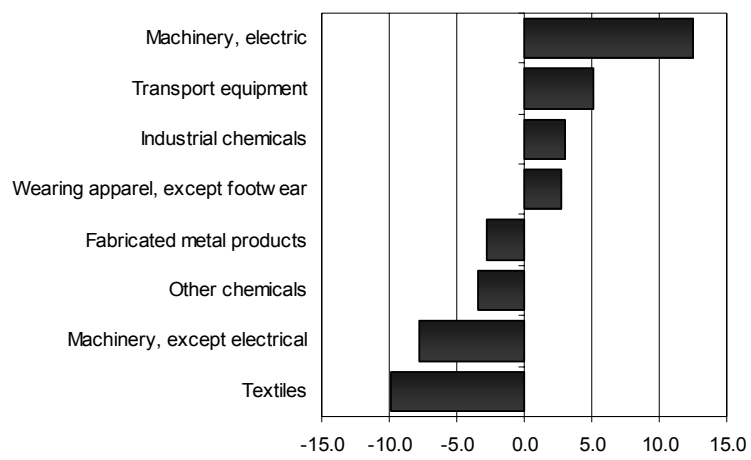

Malaysia: Changes in value added shares from 1981 to 1999

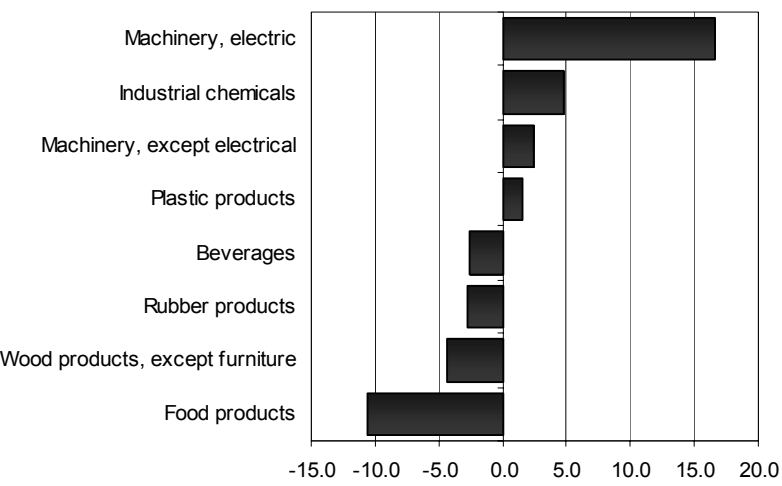

Singapore: Changes in value added shares from 1981 to 2003

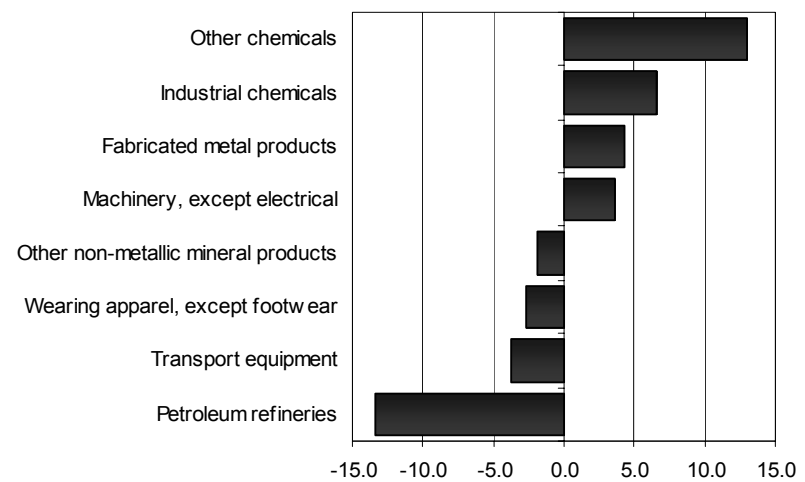

Indonesia: Changes in value added shares from 1980 to 2003)

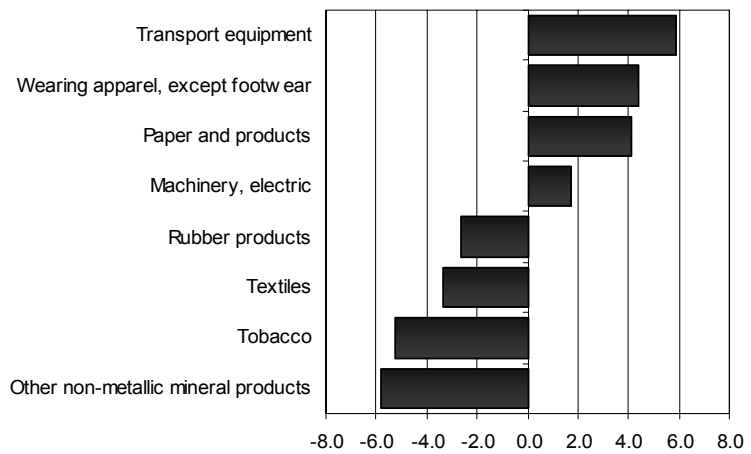

Philippine: Changes in value added shares from 1980 to 2003

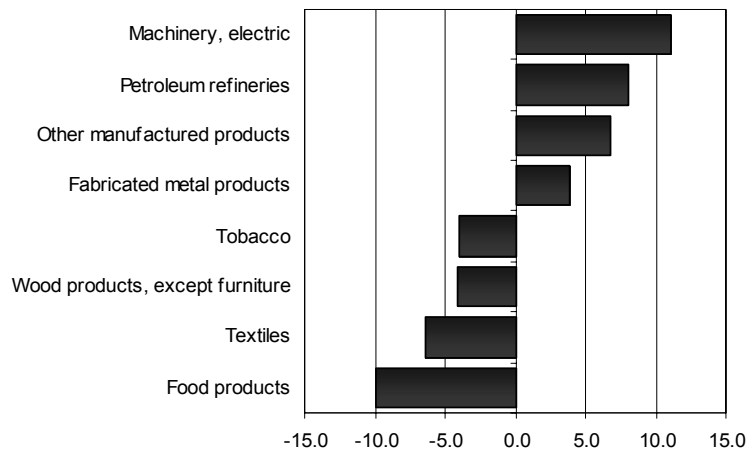

Thailand: Changes in value added shares from 1979 to 1998

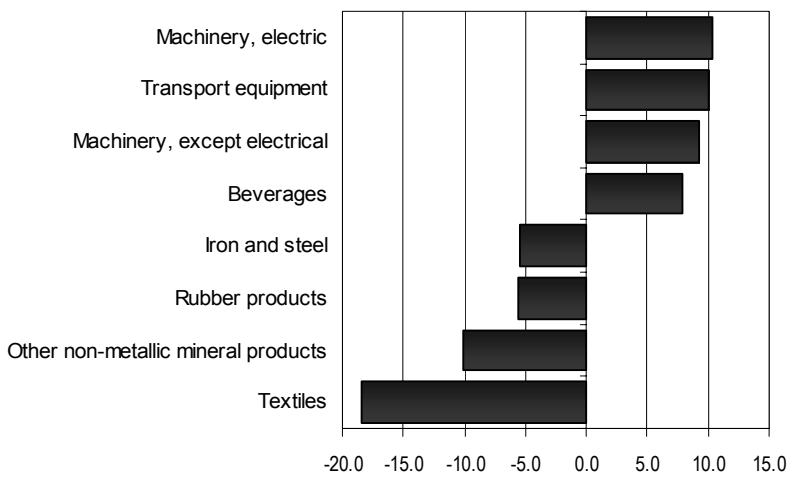

Source: calculs effectués par les auteurs à partir des informations de la Banque mondiale et de l'ONUDI. 
Graphique 2a de l'annexe. Amérique latine: évolution de la structure de l'emploi manufacturier, 2003 (ou année la plus récente) par rapport à 1980
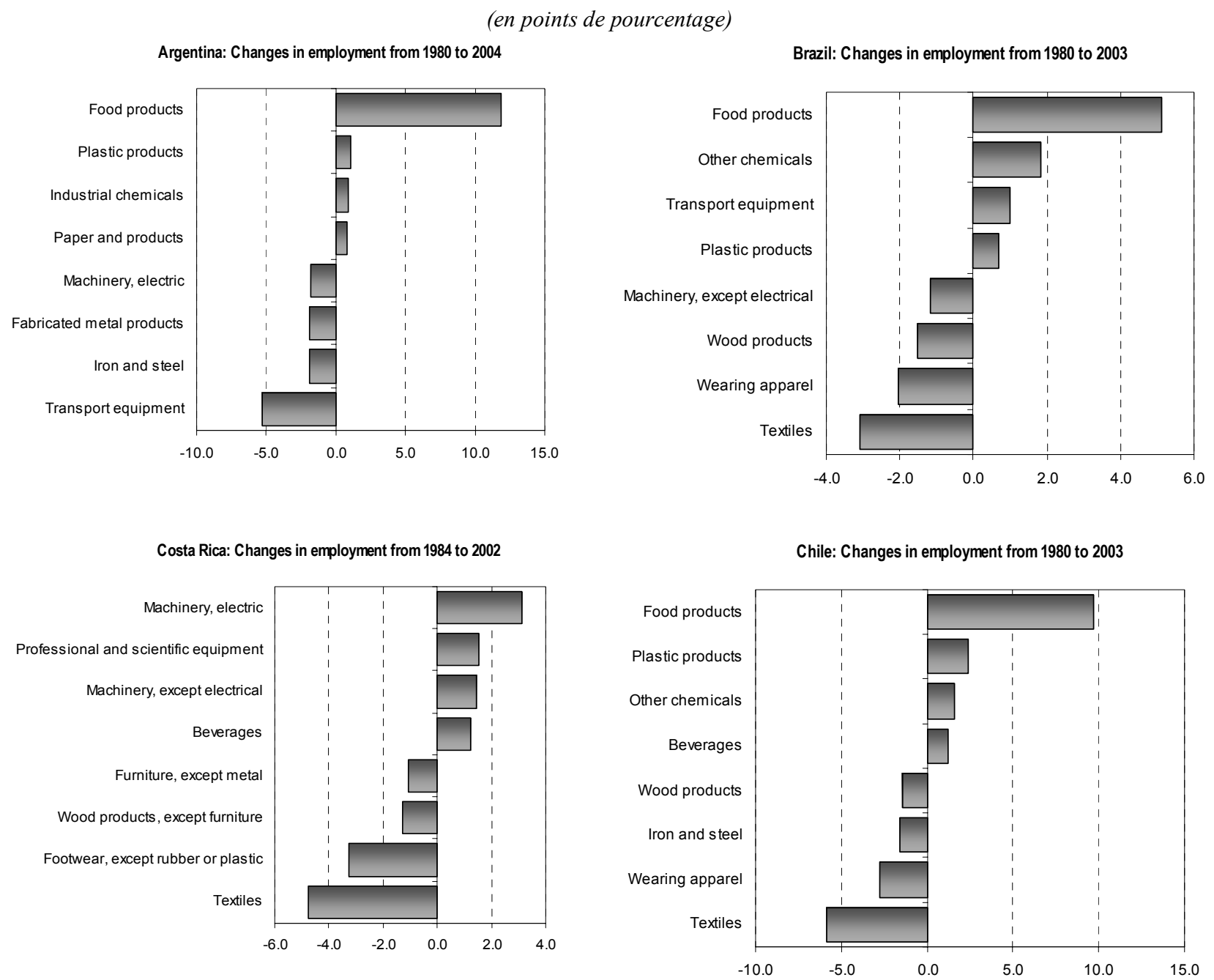

Source: calculs effectués par les auteurs à partir de la base de données PADI et des informations de l'ONUDI dans le cas du Costa Rica. 
Graphique 2a de l'annexe (suite). Amérique latine: évolution de la structure de l'emploi manufacturier, 2003 (ou année la plus récente) par rapport à 1980

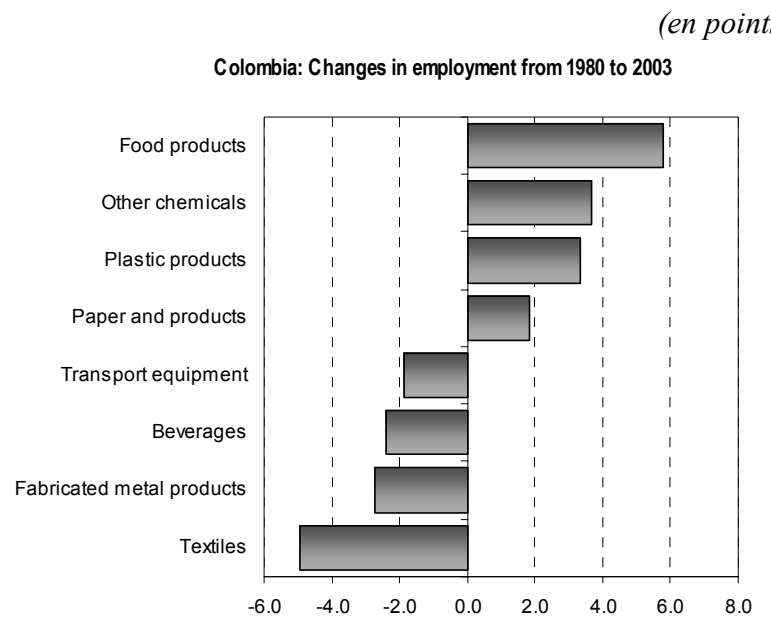

Mexico: Changes in employment from 1980 to 2003

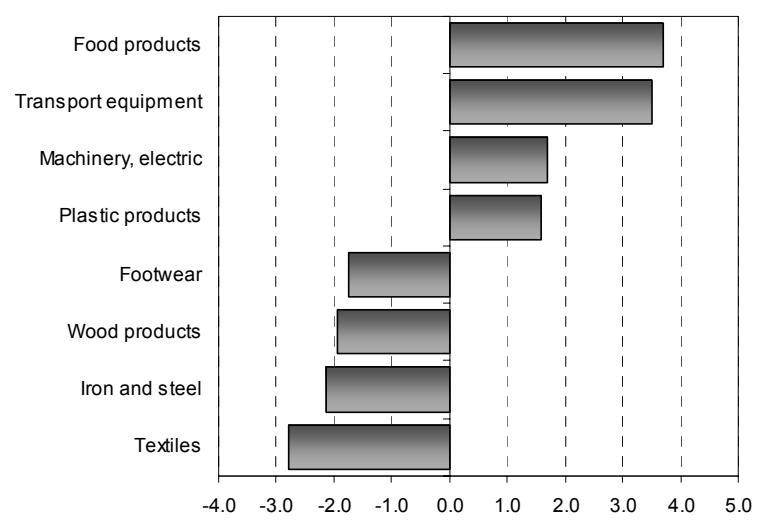

Ecuador: Changes in employment from 1980 to 2003

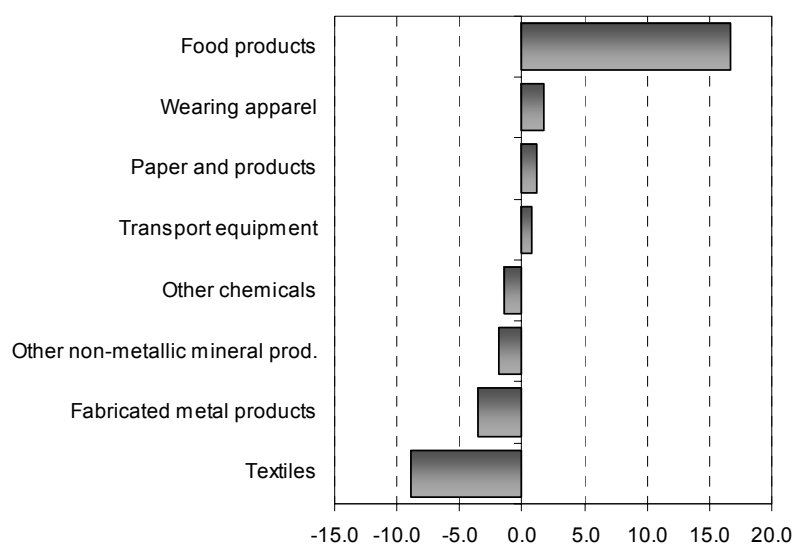

Peru: Changes in employment from 1980 to 1996

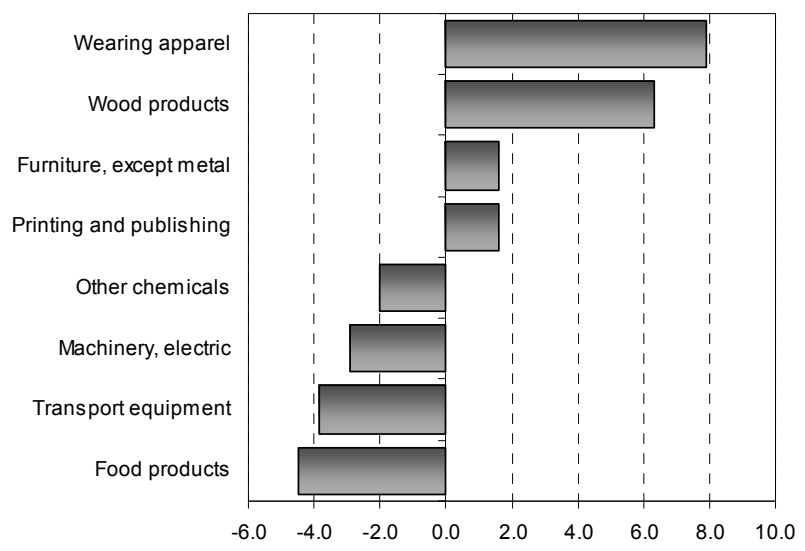

Source: calculs effectués par les auteurs à partir des informations de l'ONUDI et de la base de données PADI. 
Graphique 2b de l'annexe. Asie de l'Est: évolution de la structure de l'emploi manufacturier, 2003 (ou année la plus récente) par rapport à 1985
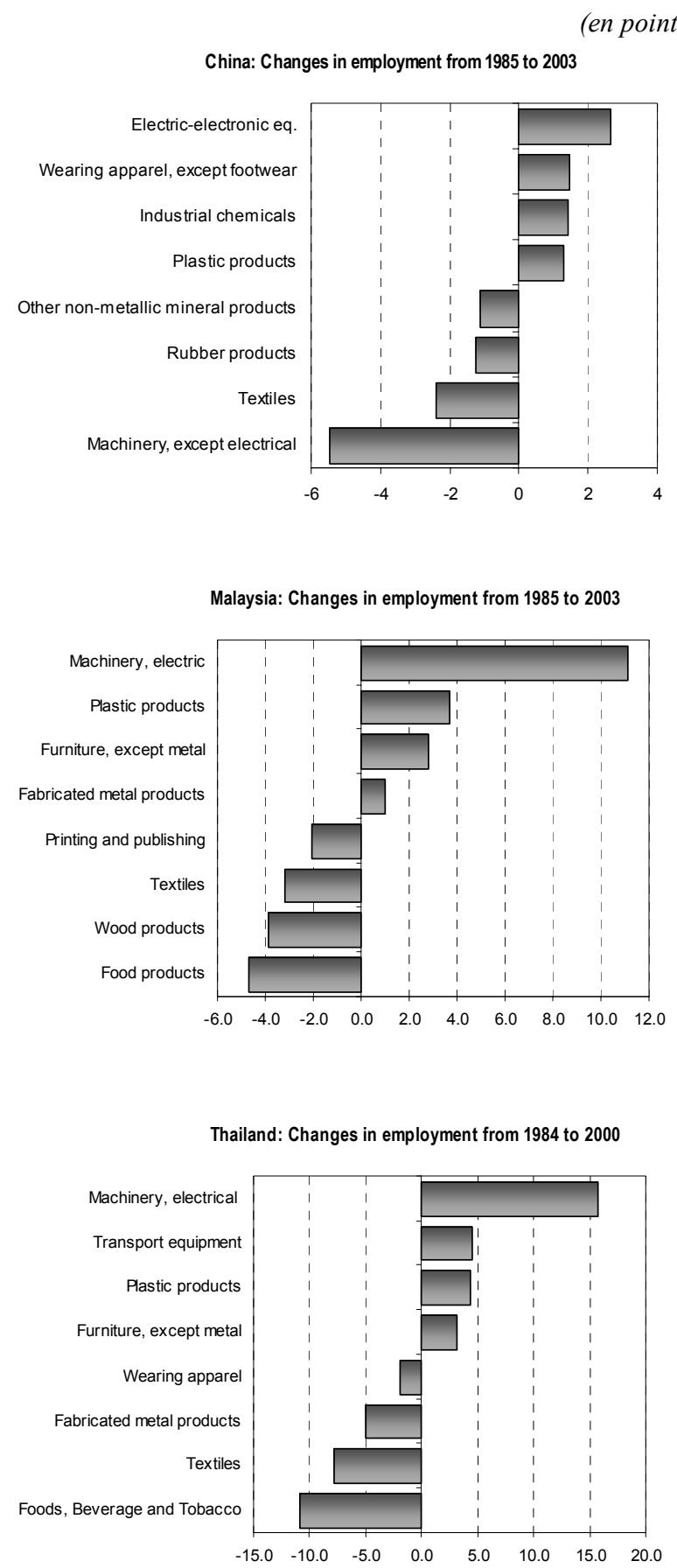

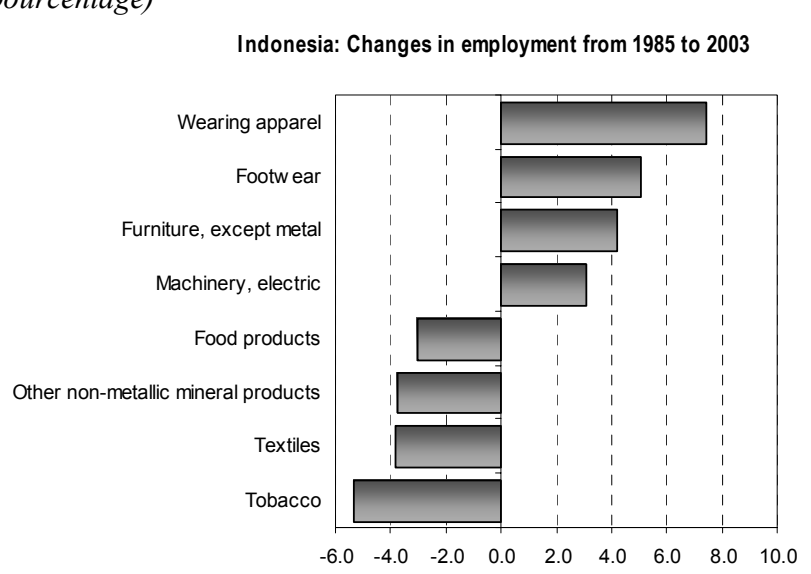

Philippines: Changes in employment from 1985 to 2003

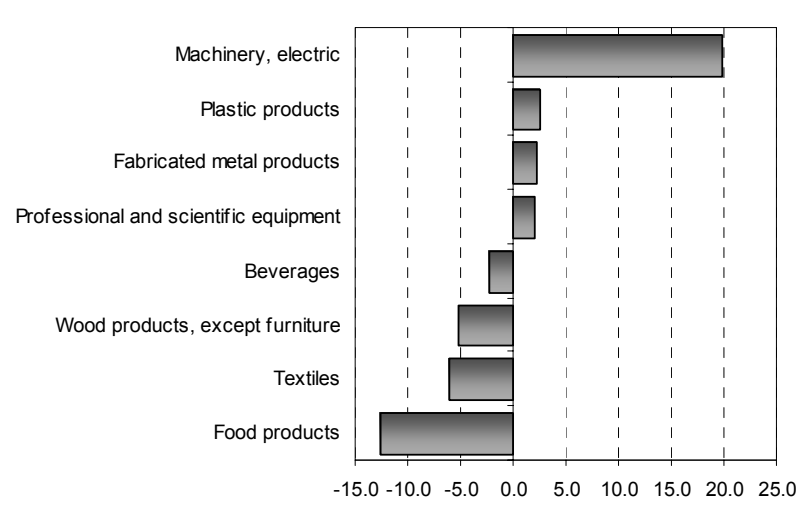

Singapore: Changes in employment from 1985 to 2005

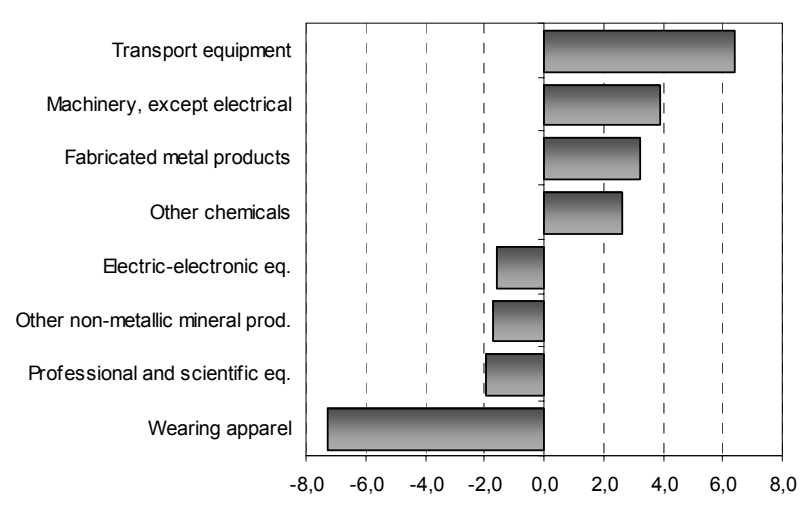

Source: calculs effectués par les auteurs à partir des statistiques de l'ONUDI, des données de l'OIT et de Szirmai et autres (2005). 
Tableau 1 de l'annexe

Amérique latine (7 pays) et Asie de l'Est (5 pays): évolution de l'emploi dans les industries manufacturières entre 1985 et 2003

(Pourcentages du total et points de pourcentage)

\begin{tabular}{|c|c|c|c|c|c|c|c|c|c|c|}
\hline \multirow[t]{2}{*}{ CITI Rév.2 } & \multirow[t]{2}{*}{ Description du secteur } & \multicolumn{3}{|c|}{$\begin{array}{l}\text { Amérique latine } \\
\text { (6 pays) }\end{array}$} & \multicolumn{3}{|c|}{$\begin{array}{l}\text { Asie de l'Est } \\
\text { (5 pays) }\end{array}$} & \multicolumn{3}{|c|}{ Chine } \\
\hline & & 1985 & 2003 & $\begin{array}{l}\text { Chan- } \\
\text { gem. }\end{array}$ & 1985 & 2003 & $\begin{array}{l}\text { Chan- } \\
\text { gem. }\end{array}$ & 1985 & 2003 & $\begin{array}{l}\text { Chan- } \\
\text { gem. }\end{array}$ \\
\hline $311+313+314$ & Produits alimentaires, boissons et tabacs & 18.8 & 23.5 & 4.8 & 25.5 & 16.5 & -9.0 & 8.0 & 8.2 & 0.2 \\
\hline 321 & Textiles & 7.2 & 4.8 & -2.4 & 15.4 & 10.2 & -5.3 & 13.0 & 10.4 & -2.6 \\
\hline $322+324$ & Articles d'habillement et chaussures & 10.4 & 7.2 & -3.2 & 8.7 & 13.6 & 4.9 & 3.7 & 6.0 & 2.3 \\
\hline 323 & Cuir & 0.9 & 0.9 & 0.0 & 0.3 & 0.8 & 0.4 & 1.5 & 3.4 & 1.9 \\
\hline 331 & Ouvrages en bois, hors meubles & 3.8 & 2.9 & -0.9 & 7.3 & 5.7 & -1.6 & 1.4 & 1.3 & -0.1 \\
\hline 332 & Meubles non métalliques & 2.6 & 2.2 & -0.5 & 1.4 & 4.4 & 3.0 & 1.3 & 0.9 & -0.4 \\
\hline 341 & Papier et articles en papier & 2.2 & 2.5 & 0.2 & 1.7 & 2.4 & 0.7 & 2.1 & 2.4 & 0.2 \\
\hline 342 & Imprimerie et édition & 3.3 & 3.7 & 0.4 & 2.4 & 1.7 & -0.7 & 1.8 & 1.2 & -0.6 \\
\hline $351+352$ & Produits chimiques industriels & 6.3 & 6.6 & 0.3 & 5.1 & 4.4 & -0.8 & 7.7 & 9.6 & 1.9 \\
\hline $353+354$ & Produits pétroliers & 1.0 & 0.9 & -0.1 & 0.3 & 0.2 & -0.1 & 0.8 & 1.2 & 0.4 \\
\hline 355 & Produits en caoutchouc & 1.3 & 1.2 & -0.1 & 4.8 & 3.8 & -1.0 & 2.3 & 1.3 & -1.0 \\
\hline 356 & Produits en matières plastiques & 2.7 & 3.6 & 1.0 & 2.6 & 5.5 & 2.9 & 1.2 & 2.9 & 1.8 \\
\hline $361+362+369$ & $\begin{array}{l}\text { Grès, verre et autres produits minéraux non } \\
\text { métalliques }\end{array}$ & 6.1 & 5.6 & -0.5 & 5.0 & 1.7 & -3.3 & 12.0 & 8.3 & -3.7 \\
\hline 371 & Produits sidérurgiques & 3.6 & 2.6 & -1.1 & 1.8 & 1.4 & -0.4 & 5.0 & 5.3 & 0.4 \\
\hline 372 & Métaux non ferreux & 1.0 & 1.1 & 0.0 & 0.2 & 0.2 & 0.0 & 1.1 & 2.2 & 1.1 \\
\hline 381 & Ouvrages en métaux & 5.7 & 5.7 & 0.0 & 4.0 & 3.1 & -0.9 & 4.7 & 3.6 & -1.1 \\
\hline 382 & Machines autres qu'électriques & 7.3 & 6.6 & -0.7 & 1.7 & 1.7 & 0.0 & 16.2 & 10.2 & -6.0 \\
\hline 383 & Machines électriques & 6.2 & 7.1 & 0.9 & 6.5 & 15.7 & 9.2 & 6.6 & 11.2 & 4.7 \\
\hline 384 & Matériel de transport & 7.0 & 8.4 & 1.4 & 3.3 & 4.8 & 1.5 & 5.1 & 6.5 & 1.4 \\
\hline 385 & Matériel professionnel et matériel scientifique & 0.6 & 1.0 & 0.4 & 0.5 & 1.4 & 0.9 & 1.4 & 1.5 & 0.1 \\
\hline 390 & Autres produits manufacturés & 1.7 & 1.8 & 0.0 & 1.4 & 1.0 & -0.3 & 3.0 & 2.2 & -0.8 \\
\hline & Totaux & 100.0 & 100.0 & 0.0 & 100.0 & 100.0 & 0.0 & 100.0 & 100.0 & 0.0 \\
\hline
\end{tabular}

Source: calculs effectués par les auteurs à partir des bases de données de l'ONUDI et PADI de la CEPALC ainsi que de Szirmai et autres (2005) dans le cas de la Chine.

${ }^{a}$ Les changements structurels régionaux correspondent à la moyenne pondérée des résultats des différents pays, calculée en utilisant l'emploi dans chaque secteur comme coefficient de pondération.

Amérique latine: Argentine, Brésil, Chili, Colombie, Équateur et Mexique.

Asie de l'Est 5: Indonésie, Malaisie, Philippines, Singapour et Thaïlande. 